UNIVERSIDADE DE SÃO PAULO

INSTITUTO DE FÍSICA DE SÃO CARLOS

DEPARTAMENTO DE FÍSICA E INFORMÁTICA

\title{
APLICAÇÃO DE ANÁLISE MULTIVARIADA DE DADOS À ESPECTROSCOPIA DE ALTA RESOLUÇÃO EM SÓLIDOS POR RESSONÂNCIA MAGNÉTICA NUCLEAR ơ
}

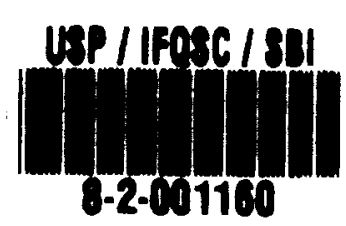

Ana Carolina de Mattos Zeri

Dissertação apresentada ao Instituto de Fisica de São Carlos, da Universidade de São Paulo, para obtenção do título de Mestre em Ciências: Física Básica.

Orientador: Prof. Dr. Tito José Bonagamba

São Carlos

1997 IFSC.USPP SERVIGO OE BISLIOTECA 


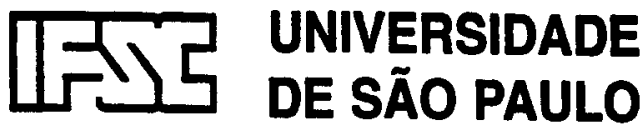

Instituto de Física de São Carlos
Av. Dr. Carlos botelho, 1465

CEP 13560-250 - São Carlos - SP Brasil

Fone (016) 274-3444

Fax (016) 272-2218

MEMBROS DA COMISSÃO JULGADORA DA DISSERTAÇĀO DE MESTRADO DE ANA CAROLINA DE MATTOS ZERI APRESENTADA AO INSTITUTO DE FÍSICA DE SÃO CARLOS, DA UNIVERSIDADE DE SÃO PAULO, EM 17 DE ABRIL DE 1997.

COMISSÃO JULGADORA:

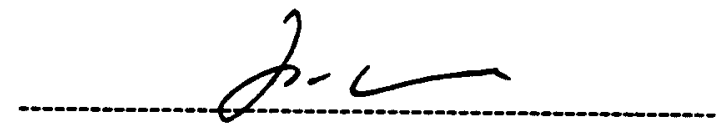

Prof. Dr. Tito Jose Bonagamba/IFSC-USP

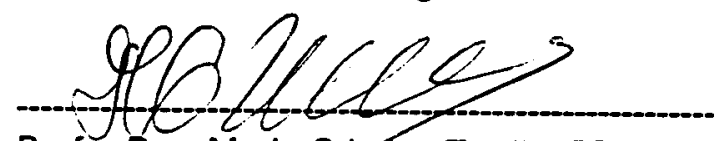

Profa. Dra. Maria Cristina Terrile/IFSC-USP

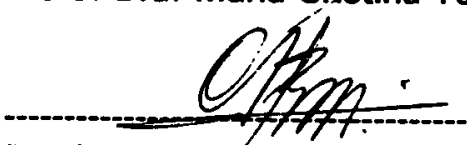

Dr. Clóvis Isberto Biscegli/EMBRAPA 


\section{SUMÁRIO}

Lista de Figuras.................................................. iv

Resumo.......................................................... vi

Abstract........................................................ vii

Introdução....................................................... 1

Capítulo 1. Uma Introdução à Ressonância Magnética

Nuclear - RMN 3

1.1.Introdução................................................................ 3

1.2.Estados de spin nuclear................................................... 4

1.3. Núcleo isolado sob a ação de um campo magnético $\vec{B}=B_{0} \hat{k} \ldots \ldots \ldots \ldots \ldots . . .6$

1.3.1Hamiltoniana de interação.........................................6

1.3.2. Separação em níveis de energia - Efeito Zeeman.................. 8

1.4.Diferença de população...................................................... 9

1.5.Valores médios do momento magnético - Precessão.......................... 11

1.5.1.Precessão do momento magnético..................................13

1.6.Sistema de spins sob a ação de um campo magnético estático e de uma perturbação dependente do tempo.............................15

1.6.1. Perturbações dependentes do tempo.................................15

1.6.2.Campo de rádio-frequência..........................................18

1.6.3. Magnetização sob ação do campo de RF...........................20

1.7.Princípio de Deteç̧ão do Sinal de RMN.....................................22

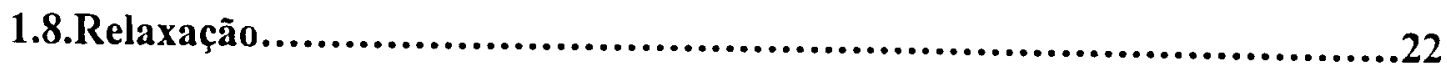

1.9.Interações nucleares........................................................27

1.9.1.Interação dipolar..................................................28

1.9.2.Interação de Anisotropia de Deslocamento

Químico - Chemical Shift...................................................30 
2.1.Introdução

2.2. Dupla Ressonância...................................................... 35

2.2.1. Desacoplamento - DEC....................................... 36

2.2.2. Polarização Cruzada............................................ 42

2.2.2.1. Termodinâmica de spins........................ 42

2.2.2.2.Transferência de Polarização - Condição de

Hartmann - Hahn.......................................... 46

2.2.2.3Quantificação a partir dos espectros de RMN.... 49

2.3. Rotação da Amostra no Ângulo Mágico - MAS.............................. 51

2.4.0 experimento CPDECMAS............................................ 53

Capítulo 3. Quimiometria e Análise Quantitativa................... 54

3.1.Introdução................................................................. 54

3.2.Análise Quantitativa...................................................... 55

3.3.Calibração Multivariada................................................... 57

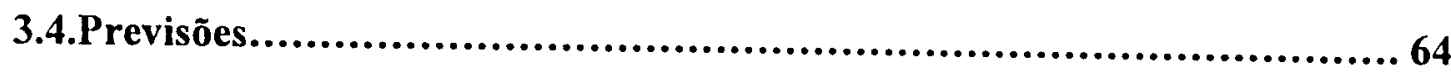

3.5.Rotina AMV .......................................................... 65

Capítulo 4. Metodologia Experimental...............................66

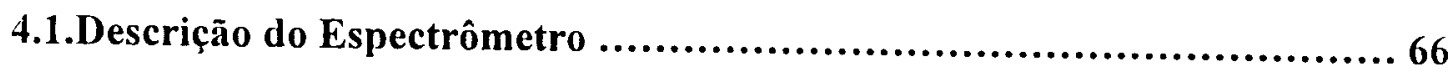

4.1.1.Transmissão de RF............................................. 68

4.1.2.Recepção de RF - Sinal de RMN...................................69

4.1.3.Sonda de Dupla Ressonância........................................ 70

4.1.4.Sistema de Rotação da Amostra......................................72

4.2.Preparação do Experimento CPDECMAS e a aquisição do sinal de ${ }^{13} \mathrm{C} . . .74$

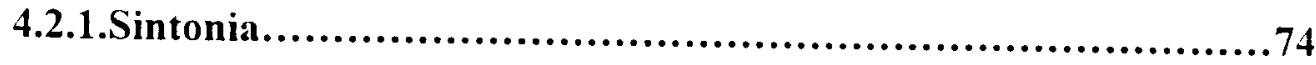

4.2.2.Ajuste do ângulo mágico e pulso $\pi / 2$ para ${ }^{13} \mathrm{C}$...................... 75

4.2.3.Ajuste do pulso $\pi / 2$ para ${ }^{13} \mathrm{C}$ - Sequência DEC.................. 77 
4.2.4.Pulso $\pi / 2$ para ${ }^{1} H$ e Condição de Hartmann-Hahn 79

4.3.Preparação das amostras............................................ 81

4.4.Tratamento dos dados...............................................82

Capítulo 5. Resultados e Discussão 86

5.1.Espectros de $\mathrm{RMN}$ de ${ }^{13} \mathrm{C}$ e resultados das previsões com análise multivariada......................................................... 86

5.3. Construção das bases de dados para calibração..................... 90

Capítulo 6. Conclusões 101

Bibliografia 103

Anexo A: Cálculo dos valores médios do momento magnético nuclear. AA.1

Anexo B: Cálculo da Probabilidade de Transição AB.1 Anexo C: Rotina AMV. AC.1 


\section{Lista de Figuras}

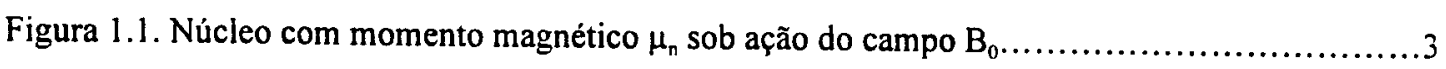

Figura 1.2. Quantização da componente $\mathrm{z}$ do momento angular................................6

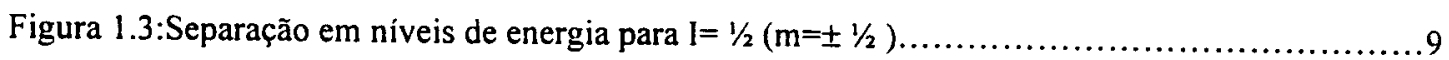

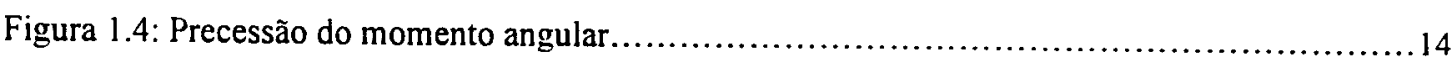

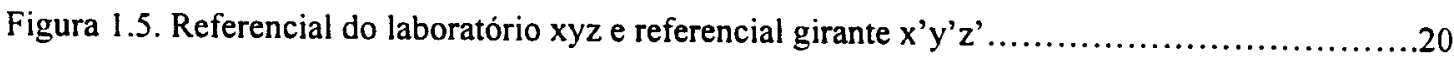

Figura 1.6. Pulso de $90^{\circ}$ aplicado sobre a magnetização.........................................22

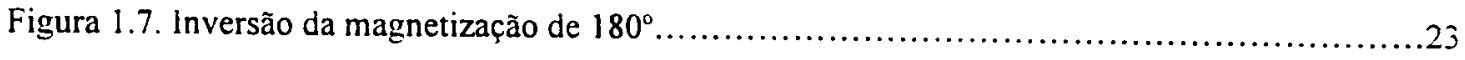

Figura 1.8. Retorno da magnetização ao equilibrio com $\mathrm{B}_{0}$ e indução do sinal de RMN..............25

Figura 1.9. FID de uma amostra contendo uma única freqüência de ressonância.....................26

Figura 1.10. FID de amostra com duas frequêencias de ressonância...............................26

Figura 1.11. Free Induction Decay - FID (a) e sua Transformada de Fourier (FFT) (b) ................27

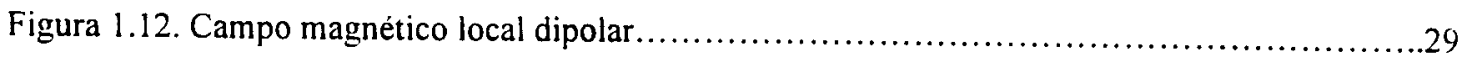

Figura 1.13. Principais regiões de deslocamento químico de ${ }^{13} \mathrm{C}$ nos espectros de $\mathrm{RMN}$.................32

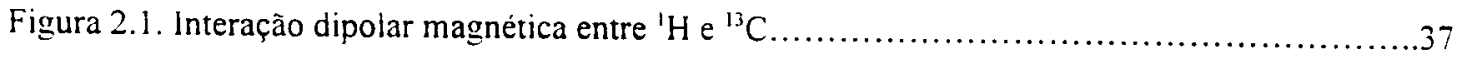

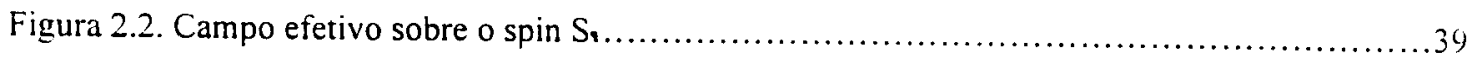

Figura 2.3. Espectro de freqüências do núcleo I para duas condições do campo $B_{1 s} \ldots \ldots \ldots \ldots \ldots \ldots . \ldots$ ]

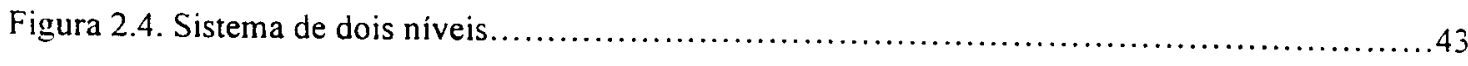

Figura 2.5. Representação dos sistemas de spin de ${ }^{13} \mathrm{C}$ e ${ }^{1} \mathrm{H}$ no experimento de Polarização.............44

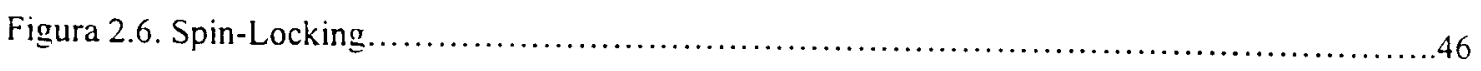

Figura 2.7. Niveis energeticos antes e depois de satisfeita a condição de Hartmann-Hahn..............47

Figura 2.8. Rotação da amostra na condição de Ángulo Mágico ..................................... 
Figura 2.9. A rotação da amostra em torno do ângulo mágico leva....

Figura 2.10. Sequência de eventos no experimento de CPDECMAS. .54

Figura 3.1. Matriz 28×2 graficada no espaço das colunas e os dois primeiros autovetores. 58

Figura 3.2. Decomposição de um espectro em uma combinação.

Figura 3.3. As matrizes u,s e v são resultantes da decomposição em valores singulares da matriz.....62

Figura 3.4.Matriz das concentrações, espectros de RMN e matriz de regressão.

Figura 4.1. Diagrama de blocos do espectrômetro do Lear.

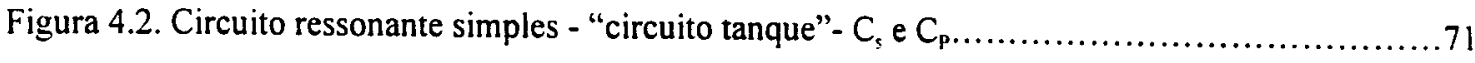

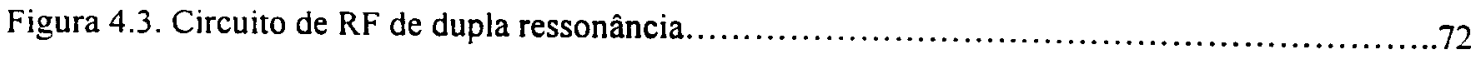

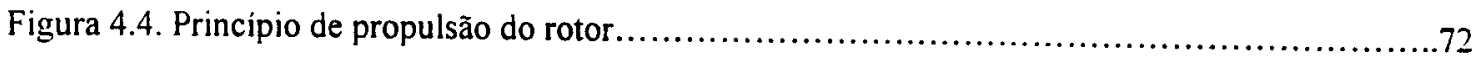

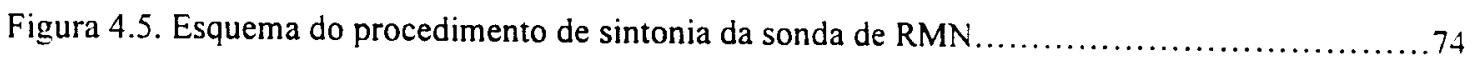

Figura 4.6. Sequência de eventos $\pi / 2$, utilizada para o ạjuste do ángulo mágico..................77

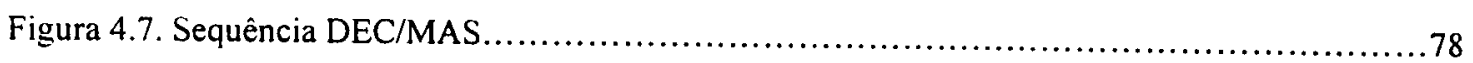

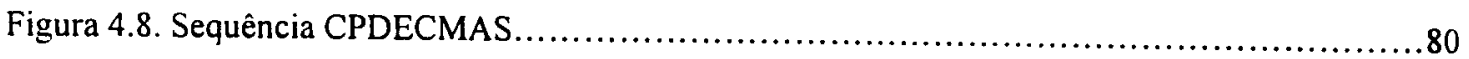

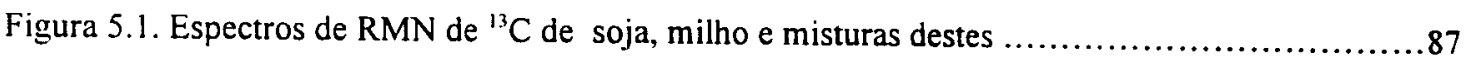

Figura 5.2. Espectros de $\mathrm{RMN}$ de ${ }^{13} \mathrm{C}$ de soja, milho, lisozima e xiloglucano de Copaifera.............88

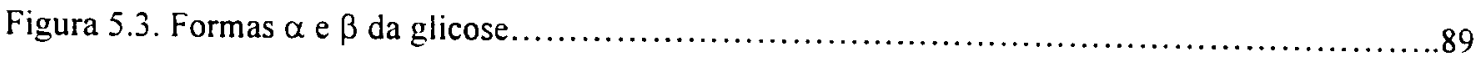

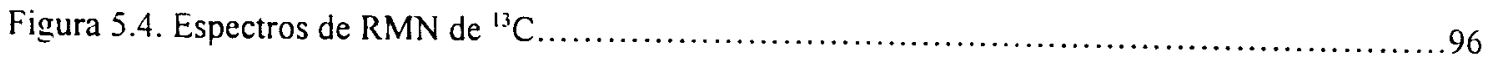

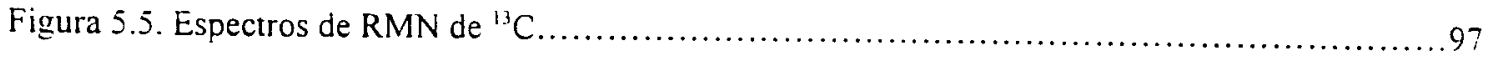

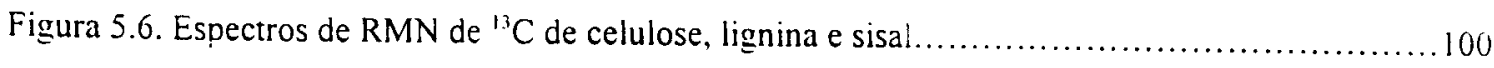




\section{RESUMO}

Neste trabalho utilizamos as técnicas de espectroscopia de alta resolução em sólidos por Ressonância Magnética Nuclear de ${ }^{13} \mathrm{C}$, Polarização Cruzada, Desacoplamento Heteronuclear e Rotação da Amostra em torno do Ângulo Mágico para o estudo de sementes e alimentos. Uma técnica de análise multivariada foi introduzida com o intuito de se desenvolver um método de calibração dos espectros a partir dos experimentos com amostras padrão, de maneira que esse método permita a determinação das concentrações dos componentes da amostra através de uma multiplicação matricial. Essa técnica consiste basicamente da Decomposição em Valores Singulares de uma matriz composta pelos espectros, seguida da regressão linear múltipla visando encontrar uma matriz de regressão entre a matriz de espectros e a matriz de concentrações das principais componentes das amostras. Essa matriz de regressão, multiplicada pelo espectro de uma nova amostra permite a previsão das concentrações dos componentes desta. As concentrações de proteína e amido foram avaliadas para cereais e alguns alimentos industrializados. 


\section{ABSTRACT}

High Resolution Solid-State ${ }^{13}$ C-NMR Spectroscopy techniques Cross Polarization, Decoupling and Magic Angle Spinning, were employed in this work for the study of the chemical composition of seeds and food. A Multivariate Analysis procedure were also employed in the development of a calibration and prediction method for the determination of the components content based on a matrix multiplication. Singular Value Decomposition was carried on the ${ }^{13} \mathrm{C}-\mathrm{NMR}$ spectra matrix followed by Multiple Linear Regression on the components content matrix with the purpose of producing a model that relates the spectra to the sample components content determined by referee methods. When the resulting model is then applied to a new sample, assuming that the correlation found between the calibration set matrices also exists in this sample, it gives the components content values. The protein and starch content were analyzed. 


\section{Introdução}

Os principais objetivos deste trabalho foram a utilização de técnicas de Espectroscopia de Alta Resolução em Sólidos por Ressonância Magnética Nuclear $(\mathrm{RMN})$ de ${ }^{13} \mathrm{C}$ : Polarização Cruzada, Desacoplamento e Rotação da Amostra em torno do Ângulo Mágico, para o estudo de sementes e alimentos, e o desenvolvimento de um método de calibração dos espectros de RMN utilizando princípios de Análise e Calibração Multivariadas.

Mesmo com a aplicação de técnicas de Espectroscopia de Alta Resolução, os espectros de RMN de amostras sólidas não apresentam a mesma resolução dos espectros característicos de amostras líquidas, com linhas estreitas e bem definidas, e a utilização da técnica de Polarização Cruzada, imprescindível na análise de ${ }^{13} \mathrm{C}$, introduz algumas dificuldades no tocante à quantificação direta da composição da amostra a partir dos espectros.

O método de calibração desenvolvido é um método de reconhecimento de padrões, que atua associando as concentrações de determinados componentes de amostras escolhidas à forma do espectro de $\mathrm{RMN}$ de ${ }^{13} \mathrm{C}$. Utilizamos a análise 
multivariada de dados na construção de modelos para a interpretação dos espectros de RMN e previsão das concentrações dos componentes considerados em outras amostras.

A partir dos espectros de $\mathrm{RMN}$ de ${ }^{13} \mathrm{C}$ de sementes, amostras padrão e alimentos, construímos modelos para a previsão das concentrações de proteína e amido, mas o método pode ser extendido à análise das concentrações de outros componentes partindose de espectros de amostras adequadas.

Os dois primeiros capitulos desta dissertação tratam dos príncípios básicos de RMN e das técnicas de Espectroscopia de Alta Resolução empregadas. Ambos foram baseados em diversos textos existentes sobre o assunto, de maneira a proporcionar uma visão geral da técnica sob diversos aspectos. Os principais livros consultados foram : Abragham, 1986; Gil e Geraldes, 1987; Cohen-Tannoudji et al, 1977; Mehring, 1982, Carrington e Mc Lachlan, 1967 e Slichter, 1989. Outros livros, bem como as teses e artigos consultados serão citados no decorrer do texto.

O terceiro capítulo traz uma introdução às técnicas de análise multivariada e uma descrição do procedimento adotado neste trabalho. No capítulo 4 temos uma breve descrição do equipamento de RMN utilizado e da metodologia adotada para os experimentos, e o capitulo 5 traz os resultados obtidos das análises dos espectros adquiridos para sementes, amostras padrão e alimentos utilizando o método de análise multivariada descrito no capítulo 3 .

A motivação para o desenvolvimento deste projeto de mestrado, bem como valiosas discussões sobre o assunto e o acompanhamento de parte do trabalho, partiram do Prof. Dr. Luiz Alberto Colnago, pesquisador do CNPDIA-EMBRAPA-São Carlos. 


\section{Capítulo 1. Uma Introdução à Ressonância Magnética Nuclear - RMN}

\subsection{Introdução}

Os núcleos atômicos possuem além do momento angular $\bar{J}$, um momento magnético $\vec{\mu}$, e essas duas grandezas vetoriais são paralelas entre si, sendo que a constante de proporcionalidade é o fator giromagnético $\gamma$ caracteristico de cada núcleo (equação 1.1) (Slichter, 1989). Quando o núcleo é submetido a um campo magnético externo, o momento magnético sofre a ação de um torque. o que causa a sua precessão ao redor do eixo do campo como mostra a figura 1.1.

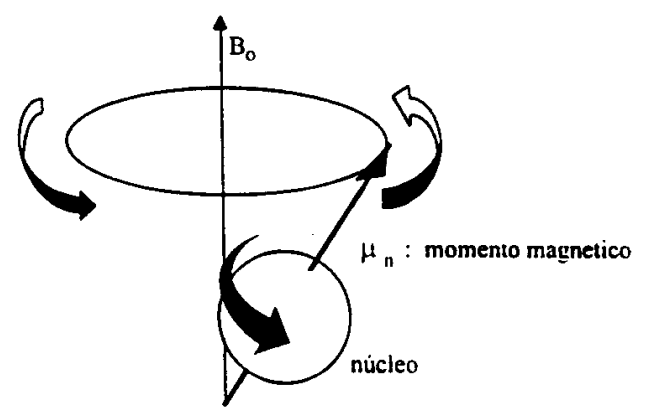

Figura 1.1. Núcleo com momento magnético $\omega_{\text {. }}$ sob ação do campo $B_{f}$. 


$$
\vec{\mu}=\gamma \vec{J}
$$

Inicialmente os momentos magnéticos possuem orientações randômicas, e com a aplicação do campo assumem orientações preferenciais. Isso leva ao surgimento de níveis de energia com diferentes populações obedecendo à distribuição de Boltzman. Uma transição entre esses níveis, provocada pela incidência de radiação provoca uma mudança no estado energético do núcleo quando a energia hv da radiação incidente for igual à diferença $\Delta \mathrm{E}$ de energia entre os níveis considerados.

O experimento de RMN consiste basicamente da aplicação de uma perturbação que modifica a distribuição de população, através da indução de transições entre níveis de energia, e da subsequente observação da volta do sistema ao equilíbrio.

\subsection{Estados de spin nuclear}

De acordo com as leis da Mecânica Quântica, o momento angular total de uma partícula é quantizado, isto significa que ele não pode assumir um valor arbitrário, mas apenas determinados valores discretos. Uma partícula descrita pelos números quânticos $\mathrm{m}_{1}$ e $\mathrm{I}$, número magnético de spin e número quântico de spin respectivamente, pode ser representada por $\left|m_{l}, I\right\rangle$.

O momento angular de spin nuclear, $\vec{J}$, é uma grandeza vetorial cujo módulo ao quadrado é função do número quântico de spin I. Sua atuação sobre uma 
partícula descrita pelos números quânticos $\mathrm{m}_{1} \mathrm{e} \mathrm{I}$, número magnético de spin e número quântico de spin respectivamente, representada por $\left|m_{l}, I\right\rangle$ fornece autovalores da forma:

$$
J^{2}\left|m_{l}, I\right\rangle=[I(I+1)] \hbar^{2}\left|m_{l}, I\right\rangle
$$

Em núcleos com mais de um nucleon, os momentos angulares de spin individuais dos prótons e nêutrons se compõem dando origem a um momento angular resultante, que pode assumir valores inteiros, semi-inteiros ou zero, dependendo do número de nucleons. Para núcleos onde o número de prótons é dado por $\mathrm{Z}$ e o número de massa (prótons mais nêutrons) por $\mathrm{A}$, o número quântico de spin I assume os valores:

$\bullet \mathrm{I}=0$, se $\mathrm{Z}$ e $\mathrm{A}$ forem pares, por exemplo:

$$
\begin{aligned}
& { }^{12} \mathrm{C}, \mathrm{Z}=12, \mathrm{~A}=6 \\
& { }^{16} \mathrm{O}, \mathrm{Z}=16, A=8
\end{aligned}
$$

-I=inteiro, se $\mathrm{Z}$ for ímpar e $\mathrm{A}$ for par:

$$
\begin{gathered}
{ }^{14} \mathrm{~N}, \mathrm{Z}=7, \mathrm{~A}=14 \rightarrow \mathrm{I}=1 \\
{ }^{2} \mathrm{H}, \mathrm{Z}=1, \mathrm{~A}=2 \rightarrow \mathrm{I}=1 \\
\bullet \mathrm{I}=\text { semi-inteiro, se A for impar: } \\
{ }^{13} \mathrm{C},{ }^{1} \mathrm{H},{ }^{15} \mathrm{~N},{ }^{19} \mathrm{~F},{ }^{31} \mathrm{P},{ }^{195} \mathrm{Pt} \rightarrow \mathrm{I}=1 / 2 \\
{ }^{11} \mathrm{~B},{ }^{23} \mathrm{Na},{ }^{35} \mathrm{Cl} \rightarrow \mathrm{I}=3 / 2 \\
{ }^{17} \mathrm{O},{ }^{27} \mathrm{Al} \rightarrow \mathrm{I}=5 / 2
\end{gathered}
$$


A projeção na direção $z$ do momento angular de spin, $\bar{J}_{z}$, também é quantizada, sendo proporcional ao número magnético de spin, $\mathrm{m}_{1}$, que pode assumir $2 \mathrm{I}+1$ valores, de -I a +I em passos inteiros:

$$
J_{z}\left|m_{l}, I\right\rangle=m_{l} \hbar\left|m_{l}, I\right\rangle
$$

onde: $\mathrm{m}_{1}=-\mathrm{I},-\mathrm{I}+1, \ldots,+\mathrm{I}$

Para $I=1 / 2, m_{1}$ pode ser igual $a+1 / 2$ ou $-1 / 2$, no caso de $I=1$ existem 3 valores possíveis para $m_{1}:+1,0$ e -1 , como ilustra a figura 1.2 , onde temos as projeções dos valores de $\vec{J}_{z}: \hbar, 0$ e $-\hbar$

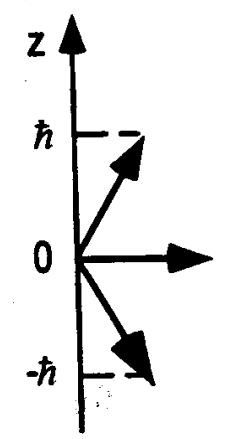

Figura 1.2. Quantização da componente $z$ do momento angular

1.3. Núcleo isolado sob a ação de um campo magnético $\bar{B}=B_{0} \hat{k}$

\subsubsection{Hamiltoniana de interação}

A equação de Schrödinger independente do tempo fornece o valor da energia total, E, da função $\Psi$ que descreve um sistema, quando sobre esta função atua o operador Hamiltoniano, $\mathrm{H}$ : 


$$
\mathrm{H}|\Psi\rangle=\mathrm{E}|\Psi\rangle
$$

O hamiltoniano é um operador representante das energias de interação a que o sistema está sujeito. Passaremos a denominar $\mathrm{H}_{\mathrm{int}}$ o hamiltoniano de interação do núcleo com um campo magnético, equação (1.5),

$$
H_{\mathrm{int}}=-\vec{\mu} \cdot \vec{B}
$$

onde:

$$
\begin{aligned}
& \vec{\mu}=\gamma \vec{J} \\
& \vec{J}=\hbar \vec{I} \\
& \vec{B}=B_{0} \hat{z}
\end{aligned}
$$

Dessa forma temos :

$$
\begin{aligned}
& H_{\mathrm{int}}=-\eta \hbar \vec{I} \cdot B_{0} \hat{z}=-\gamma \hbar I_{z} B_{0} \\
& H_{\mathrm{int}}|\Psi\rangle=E|\Psi\rangle \\
& -\hbar_{0} B_{0} I_{z}|\Psi\rangle=E|\Psi\rangle
\end{aligned}
$$

Como o operador de spin, $\mathrm{I}_{z}$, atua sobre a auto-função?

O momento angular de uma partícula com momento linear $\vec{p}$ é:

$$
\vec{J}=\vec{r} \times \vec{p}
$$

utilizando o operador diferencial : $\vec{p}=-i \hbar \vec{\nabla}$ (Cohen-Tannoudji et al., 1977), temos:

$$
\begin{gathered}
\vec{J}=-i \hbar \vec{r} \times \vec{\nabla} \\
\vec{J}=-i \hbar\left[\left(y \frac{\partial}{\partial z}-z \frac{\partial}{\partial y}\right) \hat{i}-\left(x \frac{\partial}{\partial z}-z \frac{\partial}{\partial x}\right) \hat{j}+\left(x \frac{\partial}{\partial y}-y \cdot \frac{\partial}{\partial x}\right) \hat{k}\right]
\end{gathered}
$$

Escrevendo a componente na direção $\mathrm{z}$ em coordenadas esféricas: 


$$
J_{z}=-i \hbar\left(x \frac{\partial}{\partial y}-y \frac{\partial}{\partial x}\right)=-i \hbar \frac{\partial}{\partial \varphi}
$$

O operador de spin na direção Oz é portanto:

$$
I_{z}=\frac{1}{\hbar} J_{z}=-i \frac{\partial}{\partial \varphi}
$$

\subsubsection{Separação em níveis de energia - Efeito Zeeman}

Da equação para o momento angular em coordenadas esféricas, equação (1.7), vimos que o termo $\mathrm{J}_{2}$ é uma derivada em termos da coordenada $\varphi$. Sua atuação sobre uma função de onda tem efeito apenas sobre o termo dependente dessa variável. A função de onda independente do tempo pode ser escrita como:

$$
\psi(r, \theta, \varphi)=\exp (\operatorname{im} \varphi) R(r) \Theta(\theta)
$$

e a atuação do operador momento angular leva a:

$$
\begin{aligned}
& J_{z} \psi(r, \theta, \varphi)=-i \hbar \frac{\partial}{\partial \varphi}\left(\exp \left(i m_{l} \varphi\right) R(r) \Theta(\theta)\right) \\
& J_{z} \psi(r, \theta, \psi)=\hbar I_{z} \psi(r, \theta, \varphi)=m_{l} \psi(r, \theta, \varphi)
\end{aligned}
$$

Onde $\mathrm{m}_{1}$ é o número magnético de spin já definido anteriormente.

Introduzindo a notação

$$
\left|m_{l}\right\rangle \rightarrow e^{i m \varphi} R \Theta
$$

temos:

$$
I_{z}\left|m_{l}\right\rangle=m_{l}\left|m_{l}\right\rangle
$$


A atuação das componentes $I_{x}$ e $I_{y}$ do operador de spin é mais complicada e pode ser descrita introduzindo-se os operadores $\mathrm{I}^{+}$e $\mathrm{I}^{*}$, definidos por:

$$
\begin{array}{ll}
I^{+}=I_{X}+i I_{Y} & I_{X}=\frac{I^{+}+I^{-}}{2} \\
I^{-}=I_{X}-i I_{Y} & I_{Y}=\frac{I^{+}-I^{-}}{2 i}
\end{array}
$$

Os operadores $\mathrm{I}^{+}$e I' atuam levantando e abaixando os valores de $\mathrm{m}_{1}$ da forma descrita pela equação 1.10 (Cohen-Tannoudji, 1977):

$$
\begin{aligned}
I^{+}\left|m_{l}\right\rangle & =\sqrt{I(I+1)-m_{l}\left(m_{l}+1\right)}\left|m_{l}+1\right\rangle \\
I^{-}\left|m_{l}\right\rangle & =\sqrt{I(I+1)-m_{l}\left(m_{l}-1\right)}\left|m_{l}-1\right\rangle
\end{aligned}
$$

O efeito da hamiltoniana de interação é portanto, a divisão do nivel de energia existente antes da aplicação do campo em $2 \mathrm{I}+1$ níveis. Esse efeito é conhecido como “efeito Zeeman". Da equação (1.7):

$$
\begin{aligned}
& -\gamma \hbar B_{0} I_{z}|\Psi\rangle=E|\Psi\rangle \\
& -\gamma \hbar B_{0} m_{l}|\Psi\rangle=E|\Psi\rangle
\end{aligned}
$$

Para um núcleo com spin $I=1 / 2, \mathrm{~m}_{1}$ pode ser igual a $-1 / 2$ ou $1 / 2$, e temos então dois níveis com energias $\gamma \hbar \mathrm{B}_{0} / 2$ e $-\gamma \hbar \mathrm{B}_{0} / 2$, como mostra a figura 1.3:

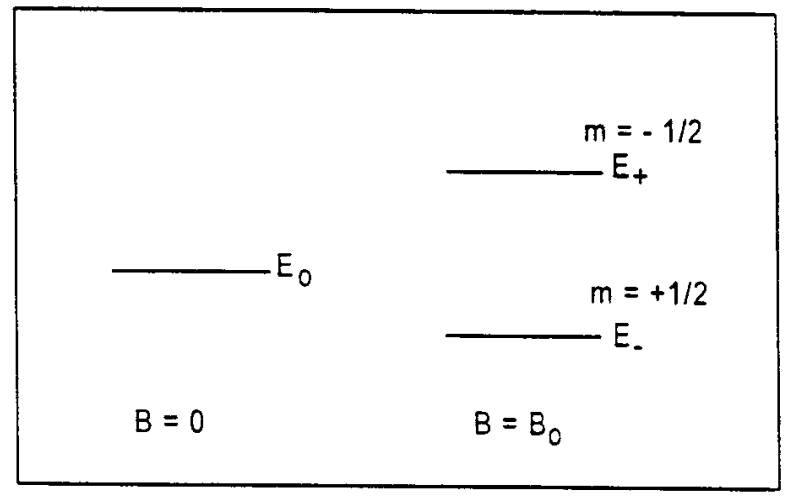

Figura 1.3: Separação em niveis de energia para $\mathrm{l}=1 / 2(\mathrm{~m}= \pm 1 / 2)$ 


\subsection{Diferença de população}

Para uma amostra real, com $\sim 10^{23}$ núcleos, a ocupação dos níveis de energia permitidos, ou seja, a população dos níveis, é dada pela distribuição de Boltzman:

$$
P_{m} \approx \exp \left(-\frac{E_{m}}{k T}\right)=\exp \left(\frac{\not \hbar B_{0} m}{k T}\right)
$$

onde $\mathrm{P}_{\mathrm{m}}$ é a população do nível $\mathrm{m}$.

Para um sistema de dois níveis. como por exemplo núcleos de hidrogênio ' $\mathrm{H}$ ( $\left.\operatorname{spin} 1 / 2, m_{1}= \pm \frac{1}{2}\right)$ submetidos a um campo $B_{0}$ de 1 Tesla à temperatura ambiente $\mathrm{T}=300 \mathrm{~K}$, podemos calcular a diferença de população. Denominando $\mathrm{N}^{+}$a população do nível de menor energia (mais populado) e $\mathrm{N}^{-}$a população do nível de maior energia (menos populado), temos:

$$
\frac{N^{+}}{N^{-}} \approx \frac{\exp \left(\frac{\hbar B_{0}}{k T} \frac{1}{2}\right)}{\exp \left(\frac{\gamma \hbar B_{0}}{k T}\left(-\frac{1}{2}\right)\right)}=\exp \left(\frac{\hbar \hbar B_{0}}{k T}\right)
$$

com: $\quad \gamma_{\mathrm{H} i}^{1}=4,2494 \times 10^{7} \mathrm{~T}^{-1} \mathrm{~s}^{-1}$

$$
\begin{aligned}
& \hbar=6.63 / 2 \pi \times 10^{-34} \mathrm{Js} \\
& \mathrm{k}=1,38044 \times 10^{-2.3} \mathrm{JK}^{-1} \\
& \mathrm{~T}=300 \mathrm{~K}
\end{aligned}
$$




$$
B=1 \text { Tesla }
$$

$$
\frac{N^{+}}{N^{-}} \approx 1,0000011
$$

Pode-se notar que a diferença de população é muito pequena, $\mathrm{N}^{+}$é muito próximo de $\mathrm{N}^{*}$, e no entanto essa diferença é que dá origem ao sinal de RMN. Podemos estudar sistemas de dois niveis induzindo transições que modificam temporariamente essa diferença de população, e observando a volta do sistema ao equilíbrio.

A diferença de população entre os estados dá origem à magnetização líquida do sistema. Podemos considerar essa magnetização como um vetor que possui as mesmas propriedades do vetor momento magnético, e que representa a resultante da associação de todos os momentos magnéticos individuais da amostra.

\subsection{Valores médios do momento magnético - Precessão}

Um sistema que possua $\mathrm{n}$ auto-estados pode num instante $\mathrm{t}$ estar num estado que é combinação linear desses auto-estados. (equação 1.14)

$$
|\Psi\rangle=\sum_{n} \alpha_{n}(t)|n\rangle
$$

Os coeficientes $\alpha_{n}(t)$ são determinados usando-se a equação de Schrödinger dependente do tempo, eq. 1.15:

$$
i \hbar \frac{\partial}{\partial}|\Psi\rangle=H|\Psi\rangle
$$


Substituindo a expressão (1.14) na (1.15)

$$
i \hbar \sum_{n} \frac{d}{d t} \alpha_{n}|n\rangle=H \sum_{n} \alpha_{n}|n\rangle
$$

multiplicando essa expresão à esquerda por $\langle m|$ :

$$
i \hbar \sum_{n} \frac{d}{d t} \alpha_{n}\langle m \mid n\rangle=\sum_{n} \alpha_{n}\langle m|H| n\rangle
$$

como $\langle m \mid n\rangle=\delta_{m ! n}$ e $H_{n}|n\rangle=E_{n}|n\rangle$ chega-se a:

$$
i \hbar \frac{d}{d t} \alpha_{n}=E_{n} \alpha_{n}
$$

cuja solução é:

$$
\alpha(t)_{n}=\alpha(0)_{n} \exp \left(-i \frac{E_{n} t}{\hbar}\right)
$$

A solução da equação de Schrödinger fica então:

$$
|\Psi\rangle=\sum_{n} \alpha_{n}(0) \exp \left(-i \frac{E_{n} t}{\hbar}\right)|n\rangle
$$

onde En é a energia do nível $\mathrm{n}$.

Por simplicidade vamos considerar um sistema de dois níveis, com número de spin $I=1 / 2$ e números magnéticos de spin iguais a $m_{1}= \pm 1 / 2$. As energias dos niveis correspondentes são $\mathrm{E}_{1 / 2}=-\gamma \hbar \mathrm{B}_{0} / 2$ e $\mathrm{E}_{-1 / 2}=\gamma \hbar \mathrm{B}_{0} / 2$. Nesse caso a autofunção é:

$$
|\Psi\rangle=c_{-} \exp \left(\frac{-i E_{+} t}{\hbar}\right)|+\rangle+c_{-} \exp \left(\frac{-i E_{-} t}{\hbar}\right)|-\rangle
$$

onde $c_{-}=a e^{-i \alpha}$ e $c_{-}=b e^{-1 / p}$.

Os valores médios de cada componente do momento magnético no instante t. de um núcleo descrito pela função (1.18) são calculados como: 


$$
\left\langle\mu_{j}\right\rangle=\hbar \hbar\left\langle I_{j}\right\rangle=\hbar \hbar\left\langle\Psi\left|I_{j}\right| \Psi\right\rangle \quad \text { com } \mathrm{j}=\mathrm{x}, \mathrm{y}, \mathrm{z}
$$

No Apêndice A temos o cálculo dos valores médios das três componentes do momento magnético, que são :

$$
\begin{aligned}
\left\langle\mu_{x}(t)\right\rangle & =\gamma \hbar a b \cos \left(\omega_{0} t+\alpha-\beta\right) \\
\left\langle\mu_{y}(t)\right\rangle & =-\gamma \hbar a b \operatorname{sen}\left(\omega_{0} t+\alpha-\beta\right) \\
\left\langle\mu_{z}(t)\right\rangle & =\frac{\gamma \hbar}{2}\left(a^{2}-b^{2}\right)
\end{aligned}
$$

Podemos concluir, das equações para os valores esperados das componentes do momento magnético, que o momento $\vec{\mu}$ executa um movimento de precessão ao redor da direção do campo magnético, como mencionamos na seção 1.2 .

Consideramos o campo na direção do eixo Oz e vimos que a componente $\vec{\mu}_{z}$ se mantém constante, enquanto que as componentes $\vec{\mu}_{X}$ e $\vec{\mu}_{Y}$ executam um movimento circular de freqüência $\omega_{0}$, que é exatamente o comportamento de um vetor precessionando ao redor do eixo $\mathrm{Oz}$.

\subsubsection{Precessão do momento magnético - visão clássica}

Um momento magnético $\vec{\mu}$, na presença de um campo magnético uniforme $\vec{B}$. sofre a ação de um torque $\tau=\vec{\mu} \times \vec{B}$. Por possuir momento angular. o núcleo se comporta como um giroscópio onde o efeito do torque é um movimento de precessão ao redor do eixo do campo, Figura 1.1. 
Consideremos que num intervalo $\Delta \mathrm{t}$, o momento angular $\mathrm{J}$ muda para $\mathrm{J}$, com uma velocidade angular $\omega$, mantendo o mesmo ângulo $\theta$ com o eixo, como mostra a figura 1.4 .

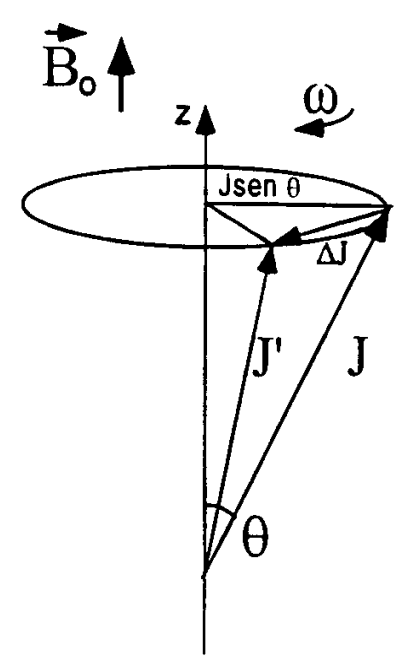

Figura 1.4: Precessão do momento angular

A diferença no momento, $\Delta \mathrm{J}=\mathrm{J}-\mathrm{J}$ ' pode ser calculada como:

$$
\Delta J=(J \operatorname{sen}(\theta)) \omega \Delta t
$$

A taxa de variação do momento angular é:

$$
\frac{d \vec{J}}{d t}=J \operatorname{sen}(\theta) \omega
$$

Para o núcleo com momento magnético e momento angular, a variação no momento angular é causada pelo torque devido à interação com o campo magnético:

$$
\frac{d \vec{J}}{d t}=\tau=\vec{\mu} \times \vec{B}
$$

e como $\vec{\mu}=\gamma \vec{J}$

$$
\frac{d \vec{\mu}}{d t}=\gamma \vec{\mu} \times \vec{B}
$$


Obtemos assim o mesmo resultado da aproximação quântica para a descrição do comportamento do momento magnético.

Das equações (1.22) e (1.23), temos ainda :

$$
\begin{aligned}
J \operatorname{sen}(\theta) \omega & =\mu B \operatorname{sen}(\theta) \\
\mathrm{e} \quad \omega & =\frac{\mu}{J} B_{0}=\gamma B_{0}
\end{aligned}
$$

é a freqüência angular de precessão, $\omega$, denominada freqüência de Larmor, proporcional ao campo magnético $\vec{B}_{0}$ e ao fator giromagnético nuclear, $\gamma=\mu / \mathrm{J}$, cujo valor difere não só para cada elemento químico como também para cada isótopo de spin diferente de zero de um mesmo elemento.

\subsection{Sistema de spins sob a ação de um campo magnético estático e de uma perturbação dependente do tempo}

Com o intuito de estudar um sistema de spins, desejamos perturbá-lo para retirálo de seu estado de equilibrio e, ao acompanhar a volta ao estado não-excitado, determinar as características desse sistema. Transições entre níveis energéticos ocasionam mudanças na magnetização líquida, e a volta dessa magnetização ao equilíbrio, depois da perturbação ser desligada, gera o sinal de RMN.

\subsubsection{Perturbação dependente do tempo - Radiofreqüência}

Consideremos um sistema de dois níveis representados por $|a\rangle$ e $|b\rangle$, com energias $E_{a}$ e $E_{b}$, sujeito a uma perturbação $V(t)$ : 


$$
V(t)=V f(t)
$$

onde $\mathrm{V}$ é um operador independente do tempo e $\mathrm{f}(\mathrm{t})$ é um fator numérico flutuante. $\mathrm{O}$ operador V, escrito na forma matricial, tem elementos na diagonal cujo efeito é uma modulação nos níveis de energia $E_{a}$ e $E_{b}$, e elementos fora da diagonal, $V_{a b}$ e $V_{b a}$, que induzem transições entre os níveis. Temos para esse sistema o hamiltoniano (1.27)

$$
H=\left[\begin{array}{cc}
E_{a} & V_{a b} f(t) \\
V_{b a} f(t) & E_{b}
\end{array}\right]
$$

e a função de onda que é solução da equação de Schrödinger:

$$
|\Psi\rangle=c_{a}(t) \exp \left(-i \frac{E_{a} t}{\hbar}\right)|a\rangle+c_{h}(t) \exp \left(-i \frac{E_{h} t}{\hbar}\right)|b\rangle
$$

Resolvendo o sistema abaixo:

$$
i \hbar \frac{\partial}{\partial}\left[\begin{array}{c}
c_{a}(t) \exp \left(-i \frac{E_{a} t}{\hbar}\right) \\
c_{h}(t) \exp \left(-i \frac{E_{h} t}{\hbar}\right)
\end{array}\right]=\left[\begin{array}{cc}
E_{a} & V_{a h} f(t) \\
V_{h a} f(t) & E_{b}
\end{array}\right]\left[\begin{array}{l}
c_{a}(t) \exp \left(-i \frac{E_{a} t}{\hbar}\right) \\
c_{h}(t) \exp \left(-i \frac{E_{b} t}{\hbar}\right)
\end{array}\right]
$$

temos:

$$
\begin{aligned}
& i \hbar \frac{\partial}{\partial} c_{u l}(t)=V_{a b} c_{h l}(t) f(t) \exp \left(i \frac{\left(E_{a}-E_{b}\right) t}{\hbar}\right) \\
& i \hbar \frac{\partial}{\partial} c_{l \prime}(t)=V_{b a} c_{a}(t) f(t) \exp \left(i \frac{\left(E_{b}-E_{a}\right) t}{\hbar}\right)
\end{aligned}
$$

Admitiremos que no instante $t=0$ o sistema se encontra no estado a, em que $c_{a}(0)=1$ e $c_{b}(0)=0$. e que a perturbação é fraca, de forma que a probabilidade de o sistema sair do estado a é pequena e então $c_{\mathrm{a}}(\mathrm{t}) \cong 1$. A integração da equação (1.28) fornece o valor da correção em $c_{h}$ num tempo $T$ posterior: 


$$
\begin{aligned}
& i \hbar\left[c_{h}(T)-c_{h}(0)\right]=V_{b a} \int_{0}^{T} c_{a}(t) f(t) \exp \left(i \frac{\left(E_{b}-E_{a}\right) t}{\hbar}\right) d t \\
& c_{b}(T)=-i \frac{V_{b a}}{\hbar} \int_{0}^{T} f(t) \exp \left(i \frac{\left(E_{h}-E_{a}\right) t}{\hbar}\right) d t
\end{aligned}
$$

A probabilidade de que ocorra uma transição para o estado b no tempo T é dada por :

$$
P(a, b)=\left|c_{h}(t)\right|^{2}
$$

Um caso em que $\mathrm{P}(\mathrm{a}, \mathrm{b})$ cresce linearmente com o tempo é aquele em que $f(t)$ é uma função periódica do tipo:

$$
f(t)=2 \cos (\omega t)
$$

na equação (1.29):

$$
c_{b}(T)=-i \frac{V_{h a}}{\hbar} \int_{0}^{r} 2 \cos (\omega t) \exp \left(i \frac{\left(E_{h}-E_{a}\right) t}{\hbar}\right) d t
$$

escrevendo $\omega_{b c t}=\frac{(E b-E a)}{\hbar}$, (ou seja, $\hbar \omega_{\mathrm{ba}}$ é a diferença de energia entre os niveis)

e sendo: $\quad \cos (\omega t)=\frac{\exp (i \omega t)+\exp (-i \omega t)}{2}$

$$
c_{h}(T)=-i \frac{V_{h a}}{\hbar} \int_{0}^{T}(\exp (i \omega t)+\exp (-i \omega t)) \exp \left(i \omega_{h a} t\right) d t
$$

A probabilidade $P(a, b)=\left|c_{b}(T)\right|^{2}$, calculada no Apêndice $B$, é igual a:

$$
P(a, b)=\frac{2 \pi\left|V_{h a}\right|^{2}}{\hbar^{2}}\left[\frac{\operatorname{sen}^{2}\left[\frac{\left(\omega_{h a}-\omega\right) T}{2}\right]}{2 \pi T\left(\frac{\omega_{h u}-\omega}{2}\right)^{2}}\right] T
$$


O fator entre colchetes na equação (1.33) é uma representação da função delta de Dirac:

$$
\delta\left(\omega_{b a}-\omega\right)=\left\{\begin{array}{l}
1 ; \omega=\omega_{b a} \\
0 ; \omega \neq \omega_{b a}
\end{array}\right.
$$

obtemos assim a Regra de Ouro de Fermi para a probabilidade de transição entre os níveis de energia a e b, equação (1.34):

$$
P(a, b)=\frac{2 \pi\left|V_{b a}\right|^{2}}{\hbar^{2}} \delta\left(\omega_{b a}-\omega\right) T
$$

\subsubsection{Campo de Radiofreqüência}

A primeira condição a ser satisfeita pela perturbação é que sua atuação forneça ao sistema uma energia $\mathrm{h} v$, onde $v=(\mathrm{Eb}-\mathrm{Ea}) / \mathrm{h}$, ou seja, a energia fornecida ao sistema deve ser igual à diferença de energia entre os niveis.

$\mathrm{O}$ fator independente do tempo da perturbação deve ser tal que $\left|\mathrm{V}_{\mathrm{ba}}\right|^{2} \neq 0$.

$$
\left|V_{b a}\right|^{2}=|\langle a|V| b\rangle|^{2} \neq 0
$$

Consideremos a perturbação aplicada ao sistema de dois niveis como um campo magnético $\vec{B}_{1}$ da forma:

$$
\vec{B}_{1}=B_{1 x} \cos (\omega t) \hat{i}
$$

ou seja, $\vec{B}_{1}$ é um campo magnético na direção x que oscila no tempo como um cosseno de frequência $\omega$. A energia de interação deste campo com o momento magnético $\vec{\mu}$ é: 


$$
H_{R F}=-\mu_{x} B_{1 x} \cos (\omega t)=-\gamma B_{1 x} \cos (\omega t) I_{x}
$$

Comparando a equação (1.36), com a equação geral de uma perturbação $V(t)$, eq.(1.26), temos que o fator dependente do tempo, $f(t)$, é igual a $\cos (\omega t)$, e que o fator independente do tempo, $\mathrm{V}$, é igual a $\left(-\gamma \mathrm{B}_{1 \mathrm{x}} \mathrm{I}_{\mathrm{x}}\right)$.

Para que a probabilidade de transição seja diferente de zero, a freqüência $\omega$ deve ser igual à diferença de energia (Eb-Ea) $/ \hbar$. Normalmente essas freqüências se encontram na faixa de radiofreqüências, ou seja, no intervalo de unidades a centenas de $\mathrm{MHz}$ $\left(10^{6} \mathrm{~Hz}\right)$. A condição para o termo $\mathrm{V}_{\mathrm{ba}}$ é satisfeita pelo campo na direção $\mathrm{x}$, como podemos verificar a seguir:

$$
V_{b u}=\langle a|V| b\rangle=-\gamma B_{1 x}\left\langle a\left|I_{x}\right| b\right\rangle
$$

Denominando $\mathrm{m}_{\mathrm{a}}$ e $\mathrm{m}_{\mathrm{b}}$ os números magnéticos de spin relativos aos estados a e $\mathrm{b}$, a atuação dos operadores de spin sobre estes estados é, a menos das constantes :

$$
\begin{aligned}
& I^{+}\left|m_{b}\right\rangle \propto\left|m_{b}+1\right\rangle \\
& I^{-}\left|m_{b}\right\rangle \propto\left|m_{b}-1\right\rangle
\end{aligned}
$$

Escrevendo o operador $\mathrm{I}_{x}$ em termos dos operadores levantamento, $\mathrm{I}^{+}$, e abaixamento. I; na equação (1.37):

$$
\begin{aligned}
V_{b a} & =-\gamma B_{1 x}\left\langle a\left|I_{x}\right| b\right\rangle=-\gamma B_{1 x}\left\langle a\left|\frac{I^{+}+I^{-}}{2}\right| b\right\rangle \\
V_{b c} & \approx\left\langle a\left|I^{+}\right| b\right\rangle+\left\langle a\left|I^{-}\right| b\right\rangle \\
V_{b a} & \approx\left\langle m_{a} \mid m_{b l}+1\right\rangle+\left\langle m_{a} \mid m_{b}-1\right\rangle
\end{aligned}
$$

Para que $\mathrm{V}_{\mathrm{ba}}$ seja diferente de zero. os níveis a e $\mathrm{b}$ devem ser tais que 


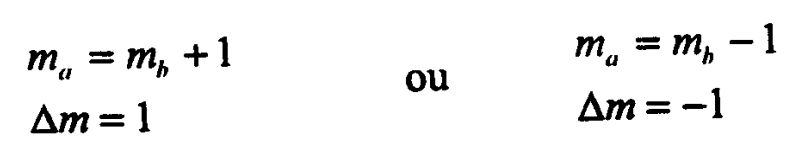

Das regras de seleção acima, vemos que a probabilidade de transição entre dois niveis a e b de um sistema sujeito à ação de um campo $\vec{B}_{1}=B_{1 x} \cos (\omega t)$, só é diferente de zero se esses níveis são adjacentes. Outra condição indispensável é que o campo $\vec{B}_{1}$ seja um campo oscilatório no plano $x y$, do tipo $\vec{B}_{1}=\mathrm{B}_{1 \mathrm{x}} \cos (\omega \mathrm{t}) \hat{i}-\mathrm{B}_{1 \mathrm{y}} \operatorname{sen}(\omega \mathrm{t}) \hat{j}$, pois o hamiltoniano de interação deve ser proporcional aos operadores levantamento e abaixamento, condição satisfeita pelas componentes nas direções $\mathrm{x}$ e y do operador de spin. Um campo na direção $z$ não induz transições entre niveis de energia pois o hamiltoniano nesse caso é proporcional a $I_{2}$, cuja atuação não modifica o estado de spin.

\subsubsection{Magnetização sob ação do campo de RF}

Antes de prosseguirmos devemos introduzir o conceito de referencial girante. Tal sistema é composto de três eixos cartesianos, $x^{\prime}, y^{\prime}$ e $z^{\prime}$, sendo que $z^{\prime}$ coincide com o eixo $z$ do referencial do laboratório. Visto do referencial do laboratório esse sistema de referência executa um movimento de rotação em torno de seu eixo z', com freqüência angular $\Omega$, e é denominado referencial girante. Na figura 1.5 temos um esquema desse sistema de eixos. 


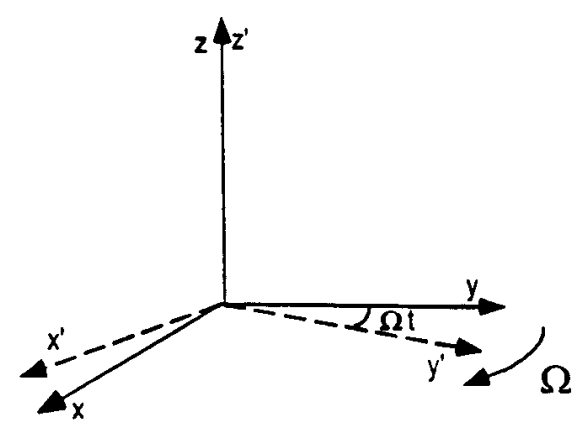

Figura 1.5. Referencial do laboratório xyz e referencial girante x'y'z'. Os eixos z e z' são coincidentes.

Em um referencial girante com a freqüência angular de precessão da magnetização líquida (freqüência de Larmor), o vetor magnetização líquida permanece estático. Assim, um campo magnético alternado $\vec{B}_{1}$, com a mesma freqüência do referencial girante, pode atuar sobre a magnetização.

Se $\vec{B}_{1}$ é aplicado na direção do eixo x' no referencial girante, forma um ângulo de $90^{\circ}$ com a magnetização. De acordo com o teorema de Larmor, a magnetização sofrerá um torque devido a $\vec{B}_{1}$, tendendo a precessionar em torno do eixo x'. A aplicação do campo de radiofreqüência durante um determinado intervalo de tempo é denominada pulso de RF. Uma combinação apropriada de intensidade e duração do campo de RF (largura do pulso) resultará num deslocamento da magnetização de qualquer ângulo desejado. Um pulso que desloque a magnetização de um ângulo de $\theta$ graus (com relação a z' ) é chamado de um pulso de $\theta$ graus. O ângulo $\theta$ é dado por:

$$
\theta=\gamma \vec{B}_{1} t
$$

onde té a duração do pulso.

Na figura 1.6 temos a aplicação de um pulso de $90^{\circ}$. ou $\pi / 2$. vista do referencial do laboratório e do referencial girante (Andrew, 1994). 

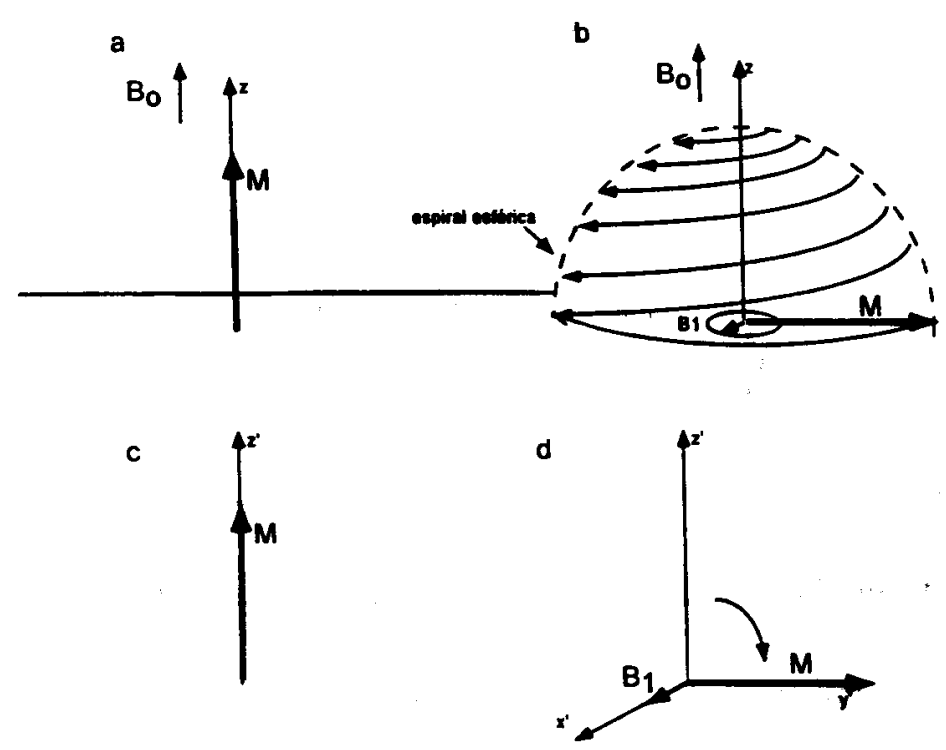

Figura 1.6. Pulso de $90^{\circ}$ aplicado sobre a magnetização. visto do referencial do laboratório (a e b) e no referencial girante (c e d).

\subsection{Princípio de deteç̧ão do sinal de $\mathrm{RMN}$}

A volta da magnetização ao seu estado inicial após a atuação do pulso de RF pode ser detectada por uma bobina que envolva a amostra. Pela Lei de Indução Eletromagnética de Faraday, a precessão da magnetização transversal induz uma força eletromotriz na bobina com a freqüência de Larmor, que é o sinal de RMN.

\subsection{Relaxação}

Um pulso de RF que inverte a direção da magnetização é chamado pulso de $180^{\circ}$ ou pulso $\pi$. Após a aplicação de tal pulso. a magnetização se encontra num estado de 
não-equilibrio, figura 1.7. O retorno da magnetização ao equilíbrio envolve o processo de relaxação nuclear. Pode-se verificar experimentalmente que esse retorno é exponencial, e a constante de tempo que caracteriza esse retorno, $T_{1}$, é o 'tempo de relaxação longitudinal' ou 'tempo de relaxação spin-rede'.

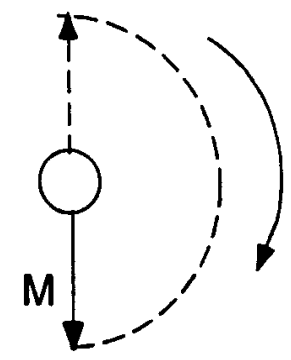

Figura 1.7. Inversão da magnetização de $180^{\circ}$.

Se a magnetização logo após o pulso $\pi$ é igual a $-\mathrm{M}_{\mathrm{o}}$, seu retorno ao valor de equilíbrio, $M_{o}$, é dado pela função (1.40):

$$
M=M_{0}\left(1-2 e^{-\frac{1}{T 1}}\right)
$$

a magnetização passa pelo valor $M=0$ quando $t=T_{1} \ln 2=0.693 T_{1}$.

O que leva a magnetização a retornar ao equilíbrio?

A existência de campos locais flutuantes no plano xy, com freqüências próximas da freqüência de Larmor, induz perturbações que levam à dissipação da energia fornecida ao sistema pelo pulso de RF. fazendo com que a magnetização volte ao seu estado inicial sob a ação do campo externo.

Tomemos como exemplo água pura à temperatura ambiente. Em toda molécula de água cada próton. ${ }^{1} \mathrm{H}$. tem em sua vizinhança próxima um outro próton, distante $1,5 \AA$ 
$\left(1,5 \times 10^{-10} \mathrm{~m}\right)$. Como cada próton tem um momento magnético, induz sobre seu vizinho próximo um pequeno campo magnético local de cerca de 5 Gauss $\left(5 \times 10^{-4}\right.$ Tesla). Esse campo local é flutuante pois as moléculas estão constantemente se reorientando e rodando de forma aleatória, devido a colisões com moléculas vizinhas, e varia entre \pm 5 Gauss, numa escala de tempo de $10^{-11} \mathrm{~s}$, o tempo de correlação do movimento molecular. A análise de Fourier mostra que esse movimento molecular cobre todas as freqüências até mais de $10^{11} \mathrm{MHz}$, o inverso do tempo de correlação.

Consideremos uma freqüência de ressonância de $100 \mathrm{MHz}$. Existe uma componente da freqüência do campo local em $10^{8} \mathrm{~Hz}$, o que significa serem possíveis movimentos dos prótons nessa freqüência.

Assim, um sistema de núcleos excitados pela aplicação de um pulso de RF pode voltar ao seu estado de equilíbrio com o campo magnético externo através de mecanismos de relaxação decorrentes dos campos locais existentes na amostra. Esses campos locais atuam como perturbações que induzem transições entre os níveis de energia.

Consideremos agora o efeito de um pulso de $\pi / 2$, que leva a magnetização ao plano perpendicular à direção do campo $\vec{B}_{0}$, como mostra a figura 1.6.

Depois do pulso de $\pi / 2$ a magnetização $\vec{M}$ precessiona no plano perpendicular ao campo externo. numa situação que também não é de equilíbrio. Essa magnetização começa então a decair transversalmente e a crescer longitudinalmente. O decaimento da magnetização transversal. assim como o correspondente decaimento do sinal de RMN. é exponencial, caracterizado pela constante $T_{2}$, o tempo de relaxação transversal. A 
magnetização líquida é a resultante de milhões de momentos magnéticos nucleares. Cada núcleo sente um campo magnético local devido à sua vizinhança e como os campos são ligeiramente diferentes, ocorre uma defasagem no movimento de precessão. No referencial girante temos um espalhamento desses momentos magnéticos ao redor do eixo z', figura 1.8, e a magnetização transversal vai a zero exponencialmente com a constante de tempo $T_{2}$, enquanto a componente longitudinal cresce também exponencialmente, com a constante de tempo $T_{1}$.

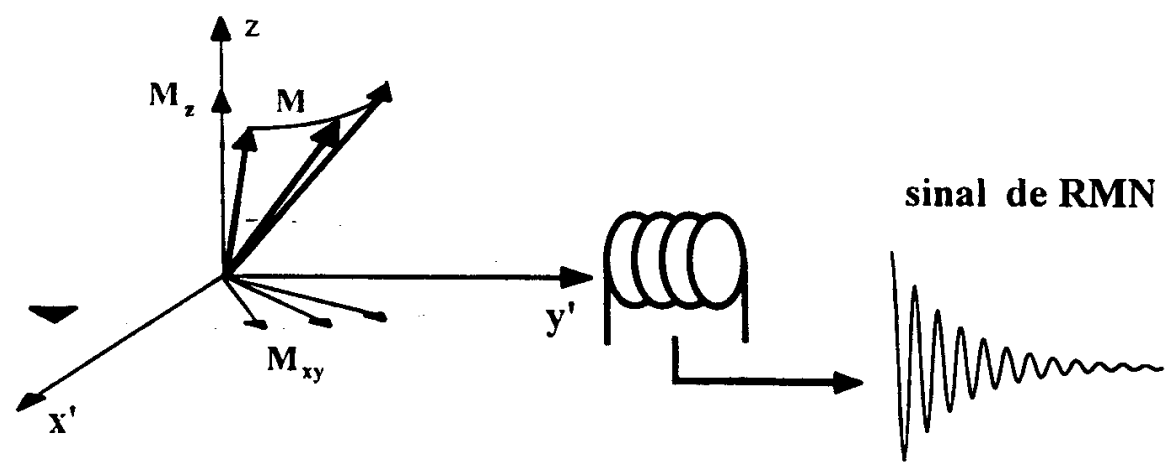

Figura 1.8. Retorno da magnetização ao equilibrio com $B_{n}$ e indução do sinal de RMN.

Uma amostra como a água pura apresenta uma única freqüência de ressonância. e a volta da magnetização ao equilíbrio induz na bobina um sinal de radiofreqüência que decai modulado por uma exponencial de constante de tempo $T_{2}$, figura 1.9. Esse sinal é denominado FID, do inglês Free Induction Decay. 


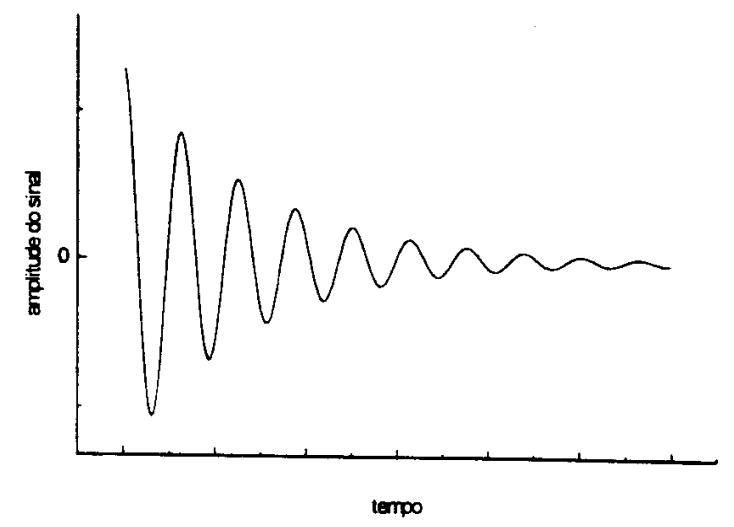

Figura 1.9. FID de uma amostra contendo uma única freqüência de ressonância.

Amostras contendo núcleos cujas freqüências de ressonância são ligeiramente diferentes apresentarão um FID resultante da superposição de sinais de RF. todos dentro do "envelope" exponencial de constante $T_{2}$, figura 1.10.

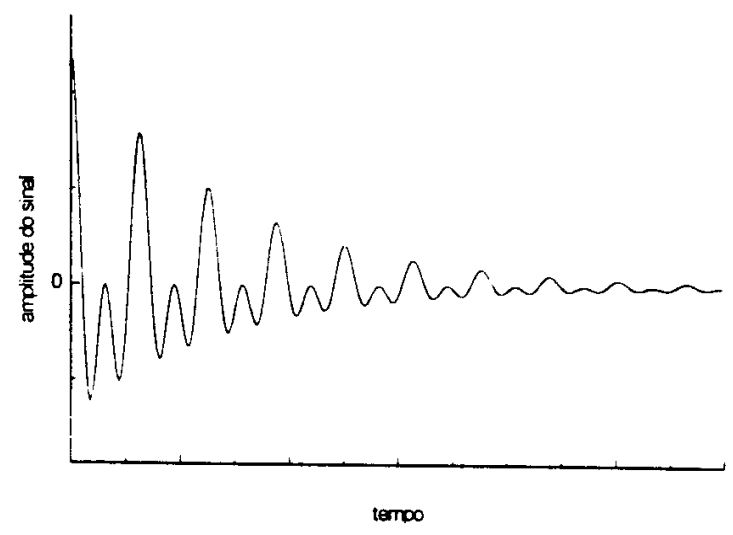

Figura 1.10. FID de amostra com duas freqüências de ressonância.

A análise de Fourier. ou Transformada de Fourier permite a avaliação do FID no dominio das freqüências, produzindo um espectro que contém informaçâo sobre todas as 
freqüências que compõem o sinal, que são as diversas freqüências de ressonância dos núcleos presentes na amostra, figura 1.11 .

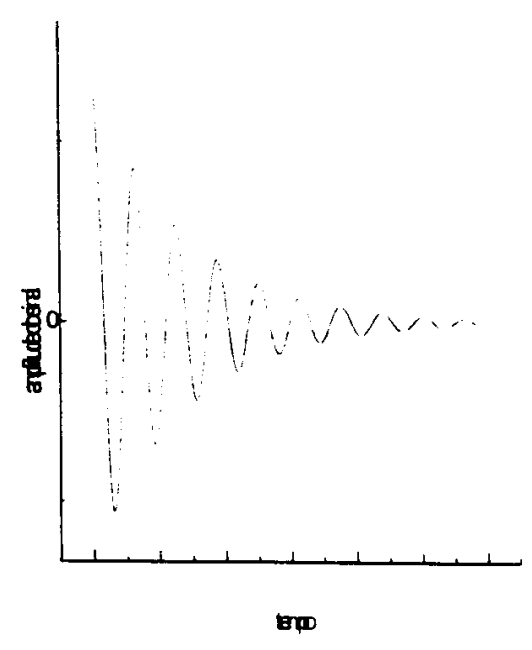

a

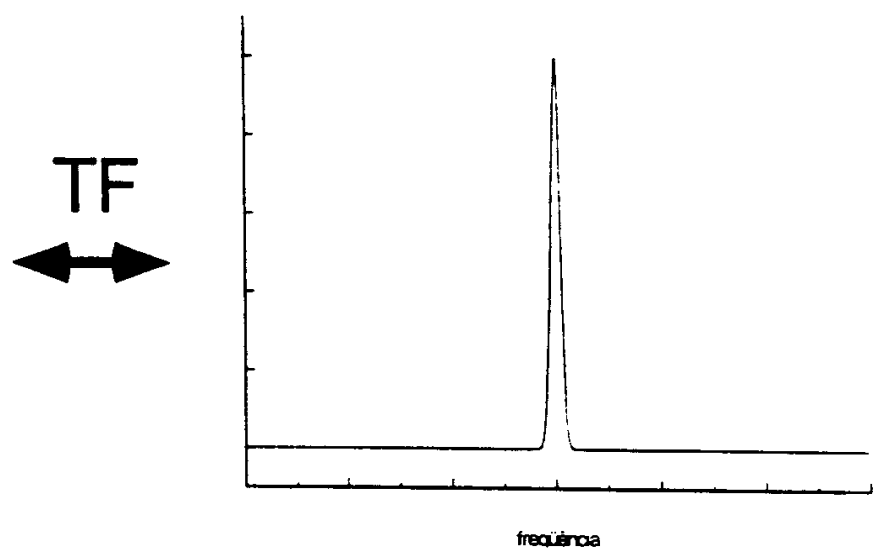

b

Figura 1.11. Free Induction Decay - FID (a) e sua Transformada de Fourier (FFT) (b)

A área da linha espectral obtida pela transformada de Fourier do FID é proporcional ao número de spins que produzem esse FID, permitindo portanto uma correlação entre as linhas espectrais e as concentrações dos núcleos presentes na amostra (Gil \& Geraldes, 1987).

\subsection{Interações nucleares}

Os processos de relaxação se devem a diversas interações existentes entre os núcleos e entre os núcleos e a rede. As mais importantes para este trabalho são:

- interação dipolar 
- interação de anisotropia de deslocamento químico

O efeito dessas interações é a produção de pequenos campos magnéticos locais ao longo da amostra. Dessa forma, núcleos da mesma espécie que se encontrem em ambientes químicos diferentes podem ser diferenciados, pois as freqüências de ressonância e a relaxação nuclear são afetadas pelos campos locais que variam ao longo da amostra.

O hamiltoniano de spin total que descreve as interações a que o sistema de spins está sujeito pode ser decomposto em uma soma de várias parcelas, e em nosso caso consideramos aquelas correspondentes às interações Zeeman, Deslocamento Químico e Dipolar:

$$
\mathcal{H}=\mathcal{H}_{\mathrm{Z}}+\mathcal{H}_{\mathrm{DQ}}+\mathcal{H}_{\mathrm{D}}
$$

\subsubsection{Interação dipolar}

Numa amostra real, a freqüência de ressonância de um núcleo não depende apenas do campo externo $\bar{B}_{0}$. Dependendo do seu posicionamento. o núcleo "sente" campos locais diferentes produzidos por núcleos vizinhos (Bonagamba, 1991). Consideremos por exemplo um núcleo de carbono-13, ${ }^{13} \mathrm{C}$, e um núcleo de hidrogênio, ${ }^{\prime} \mathrm{H}$, separados por uma distância $\mathrm{r}_{12}$, figura 1.12 . 


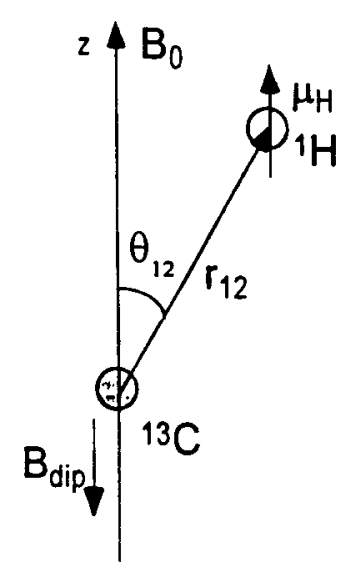

Figura 1.12. Campo magnético local dipolar

Atuando sobre o núcleo de carbono existirá, além do campo $\bar{B}_{0}$, um campo local devido ao momento magnético do núcleo de hidrogênio, e sua freqüência de ressonância passará a depender da magnitude desse campo local $\bar{B}_{d t p}$. O campo $\bar{B}_{d l p}$, equação (1.41), depende em primeira aproximação, da distância entre os núcleos, $\mathrm{r}_{12}$, do momento magnético do hidrogênio, $\mu_{\mathrm{H}}$, e do ângulo formado entre o vetor internuclear e o eixo do campo externo, $\theta_{12}$ :

$$
\vec{B}_{d i p} \approx \frac{\mu_{H}}{r_{12}^{3}}\left(1-3 \cos ^{2} \theta_{12}\right)
$$

Numa amostra sólida existem muitos pares ij de núcleos com distâncias internucleares $\left(r_{i j}\right)$ e ângulos $\theta_{i j}$ diferentes. dando origem a várias freqüências de ressonância diferentes, e produzindo assim uma linha espectral larga. 


\subsubsection{Interação de Anisotropia de Deslocamento Químico (Chemical Shift )}

A interação de Deslocamento Químico deve-se às interações dos elétrons com o campo externo e dos elétrons com o núcleo. $O$ campo externo $\vec{B}_{0}$ induz, via circulação dos elétrons nas nuvens eletrônicas, uma corrente, que por sua vez produz um pequeno campo magnético sobre o núcleo, dado por $\vec{B}_{0} \tilde{\sigma}$ (Gil \& Geraldes, 1987). $\tilde{\sigma}$ é o fator de blindagem magnética, um tensor de segunda ordem cujos elementos dependem da orientação da nuvem eletrônica com relação ao campo externo. O campo efetivo no sitio nuclear é dado por:

$$
\begin{aligned}
& \vec{B}_{c f}=\vec{B}_{0}-\vec{B}_{0} \tilde{\sigma} \\
& \vec{B}_{c f}=\vec{B}_{0}(1-\tilde{\sigma})
\end{aligned}
$$

O fator de blindagem magnética sofre influência tanto da densidade de elétrons na nuvem eletrônica como da orientação dessa nuvem com relação ao campo externo. Com isso, núcleos que se encontram em ambientes químicos diferentes apresentam freqüências de ressonância ligeiramente diferentes. Definida uma freqüência de referência. para uma amostra padrão como por exemplo o TMS, $\mathrm{Si}\left(\mathrm{CH}_{3}\right)_{4}$, para amostras de ${ }^{13} \mathrm{C}$, a distância da freqüência no espectro com relação à freqüência de referência é denominada Deslocamento Químico (CS. do inglês, Chemical Shift). e é dada em partes por milhão (ppm) da freqüência de ressonância do núcleo estudado.

Pode-se encontrar um sistema de eixos $x^{\prime}$. $y^{\prime}$ e z $z^{\prime}$ o sistema de eixos principais. em que o tensor $\tilde{\sigma}$ é diagonal (Gil \& Geraldes. 1987). Nesse sistema. o fator de 
blindagem tem uma dependência com a orientação do eixo $z$ ' em relação a $\bar{B}_{0}$ da forma $\left(3 \cos ^{2} \theta-1\right)$. Em amostras líquidas, devido aos movimentos brownianos rápidos e isotrópicos das moléculas o termo com dependência em $\theta$ se anula, pois o valor médio de $\cos ^{2} \theta$ é igual a $1 / 3$. Temos então apenas o efeito da componente isotrópica do tensor, que é uma constante, e observamos o espectro isotrópico, com linhas bem definidas e espaçadas. Assim, considera-se apenas a hamiltoniana Zeeman, pois o efeito da hamiltoniana de deslocamento químico é igual para todos os núcleos da amostra.

Num sólido policristalino todas as orientações das nuvens eletrônicas e portanto as orientações dos eixos que diagonalizam o tensor $\tilde{\sigma}$ com relação ao campo externo são possiveis e não temos o efeito médio como no caso de líquidos, devido à ausência de movimentos moleculares. Com isso cada linha espectral é alargada, apresentando um padrão relativo às várias orientações possiveis das nuvens eletrônicas. Técnicas especiais são utilizadas para que se possa observar espectros com linhas bem definidas para sólidos, as denominadas técnicas de Espectroscopia de Alta Resolução, descritas no próximo capítulo desta dissertação.

Neste trabalho nos interessam principalmente as informações espectrais referentes aos conteúdos de proteina e carboidratos das amostras. Na figura 1.13 temos os valores de deslocamento químico de ${ }^{13} \mathrm{C}$ para os sinais relativos a esses grupos estruturais. 


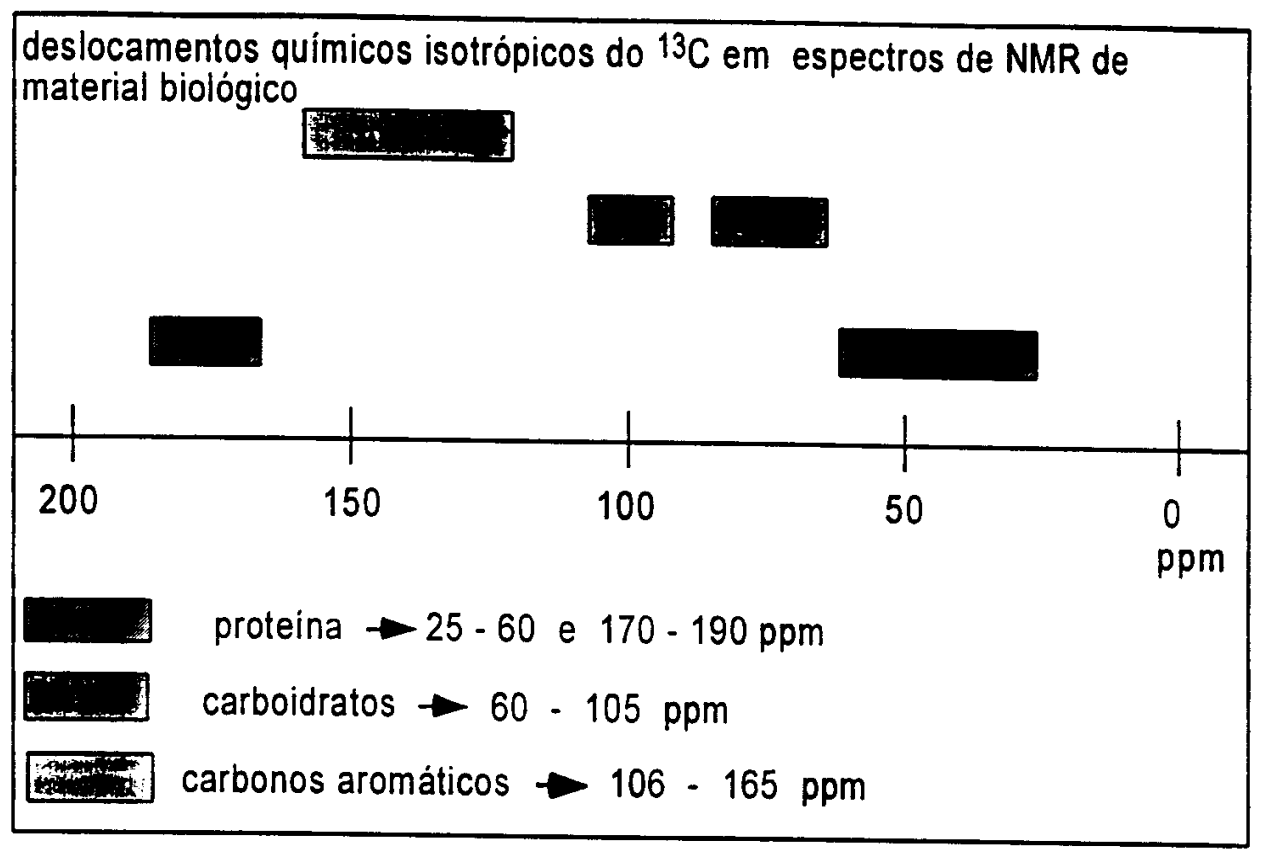

Figura 1.13. Principais regiões de deslocamento químico de ${ }^{13} \mathrm{C}$ nos espectros de $\mathrm{RMN}$ de material biológico com relação ao TMS.

Carbonos de proteína apresentam sinais entre 40 e $60 \mathrm{ppm}$, e entre 170 e 190 ppm, e o pico em $171 \pm 3$ ppm é especialmente importante na determinação do conteúdo de proteina, estando relacionado com a presença de carbonila $(C=O)$. Carboidratos apresentam picos em 60, 71, 74 e 100 ppm aproximadamente (Rutar, 1982). 


\section{Capítulo 2. Espectroscopia de Alta Resolução}

\subsection{Introdução}

Aumentar a resolução dos espectros que permitem a caracterização das amostras é o desejo comum a todos que utilizam as várias técnicas de espectroscopia existentes. As propriedades físicas das amostras e as limitações dos equipamentos são as principais fontes dos problemas enfrentados pelos espectroscopistas. Em RMN de líquidos, a inomogeneidade do campo magnético já foi um problema que atualmente pode ser considerado como praticamente resolvido para grande parte das aplicações práticas. Até recentemente, medidas de espectros de RMN de alta resolução. com separação entre linhas menor que $0.1 \mathrm{~Hz}$. estavam restritas a amostras liquidas e substâncias sólidas passíveis de dissolução em solventes apropriados, pois as técnicas disponiveis não resolviam os problemas intrinsecos dos sólidos.

As interações dipolares magnéticas, homo e heteronucleares, e o deslocamento químico anisotrópico são fatores que contribuem para o alargamento das linhas espectrais dos sólidos, dificultando a observação dos deslocamentos químicos isotrópicos. Estas interações também existem em liquidos. mas são promediadas a zero 
devido ao movimento browniano das moléculas (Bonagamba, 1991). Um outro fato a ser considerado para sólidos é que alguns núcleos de grande interesse como ${ }^{13} \mathrm{C}$ e ${ }^{29} \mathrm{Si}$, que são pouco abundantes e têm um fator giromagnético $(\gamma)$ pequeno, apresentam longos tempos de relaxação spin-rede. Com isso devemos utilizar longos tempos de repetição do experimento. Este fato, aliado à baixa abundância dos núcleos de interesse, torna os experimentos extensos demais, pois a aquisição e promediação de um grande número de transientes se faz necessária para a obtenção de sinais com relação sinal/ruído razoáveis.

Processos de solubilização das amostras nem sempre são possiveis pois existem substâncias importantes que são pouco solúveis e até insolúveis, e ainda substâncias que são dramaticamente modificadas em sua estrutura pelos processos de solubilização.

O crescente interesse pelas propriedades típicas das amostras sólidas, como estrutura molecular e mobilidade, (em polímeros e cristais por exemplo), tem levado à busca de outras soluções para os problemas que limitam a observação dos espectros de alta resolução em sólidos.

As técnicas mais utilizadas para a obtenção de espectros de alta resolução de amostras sólidas são a Rotação da Amostra no Ângulo Mágico - MAS (Magic Angle Spinning) que elimina a interação dipolar e a anisotropia de deslocamento químico e as técnicas de Dupla Ressonância: Polarização Cruzada - CP (Cross Polarization) e Desacoplamento Heteronuclear - DEC (Decoupling). A técnica DEC também é utilizada com o intuito de eliminar os efeitos da interação dipolar entre os núcleos abundantes. no caso 'H. e raros, ${ }^{15} \mathrm{C}$. A técnica de $\mathrm{CP}$ proporciona o aumento da polarização dos núcleos 
raros, através da transferência de polarização dos núcleos abundantes. Com isso temos o aumento da sensibilidade do experimento, pois para os núcleos de interesse em nossos experimentos, ${ }^{1} \mathrm{H} \mathrm{e}{ }^{13} \mathrm{C}$, por exemplo, o aumento da magnetização do ${ }^{13} \mathrm{C}$ é de um fator 4 . Outra característica importante da $\mathrm{CP}$ é a diminuição do tempo de repetição do experimento, que deve ser igual a $5 \mathrm{~T} 1$, e o $T_{1}$ nesse caso é o do núcleo abundante, bem menor que o $T_{1}$ do núcleo raro $\left(T_{1}\right.$ do ${ }^{13} \mathrm{C}$ em sólidos $=10 \mathrm{~s}$, enquanto que o $T_{1}$ do ${ }^{1} \mathrm{H}$ em sólidos é da ordem de $10^{-3} \mathrm{~s}$ ).

Nosso objetivo é a obtenção de espectros de alta resolução para os núcleos de ${ }^{1.3} \mathrm{C}$ em amostras biológicas, que apresentam uma baixa abundância natural, de cerca de 1\%, enquanto que os núcleos de ${ }^{1} \mathrm{H}$ existem com abundância natural de $100 \%$. Para a excitação do carbono utilizamos um campo de freqüência igual a $21,3 \mathrm{MHz}$ e para a excitação do hidrogênio, a freqüência do campo de RF é aproximadamente $85 \mathrm{MHz}$.

\subsection{Dupla Ressonância}

As técnicas de Dupla Ressonância se caracterizam pela atuação de um segundo campo de RF, $\vec{B}_{2}$, sobre o sistema de spins. Tal como o campo $\vec{B}_{1}$, que gira com freqüência $v_{1}, \vec{B}_{2}$ é um vetor rotativo no plano $x y$, de freqüência $v_{2}$, perpendicular ao campo estático $\vec{B}_{0}$. 


\subsubsection{Desacoplamento - DEC}

Sabemos que a freqüência de ressonância de um núcleo depende diretamente do campo magnético efetivo existente sobre ele. Se além do campo magnético externo $\vec{B}_{0}$, aplicado na direção z, atua sobre esse núcleo um campo magnético de origem dipolar, também na direção do eixo $z$, a freqüência de ressonância passa a depender também da intensidade desse campo.

A eliminação do alargamento de linha causado pela interação dipolar heteronuclear é possivel utilizando-se a técnica de Desacoplamento Heteronuclear (DEC). Essa técnica, proposta por Sarles e Cotts, 1958, anula o efeito do campo magnético dipolar local produzido pelos núcleos abundantes sobre os núcleos raros. $\mathrm{O}$ desacoplamento se dá pela redução do momento magnético efetivo do núcleo abundante, através da aplicação de um campo de RF em ressonância perpendicularmente ao eixo $z$ ( o campo $\vec{B}_{2}$, que passaremos a denominar $\vec{B}_{1 S}$ ). Esse campo mantém o momento magnético do 'H em rotação, precessionando ao redor do eixo do campo. Assim, o valor médio de $\mu_{11}$ na direção $z$ é nulo durante a aplicação do campo, figura 2.1.b, anulando a interação dipolar, pois o campo dipolar induzido sobre os núcleos de ${ }^{1.3} \mathrm{C}$ é nulo. $<\mathrm{B}_{\mathrm{dip}}>=0$. 


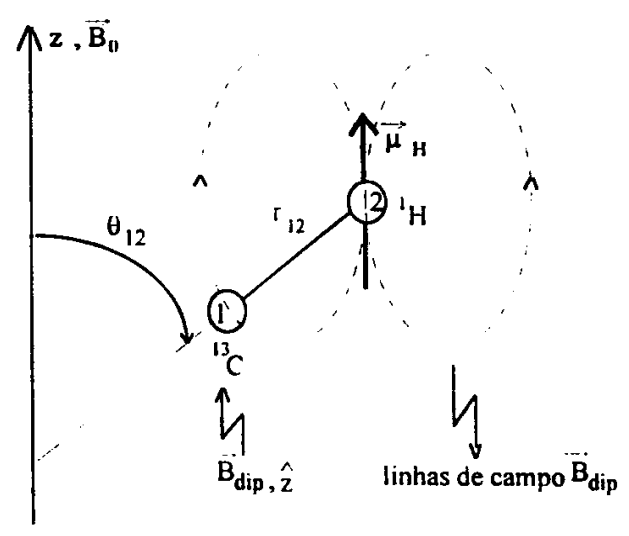

a)

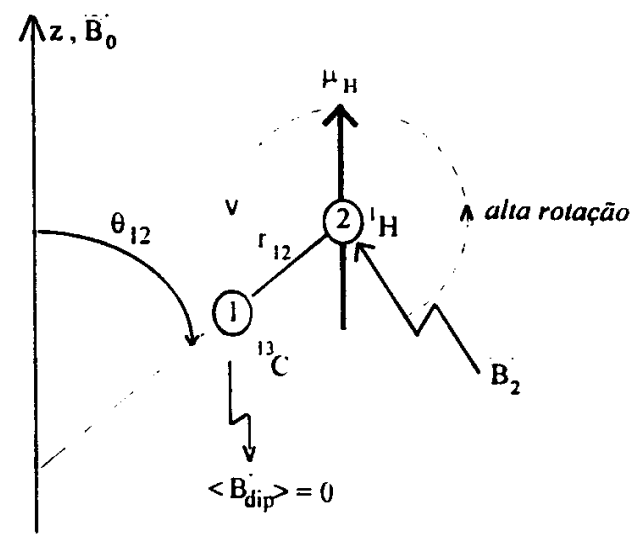

b)

Figura 2.1. Interação dipolar magnética entre ${ }^{1} \mathrm{H}$ e ${ }^{13} \mathrm{C}$. a). Efeito do momento magnético do ${ }^{\prime} \mathrm{H}$ sobre o ${ }^{13} \mathrm{C}$. b). Anulação do campo dipolar induzido no sítio do ${ }^{13} \mathrm{C}$ devida à rotação de $\mu_{\mathrm{H}}$

Analisaremos a hamiltoniana de spin, (Bonagamba.1991), em que consideramos apenas os termos com componentes na direção z, equação (2.1). I representa o núcleo raro, ${ }^{13} \mathrm{C}$, e $\mathrm{S}$ representa o núcleo abundante, ${ }^{1} \mathrm{H}$ :

$$
H=-\gamma_{1} \hbar B_{0} I_{Z}-\gamma_{s} \hbar B_{0} S_{Z}+D I_{Z} S_{Z}+H_{k r}^{s}
$$

Os dois primeiros termos representam as interações Zeeman dos spins I e S com o campo externo $\vec{B}_{0}$, o terceiro termo representa a interação dipolar entre os núcleos I e $\mathrm{S}$, onde $D$ é dado por:

$$
D=\frac{\gamma_{,} \gamma_{S S}}{r^{3}} \hbar^{2}\left(1-3 \cos ^{2} \theta_{I S}\right)
$$

na equação (2.2), $\theta_{\mathrm{IS}}$ é o ângulo formado pelo vetor internuclear e o campo externo. e o quarto termo representa o hamiltoniano de interação do campo de RF com o spin S. dado por:

$$
H_{M !}^{s}=-\gamma_{S} \hbar B_{1 . S}\left(S_{X} \cos \omega_{S} t-S_{Y} \operatorname{sen} \omega_{S} t\right)
$$


Consideraremos o problema em um sistema de referência duplo, ou seja, para os spins I o sistema do laboratório, e para os spins S um referencial girante em torno do eixo $z$, com freqüência $\omega_{\mathrm{s}}$.

Se a hamiltoniana original $\mathrm{H}$ e a função de onda $\Psi$ obedecem a equação (2.4):

$$
-\frac{\hbar}{i} \frac{\partial \Psi}{\partial}=H \Psi
$$

podemos definir a função de onda transformada no referencial girante de S como:

$$
\Psi^{\prime}=e^{-i \omega * S_{*}} \Psi
$$

que substituída na equação (2.4) fornece :

$$
-\frac{\hbar}{i} \frac{\partial \Psi^{\prime}}{\partial}=H \Psi
$$

onde

$$
\begin{aligned}
& H^{\prime}=-\gamma_{1} \hbar B_{0} I_{Z}-\gamma_{s} \hbar B_{0} S_{Z}+D I_{Z} S_{Z}+\hbar \omega_{S} S_{Z}-\gamma_{S} \hbar B_{1 S} S_{X} \\
& H^{\prime}=-\gamma_{1} \hbar B_{0} I_{Z}-\gamma_{S} \hbar \vec{B}_{c f} . \vec{S}+D I_{Z} S_{Z}
\end{aligned}
$$

é o hamiltoniano transformado, e $\mathrm{B}_{\text {ef,S }}$ é o campo efetivo sobre o spin $\mathrm{S}$ :

$$
\vec{B}_{c f . S}=B_{1 . S} \hat{i}+\left[B_{0}-\left(\frac{\omega_{s}}{\gamma_{s}}\right)\right]^{k}
$$

podemos definir ainda, para facilitar a notação:

$$
b_{0 . S}=B_{0}-\left(\frac{\omega_{S . S}}{\gamma_{S}}\right)
$$

Considerando que o campo de RF aplicado é intenso o suficiente para que a condição (2.10) seja satisfeita, podemos considerar o termo $\mathrm{DI}_{2} \mathrm{~S}_{7}$ como uma perturbação e resolver o hamiltoniano não perturbado (equação 2.11). 


$$
\begin{aligned}
& \left.\left.\gamma_{S} \hbar B_{e f, S}\right\rangle\right\rangle D \\
& \dot{H_{n p}}=-\gamma_{1} \hbar B_{0} I_{Z}-\gamma_{S} \hbar \vec{B}_{e f} \cdot \vec{S}
\end{aligned}
$$

Podemos definir um novo sistema de coordenadas, onde o eixo z' fique na direção do campo efetivo $B_{\text {ef,S }}$, e o eixo y permaneça o mesmo, como mostra a figura 2.2:

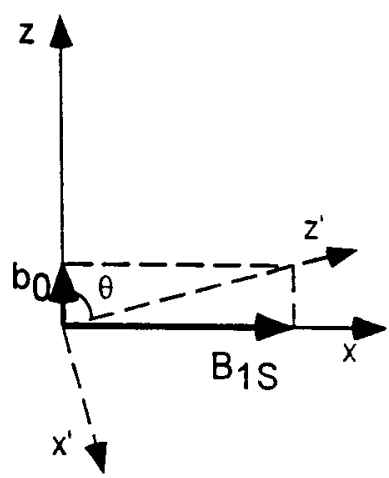

Figura 2.2. Campo efetivo sobre o spin $\mathrm{S}$

e a componente $S_{Z}$ da magnetização é dada por:

$$
S_{z}=S_{:} \cdot \cos \theta-S_{x} \cdot \operatorname{sen} \theta
$$

onde o ângulo $\theta$ é tal que:

$$
\cos \theta=\frac{b_{0 . s}}{\sqrt{\left(B_{1 . S}\right)^{2}+\left(b_{0 . S}\right)^{2}}}
$$

O hamiltoniano não perturbado, dado pela equação (2.14), fornece auto-estados que são funções de $\mathrm{I}_{Z}$ e $\mathrm{S}_{Z}$ :

$$
H_{m p}^{\prime}=-\gamma_{1} \hbar B_{0} I_{Z}-\gamma_{S} \hbar B_{c f} S_{Z}
$$

No novo referencial a perturbação fica na forma:

$$
D I_{Z} S_{Z}=D I_{Z}\left(S_{Z} \cos \theta-S_{r} \operatorname{sen} \theta\right)
$$


e com a perturbação, os auto-valores de energia ficam:

$$
E_{m, m s^{\prime \prime}}=-\gamma_{l} \hbar B_{0} m_{l}-\gamma_{s} \hbar B_{c f, s} m_{S^{\prime \prime}}+D m_{l} m_{S^{\prime \prime}} \cos \theta
$$

Um campo de RF em ressonância com os spins $\mathrm{I}, \vec{B}_{1 /}$, induz transições obedecendo a regra de seleção (2.17):

$$
\left\langle m_{l} m_{S^{\prime}}\left|I_{X}\right| m_{l}^{\prime} m_{S^{\prime \prime}}\right\rangle=\left\langle m_{l}\left|I_{X}\right| m_{l}^{\prime}\right\rangle \delta_{m_{S} m_{S}}
$$

com diferenças de energia $\Delta \mathrm{E}$ dadas por (2.18):

$$
\begin{aligned}
& \Delta E\left(m_{S^{\prime}}\right)=\gamma_{i} \hbar B_{0}-D m_{S} \cos \theta \\
& =\gamma_{i} \hbar B_{0}-D m_{S} \frac{b_{0 . S}}{\sqrt{\left(b_{0 . S}\right)^{2}+\left(B_{1 S}\right)^{2}}}
\end{aligned}
$$

onde $m_{s}= \pm 1 / 2$.

Correspondendo aos dois valores de $\mathrm{m}_{\mathrm{S}}$, existem duas linhas no espectro do núcleo I, cujo espaçamento é função do quanto a freqüência do campo de RF aplicado sobre o núcleo S difere da freqüência de ressonância desse núcleo. Quando o campo $\vec{B}_{1 . S}$ estiver sintonizado nessa freqüência, ou seja $\omega_{S}=\omega_{0 S}$, teremos $b_{0 S}=0$, e existirá apenas uma transição possível. Com isso o espectro do spin I consistirá de apenas uma linha, para $\omega_{1}=\omega_{0(1)}$. desaparecendo o efeito da interação dipolar, figura (2.3). 

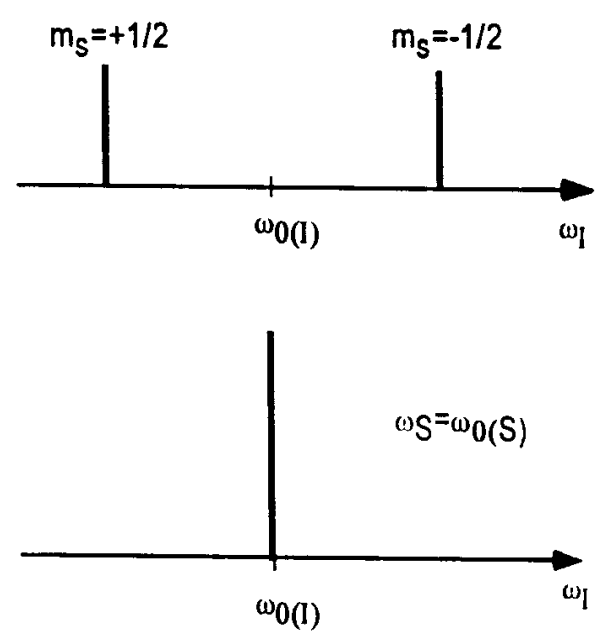

Figura 2.3. Espectro de freqüências do núcleo I para duas condições do campo $B_{I S}: \omega_{S} \neq \omega_{0}$ e $\omega_{S}=\omega_{0}$.

No entanto, essa condição de ressonância para o campo de RF $\vec{B}_{1 S}$, aplicado sobre os spins $S$ introduz um novo problema. Para que a condição de ressonância seja satisfeita para todos os hidrogênios presentes na amostra, a banda espectral do pulso de RF deve ser larga o suficiente para abranger toda a faixa de deslocamentos químicos do 'H. No entanto a duração do pulso é pré-determinada, devendo ser igual ao tempo de aquisição do FID do núcleo raro, tempo durante o qual se deseja eliminar a interação dipolar. Como o tempo de aquisição é relativamente longoo. no domínio das freqüências a banda espectral do pulso aplicado sobre os hidrogênios é estreita, satisfazendo a condição de ressonância para poucos núcleos. Técnicas especiais de modulação (em fase e/ou amplitude) da RF podem ser utilizadas para alargar a banda espectral, de modo que se possa satisfazer a condição de ressonância para todos os núcleos em questão (Silva, 1994). 


\subsubsection{Polarização Cruzada}

Os longos tempos de relaxação spin-rede e a baixa sensibilidade dos núcleos raros são problemas enfrentados pelos espectroscopistas de RMN no estudo de sólidos. Enquanto o 'H é $100 \%$ abundante, o ${ }^{13} \mathrm{C}$ apresenta abundância natural de apenas $1 \%$. A técnica de polarização cruzada, proposta em 1973 por Pines, Gibby e Waugh (Pines et al., 1973), minimiza os problemas com a baixa sensibilidade e os longos tempos de relaxação possibilitando o aumento da magnetização dos núcleos raros através da transferência de magnetização dos núcleos abundantes, e permitindo que a relaxação seja efetuada com o T, do núcleo abundante. que é geralmente menor. Utilizando o conceito de temperatura de spin. introduzido por Redfield, 1969, podemos descrever os principios básicos desta técnica.

\subsubsection{Termodinâmica de spins}

Sistemas de spins cujas distribuições de população no estado de equilíbrio obedecem à distribuição de Boltzmann podem ser caracterizados por uma temperatura de spin.

Para um sistema de dois níveis. figura 2.4. onde $n+$ é a população do nível de menor energia e n- a população do nivel de maior energia. sabemos que as populações se relacionam de acordo com a equação (2.19) : 
Figura 2.4. Sistema de dois niveis.

$$
\frac{n-}{n+}=\exp \left(-\frac{\Delta E}{k T_{s}}\right)=\exp \left(-\frac{\eta \hbar B_{0}}{k T_{s}}\right)
$$

onde $\mathrm{k}$ é a constante de Boltzmann e $\mathrm{T}_{\mathrm{s}}$ é a temperatura de spin. Quando $\mathrm{n}+>\mathrm{n}-$, a correspondente temperatura de spin é baixa, e quando as populações são aproximadamente iguais temos uma alta temperatura de spin.

A magnetização liquida é proporcional à diferença de população entre os níveis. Da lei de Curie para a magnetização, equação (2.20), temos que esta é inversamente proporcional à temperatura de spin:

$$
\vec{M}=C \frac{\vec{B}_{0}}{T_{s}}
$$

onde $\mathrm{C}$ é a constante de Curie, dada por (2.21):

$$
C=\frac{1}{4} k(\not \hbar)^{2} \Lambda
$$

onde $\mathrm{N}$ é o número de núcleos por unidade de volume e $\gamma$ é o fator giromagnético.

Mantendo $\vec{B}_{0}$ constante, podemos alterar a diferença de população dos níveis. e portanto a magnetização líquida. através de uma alteração na temperatura de spin do sistema.

Em sólidos. os sistemas de spins de ${ }^{15} \mathrm{C}$ e ${ }^{1} \mathrm{H}$ podem ser considerados como 43

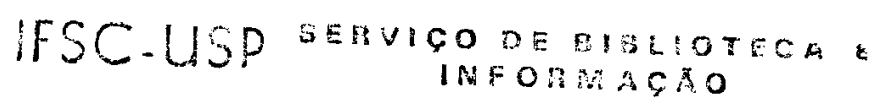


sistemas térmicos praticamente isolados da rede, figura 2.5 , pois possuem tempos de relaxação spin-rede, $T_{1}$, muito longos (alguns segundos). Esses sistemas podem ser considerados ainda como sendo "térmicamente isolados" um do outro, pois a diferença nos niveis de energia Zeeman não permite que ocorram trocas de energia entre eles. No experimento de polarização cruzada, induzindo o "contato térmico" entre os sistemas de spins, permite-se o aumento da magnetização dos núcleos raros através da troca de "calor" entre os dois sistemas (Bonagamba,1991). O sistema de núcleos abundantes, neste caso núcleos de ' $\mathrm{H}$, é considerado como um reservatório térmico para os núcleos raros $\left({ }^{13} \mathrm{C}\right)$, pois sua temperatura de spin muda muito pouco após o contato térmico como veremos adiante.

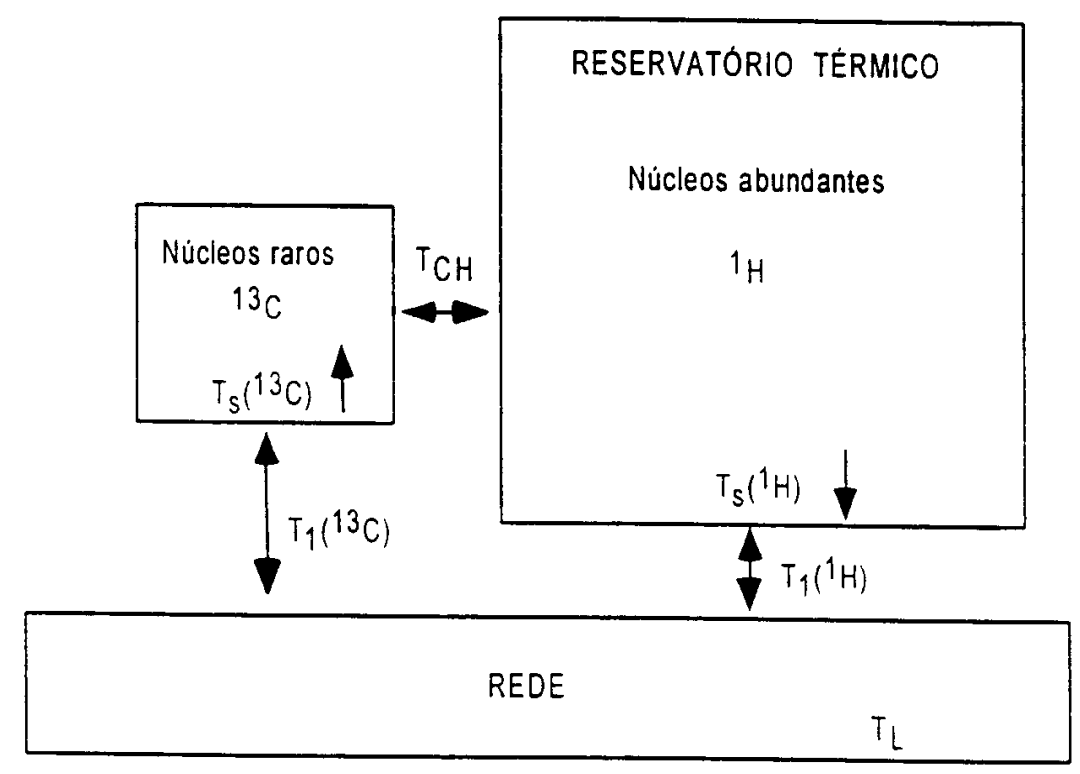

Figura 2.5. Representação dos sistemas de spin de ${ }^{13} \mathrm{C}$ e ${ }^{1} \mathrm{H}$ no experimento de Polarização

Cruzada.

$\mathrm{O}$ primeiro passo no experimento de $\mathrm{CP}$ é a magnetização dos núcleos abundantes. $M_{11}$. ao longo do campo $\vec{B}_{10}$. Em seguida ocorre o "resfriamento" do 
sistema de spins de ${ }^{1} \mathrm{H}$, através do processo de spin locking, figura 2.6. Inïcialmente um campo de rf, $\vec{B}_{1 H}$, é aplicado na forma de um pulso de $90^{\circ}$, levando a magnetização ao plano $x y$. Segue-se a mudança de $90^{\circ}$ na fase do campo de RF. o que deixa esse campo paralelo à magnetização. Com isso a magnetização fica travada na direção de $\vec{B}_{1 H}$. Neste momento temos uma magnetização intensa, que foi produzida por um campo alto, da ordem de $10^{4}$ Gauss, alinhada com um campo bem menor, da ordem de 10 Gauss. Da lei de Curie podemos afirmar que depois do spin locking a temperatura de spin dos núcleos de 'H é bem menor que a inicial, o que pode ser verificado pelas equações abaixo:

$$
\text { inicialmente: } \vec{M}_{\|}=C_{H} \frac{\vec{B}_{0}}{T_{l}}
$$

onde $T_{L}$ é a temperatura da rede, igual à temperatura ambiente $(\sim 300 \mathrm{~K})$.

$$
\text { depois do spin locking: } \vec{M}_{H}=C_{H} \frac{\vec{B}_{1 H}}{T_{H}}
$$

Como a magnetização não foi modificada podemos igualar as expressões (2.22) e (2.23):

$$
C_{H} \frac{\vec{B}_{0}}{T_{l}}=C_{H}^{\prime} \frac{\vec{B}_{1 H}}{T_{H}}
$$

Sendo $\vec{B}_{1 H}<<\vec{B}_{0}$, chega-se a :

$$
T_{H}=\frac{\bar{B}_{1 H}}{\vec{B}_{0}} T_{l}
$$

e portanto $T_{11}<<T_{1}$. Os spins inicialmente em equilíbrio térmico com a rede. a uma temperatura de aproximadamente $300 \mathrm{~K}$. são resfriados a uma temperatura da ordem de $0.1 \mathrm{~K}$. Isso pois $\bar{B}_{0}$ é da ordem de $10^{4}$ Gauss e $\bar{B}_{1 H}$ é da ordem de 10 Gauss. 


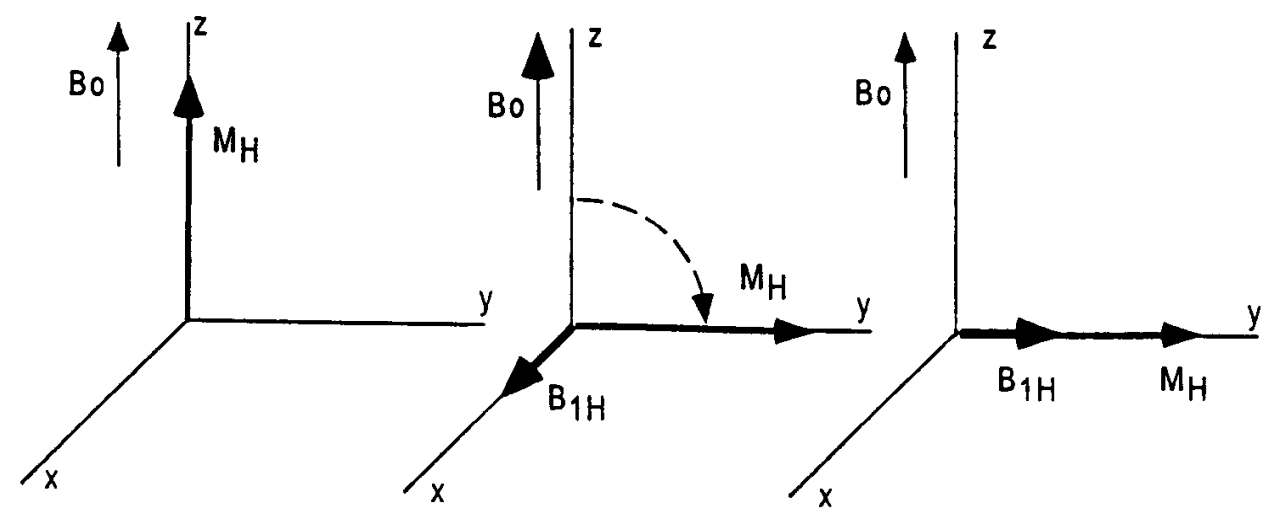

Figura 2.6. Spin-Locking. Inicialmente a magnetização é produzida na direção de $\mathrm{B}_{0}$. $\mathrm{A}$ aplicação de $\mathrm{B}_{1}$ leva a magnetização ao plano xy. Mudando a fase de $B_{1}$ a magnetização fica travada na direção do campo.

\subsubsection{Transferência de Polarização - Condição de Hartmann-Hahn}

Durante o processo de spin-locking para os núcleos de 'H, com a aplicação do campo $\vec{B}_{1 H}$, os núcleos de ${ }^{13} \mathrm{C}$ são irradiados com um campo de $\mathrm{RF}$ em ressonância, $\vec{B}_{1}$. Se os campos $\vec{B}_{16}$ e $\vec{B}_{1 H}$ satisfazem a condição de Hartmann-Hahn (Hartmann \& Hahn, 1962), equação (2.26). então as diferenças de energia dos niveis Zeeman para os dois núcleos se igualam em seus respectivos referenciais girantes, permitindo a interação entre os sistemas. figura 2.8 .

$$
\gamma_{H} \vec{B}_{1 H}=\gamma_{r}, \vec{B}_{16}
$$



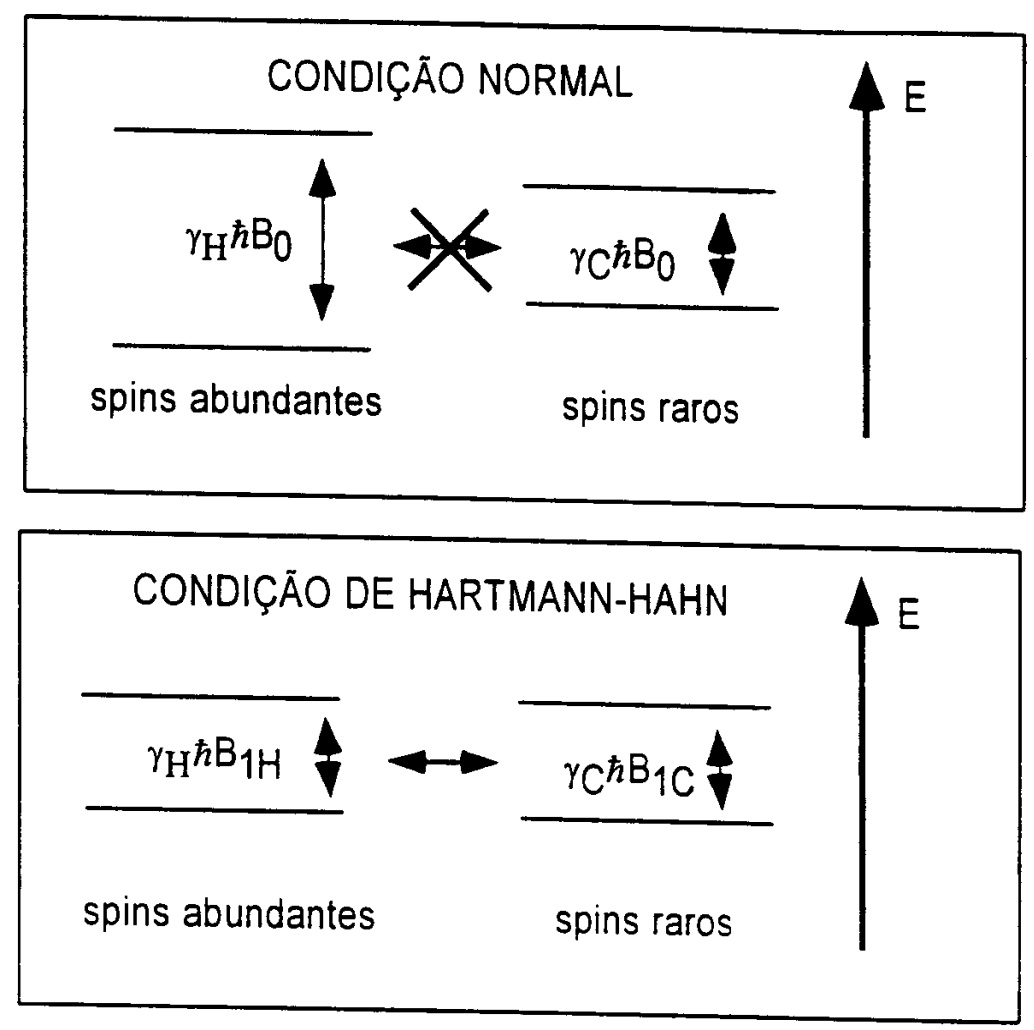

Figura 2.7. Niveis energéticos antes e depois de satisfeita a condição de Hartmann-Hahn.

Após o processo de spin-locking, os núcleos de ' $\mathrm{H}$ se encontram num estado de baixa temperatura de spin e podem ser comparados a um grande reservatório de calor à temperatura $T_{\mathrm{H}}$. Os núcleos de ${ }^{13} \mathrm{C}$, menos sensiveis. dão origem a uma magnetização pequena, e portanto sua temperatura de spin é alta.

Quando a condição de Hartmann-Hahn é satisfeita, a equalização dos níveis de energia Zeeman dos dois sistemas equivale ao estabelecimento de um contato térmico entre o sistema de núcleos de ${ }^{13} \mathrm{C}$, a uma temperatura elevada, e o sistema de núcleos de ${ }^{\prime} \mathrm{H}$, previamente resfriado. Decorrido um tempo de contato $\mathrm{T}_{\mathrm{C}}$ - a temperatura final atingida pelos dois sistemas é praticamente igual àquela do reservatório de 'H. Ocorreu. portanto. um resfriamento do sistema de núcleos de ${ }^{1} \mathrm{C}$. o que equivale a um aumento na 
sua magnetização, sem que tenham ocorrido mudanças significativas no sistema de 'H.

O processo de CP possibilita dessa forma, um aumento na magnetização dos núcleos de

${ }^{13} \mathrm{C}$, como podemos verificar a seguir.

O estabelecimento da condição de Hartmann-Hahn proporciona a redistribuição de energia entre os sistemas. Sabendo que a energia é dada por $E=-\vec{M} \cdot \vec{B}$ temos:

$$
\left(-C_{C} \frac{B_{1 C}^{2}}{T_{C}}-C_{H} \frac{B_{1 H}^{2}}{T_{H}}\right)=\left(-C_{H} \frac{B_{1 H}^{2}}{T_{E}}-C_{C} \frac{B_{1 C}^{2}}{T_{E}}\right)
$$

onde $\mathrm{C}_{\mathrm{H}}$ e $\mathrm{C}_{\mathrm{C}}$ são respectivamente as constantes de Curie para hidrogênio e carbono, dadas por:

$$
C_{H}=\frac{1}{4} k\left(\gamma_{H} \hbar\right)^{2} N_{H} \text { e } C_{c}=\frac{1}{4} k\left(\gamma_{c} \hbar\right)^{2} N_{c}
$$

Como $\gamma_{1} \sim 4 \gamma_{C}$ e sendo $N_{H}>>N_{C}$, (N é o número de núcleos de cada espécie), chega-se a:

$$
T_{l:} \approx T_{H}
$$

Podemos calcular ainda o aumento na magnetização do carbono:

$$
\begin{aligned}
& M_{c}=C_{c} \frac{\vec{B}_{1}}{T_{l:}} \\
& M_{c}=C_{c} \cdot\left(\frac{\gamma_{H H}}{\gamma_{\varsigma}} B_{1 H}\right)\left(\frac{B_{0}}{B_{1 H} T_{l .}}\right) \\
& M_{c}=\frac{\gamma_{H}}{\gamma_{c}} M_{c}^{0}
\end{aligned}
$$

onde $\mathrm{M}^{0}{ }_{C}$ é a magnetização inicial do ${ }^{13} \mathrm{C}$, dada por:

$$
M_{c}^{0}=C_{c}, \frac{B_{0}}{T_{l}}
$$


Temos então, da equação (2.32), o aumento na magnetização do carbono de um fator 4, proporcional à razão dos fatores giromagnéticos.

$$
M_{r} \cong 4 M_{r}^{0}
$$

\subsubsection{Quantificação a partir dos espectros de RMN}

Um problema intrínseco da espectroscopia de alta resolução em sólidos é que a utilização da polarização cruzada nem sempre permite a quantificação correta das substâncias analisadas a partir do espectro. Isso ocorre pois, citando o exemplo do ${ }^{1.3} \mathrm{C}$. grupos $\mathrm{CH}_{\|}$com número de hidrogênios (n) distintos, possuem tempos de relaxação diferentes. e tanto a transferência de polarização quanto a relaxação são diferenciadas para cada grupo.

Os tempos de relaxação envolvidos no experimento de CP são:

- tempo de relaxação cruzada - $\mathrm{T}_{\mathrm{CH}}$;

- tempo de relaxação spin-rede no referencial girante do ' $\mathrm{H}-\mathrm{T}_{1 \rho \mathrm{pH}}$ :

- tempo de relaxação spin-rede do 'H - $\mathrm{T}_{1 \mathrm{H}}$.

A manipulação da sequência de pulsos (eventos) do experimento permite a utilização desses diversos tempos de relaxação para o contraste entre linhas espectrais, permitindo a supressão completa do sinal de um tipo de carbono. Pode-se distinguir entre carbonos mais ou menos protonados e até determinar os tempos de relaxaçâo de cada grupo $\mathrm{CH}_{n}$ presente na amostra. através da variação nas amplitudes relativas das 
linhas induzida por essa manipulação dos tempos de relaxação (Bonagamba, 1991).

Temos portanto uma eficiência variável da polarização cruzada para carbonos de diferentes tipos. Durante o tempo de contato da polarização, $T_{C}$, a magnetização do carbono é intensificada de acordo com a constante de tempo de polarização cruzada, $\mathrm{T}_{\mathrm{CH}}$, e em seguida ocorre a relaxação com a constante de tempo $T_{1 \rho}\left({ }^{1} \mathrm{H}\right)$, a constante de tempo de relaxação spin-rede do 'H no referencial girante. A situação ideal ocorre quando :

$$
T_{C . H}<T_{c}<T_{1 \rho}\left({ }^{\prime} H\right)
$$

Em geral, carbonos alifáticos diretamente ligados a hidrogênios são polarizados mais rapidamente que carbonos aromáticos. especialmente aqueles en estruturas altamente condensadas, que apresentam longos $\mathrm{T}_{\mathrm{CH}}$. Para um sólido homogêneo a nível molecular, existe um único tempo de relaxação do ${ }^{1} \mathrm{H}$ no referencial girante, $T_{\mid \rho}\left({ }^{1} \mathrm{H}\right)$, para todos os hidrogênios. Isso significa que os hidrogênios se encontram num estado de "comunicação" perfeita, ou seja, pode ocorrer a difusão de spins. Em sólidos heterogêneos a nivel molecular, constituídos de domínios de estruturas diferentes, existe um $T_{1 p}\left({ }^{\prime} H\right)$ diferente para cada domínio. O tempo de contato escolhido para nossos experimentos, igual a Ims. é um valor padronizado para experimentos de CP em amostras orgânicas (Preston. 1996).

A quantificação dos componentes das amostras a partir dos espectros requer portanto, uma padronização dos parâmetros experimentais e a calibração desses espectros com relação a um método de análise de referência. Espectros de substânciaspadrão e suas respectivas concentraçôes são avaliadas com um procedimento de 
Calibração Multivariada permitindo a construção de uma matriz de calibração. A multiplicação de um espectro por essa matriz fornece os valores das concentrações das componentes desejadas. Esse procedimento se encontra descrito no próximo capítulo desta dissertação.

\subsection{Rotação da Amostra no Ângulo Mágico - MAS}

Da equação para o campo dipolar local (2.2), vemos que a anisotropia da interação dipolar é descrita pelo termo $\left(1-3 \cos ^{2} \theta\right)$ onde $\theta$ é a inclinação do vetor internuclear com relação ao campo externo, $\vec{B}_{0}$ (figura 2.1.a)). Como os vetores internucleares assumem diferentes orientações com relação ao campo externo, o campo dipolar local é diferente em cada sítio da amostra. Isso resulta numa larga faixa de freqüências de ressonância que se superpõe, dando origem a espectros com linhas largas. Se todos os vetores internucleares assumirem uma orientação tal que $\theta=54^{\circ} 44^{\prime}$, figura

2.8, o Ângulo Mágico, o termo $\left(1-3 \cos ^{2} \theta\right)$ se anula. eliminando a interação dipolar e permitindo a obtenção de espectros com boa resolução. 


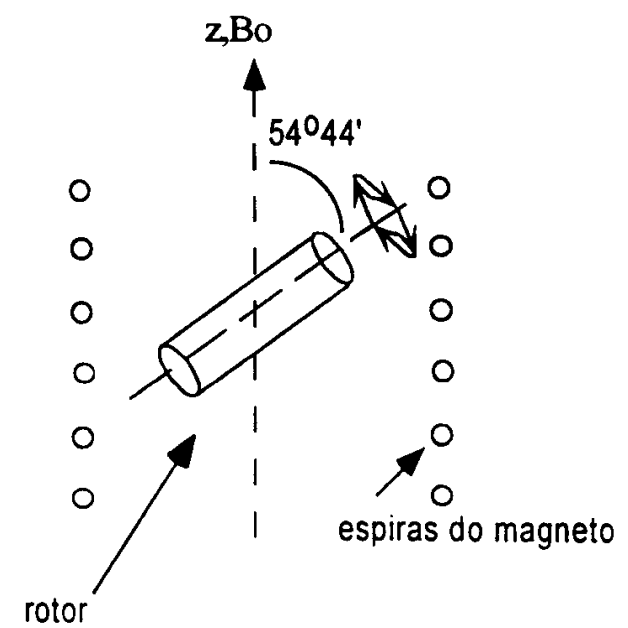

Figura 2.8. Rotação da amostra na condição de Ângulo Mágico sob a ação do campo magnético $\vec{B}_{0}$.

Em 1959. Andrew (Andrew et al., 1959) e Lowe (Lowe, 1959) propuseram independentemente uma técnica para eliminação da interação dipolar, que consiste da rotação da amostra em torno de um eixo inclinado de $54^{\circ} 44^{\prime}$ com relação ao eixo do campo $\vec{B}_{0}$ (figura 2.8, acima). Essa técnica é conhecida como MAS, do inglês Magic Angle Spinning, ou Rotação da amostra no Ângulo Mágico. Como efeito dessa rotação, em média todos os vetores internucleares são levados a assumir a orientação do eixo, (figura 2.9), que no caso é igual ao Ângulo Mágico, e temos então a eliminação da interação dipolar. A anisotropia de Deslocamento Químico também é eliminada, pois também depende do fator $\left(3 \cos ^{2} \theta-1\right)$, além de ser destruída pelo fato de que com a rotação temos o efeito do valor médio de $\cos ^{2} \theta$. que é igual a $1 / 3$, anulando o termo anisotrópico do tensor de blindagem magnética $\tilde{\sigma}$ (equação 1.42).

A freqüência angular da rotação também é um fator importante. devendo ser maior que a largura da banda estática. isto é. maior que a largura em freqüência do espectro obtido para a amostra sem rotação (Bonagamba. 1991). 


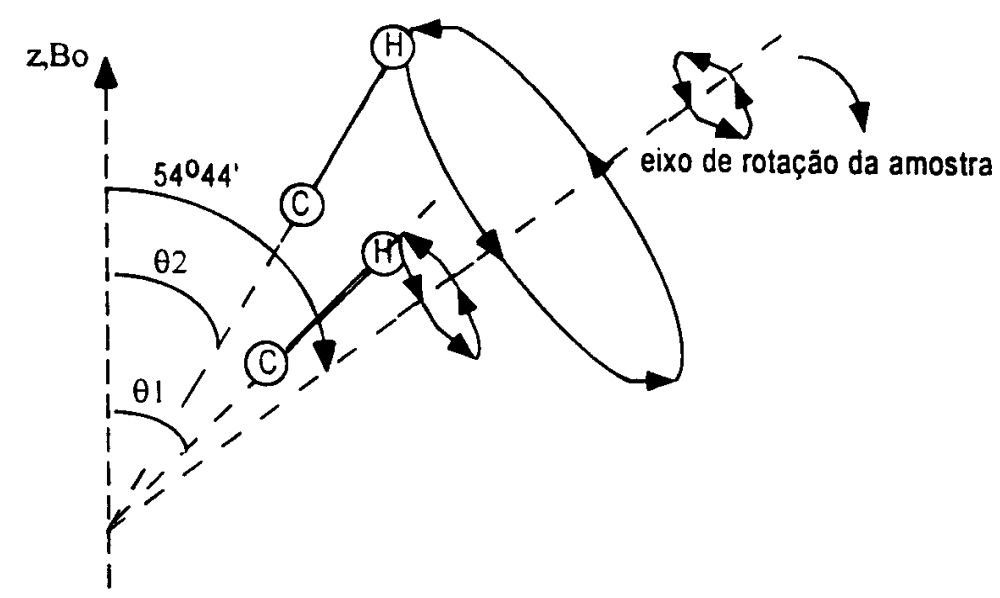

Figura 2.9. A rotação da amostra em torno do ângulo mágico leva todos os dipolos a assumirem uma orientação média igual ao ângulo mágico, $54^{\circ} 44^{\prime}$.

\subsection{O experimento CPDECMAS}

A figura 2.10 mostra a sequência de eventos para o experimento de CPDECMAS, combinação das técnicas de espectroscopia de alta resolução Polarização Cruzada, Desacoplamento e Rotação da Amostra no Ângulo Mágico proposta inicialmente por Schaefer e Stejskal em 1976 ( Schaefer \& Stejskal, 1976). O primeiro passo é o pulso de RF de $90^{\circ}$ na direção x para o 'H, seguido da mudança de fase da RF para o spin-locking (SL) juntamente com a aplicação do campo de $\mathrm{RF} \mathrm{B}_{\mathrm{IC}}$ sobre os núcleos de ${ }^{15} \mathrm{C}$ satisfazendo a condição de Hartmann-Hahn (HH) durante o tempo de contato, $\mathrm{T}_{\mathrm{C}}$. Durante a aquisição do sinal do ${ }^{13} \mathrm{C}$, o FID, o campo de RF no canal do ${ }^{1} \mathrm{H}$ (DEC) tem a função de promover o desacoplamento. O tempo de repetição do experimento. $T_{R}$. é maior ou igual a $5 T_{I I I}$ assegurando que todos os núcleos de ${ }^{1} \mathrm{H}$ relaxem totalmente. A Rotação da Amostra em torno do Ângulo Mágico (MAS) é mantida durante todo o experimento. Na figura 2.10 representamos além da sequéncia de 
pulsos utilizada no experimento, o crescimento exponencial da magnetização do ${ }^{13} \mathrm{C} . \mathrm{M}_{\mathrm{C}}$. o sinal FID, adquirido durante o tempo de aquisição $T_{\text {aq }}$, e o decaimento da magnetização do ${ }^{~} \mathrm{H}, \mathrm{M}_{\mathrm{H}}$, durante o spin-locking e tempo de contato.

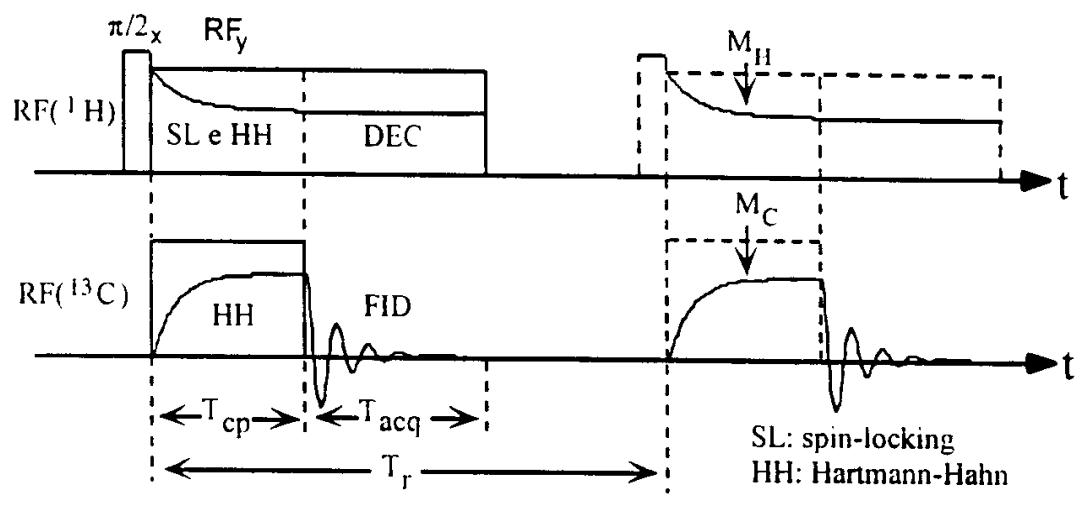

Figura 2.10. Sequência de eventos no experimento de CPDECMAS, a Rotação da Amostra em torno do Ângulo Mágico é mantida durante todo o experimento. 


\section{Capítulo 3. Quimiometria e Análise Quantitativa}

\subsection{Introdução}

A Quimiometria é a disciplina que trata da aplicação de métodos matemáticos e estatísticos à química. Dentre estes métodos, a Calibração Multivariada é especialmente útil em análises espectrais pois a utilização simultânea de muitos espectros pode aumentar a precisão e aplicabilidade de análises quantitativas. Com calibrações multivariadas desenvolvem-se modelos empiricos que relacionam as múltiplas intensidades espectrais de amostras de calibração às concentrações pré-determinadas dos componentes destas amostras. Estas relações empíricas podem ser utilizadas na análise de espectros de amostras desconhecidas para a previsão das concentrações de seus componentes.

Alguns dos métodos de calibração mais conhecidos são: MLR (Multiple Linear Regresion) - Regressão Linear Múltipla, PCR (Principal Components Regresion) Regressão nas Componentes Principais e PLS (Partial Least Squares) - Mínimos Quadrados Parciais. Descrições detalhadas e comparações entre estes métodos encontram-se em (Martin et al., 1992), (Geladi \& Kowalski, 1986), (Beebe e Kowalski. 1987), (Thomas e Haaland, 1988) e (Thomas e Haaland. 1990). A grande maioria dos 
trabalhos publicados nesta área referem-se a aplicações da análise multivariada a espectros de absorção no Infravermelho próximo (Sarver \& Krueger, 1991), (Haaland \& Thomas, 1988), e (Beebe \& Kowalski, 1987) e em dicroismo circular (Compton \& Curtis Johnson, 1986) e (Greenfield, 1996), no entanto os conceitos básicos discutidos se aplicam também à espectroscopia por ressonância magnética nuclear. Aplicações da metodologia à RMN se encontram em (Kuessel et al., 1996), (Stoyanova et al., 1995), (Lenholm \& Iversen. 1995) e (Vogels et al.,1996).

Procuramos com este trabalho desenvolver um método simples para a quantificação dos espectros de ${ }^{13} \mathrm{C}$ por RMN em amostras sólidas. Nosso primeiro objetivo foi a determinação do conteúdo de proteina e amido em sementes e alimentos. Esse método de calibração do espectrômetro permite que utilizemos um método indireto como a espectroscopia por RMN para a determinação de propriedades das amostras que normalmente são determinadas por análises químicas, como no caso das concentrações de proteína e açúcares. Uma das vantagens que o método oferece é a facilidade na interpretação dos espectros, especialmente de espectros de sólidos por RMN, onde mesmo com a utilização de técnicas de alta resolução, geralmente não se obtém linhas muito estreitas e existem superposições.

\subsection{Análise Quantitativa}

O desenvolvimento de um método de quantificação envolve a seleção de amostras de calibração representativas, a obtenção dos espectros e de análises de 
referência, o pré-tratamento dos dados, a modelagem estatística e a validação do modelo (Martin et al., 1992).

O conjunto de amostras de calibração deve ser uma boa representação do conjunto de amostras que serão avaliadas posteriormente com o modelo. Existem vários procedimentos para a determinação do melhor conjunto, entre eles a análise de 'clusters'. ou agrupamentos. em que amostras com características semelhantes são separadas em grupos e escolhe-se um representante de cada grupo. A diversidade espectral também é um critério adotado na escolha das amostras. Espectros de substâncias puras e de misturas destas em proporções conhecidas podem ser utilizados na construção do modelo. sendo esta uma tática válida quando não se dispõe de métodos de análise de referência.

A fase de pré-tratamento dos dados consiste em manipular os dados de modo a minimizar problemas com interferência do equipamento e corrigir linhas de base por exemplo. Normalizações e derivações em cada espectro, centralização na média e escalonamento das variáveis, sâo algumas das operaçōes normalmente utilizadas. sendo que o procedimento a ser adotado depende da técnica espectroscópica (Martin et al. 1992).

As concentrações das componentes das amostras de calibração são obtidas a partir de análises de referência tais como o método de Kjeldahl (AACC 1986) para determinação do conteúdo de proteína baseado na concentração de Nitrogênio, o método de Lowry (Lowry et al.. 1951) também para determinação do conteúdo de proteina e o método de Dubois (Dubois et al., 1956) para determinação do conteúdo de açúcares. Os 
dois últimos métodos apresentam o inconveniente de exigir amostras solúveis em água, o que impossibilitou a análise de sementes de soja e milho. Chan e Wasserman (Chan e Wasserman, 1993) descrevem um método BCA para determinação do conteúdo de proteína em cereais no estado sólido, utilizando um ácido. Tanto o método Kjeldahl quanto o BCA apresentam o inconveniente de destruir as amostras avaliadas, o que não ocorre com as amostras avaliadas por espectroscopia de RMN no estado sólido, em que estas podem ser utilizadas para outras análises após as medidas.

Para a validação do modelo utilizamos um método onde em cada passo, um dos espectros é retirado, e o modelo de calibração construído com os espectros restantes é utilizado para a previsão das concentrações desse espectro. Repete-se o ciclo até que todos os espectros do conjunto tenham sido avaliados, e o modelo é considerado adequado quando os desvios nessas previsões são mínimos.

\subsection{Calibração Multivariada}

A modelagem estatística envolve a utilização de um método de calibração multivariada. O método de Regressão Linear Múltipla - MLR, também denominado "mínimos quadrados inverso" ou método da matriz P é um dos métodos utilizados na modelagem de dados de absorção no infravermelho próximo para predição (Martin et al., 1992). Neste método seleciona-se do espectro alguns comprimentos de onda e as respectivas intensidades são utilizadas na construção do modelo de calibração. considerando-se a concentração como função linear da absorbância. Este é um bom 
método quando se dispõe de dados lineares, com pouco ruído e onde não existem interferências ou interações entre os constituintes das amostras. Como é feita a compressão dos dados através da eliminação de grande parte da informação espectral, a MLR é passível de erros grandes se os comprimentos de onda não são escolhidos adequadamente.

O método PCR utiliza a Decomposição em Valores Singulares, SVD (do inglês Singular Value Decomposition) (Sarver \& Krueger, 1991). A SVD corresponde à deteminação dos autovetores e autovalores da matriz dos dados. Esses autovetores, ou componentes principais, formam uma base ortonormal que descreve as direções de maior variação dos dados. No exemplo da figura 3.1 , cada ponto tem um novo conjunto de coordenadas, suas projeções no novo sistema de eixos, os autovetores, e esses novos eixos podem ser mais eficientes para a descrição da variação ou do espalhamento das variáveis.

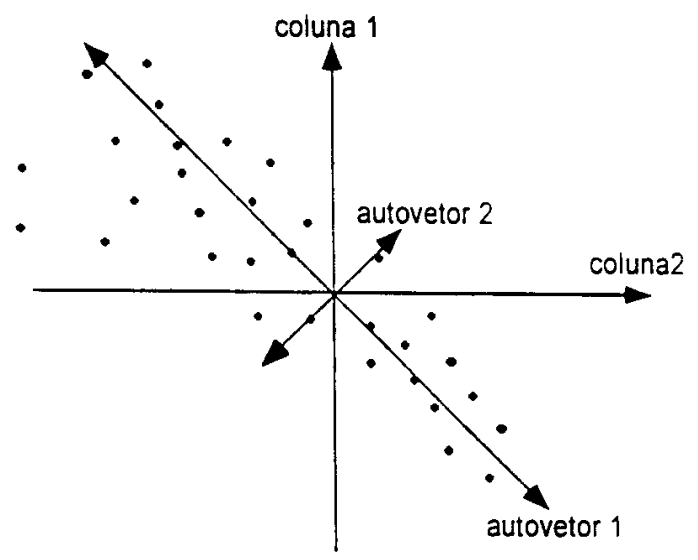

Figura 3.1. Matriz 28x2 graficada no espaço das colunas e os dois primeiros autovetores

No exemplo da figura 3.1 o objeto (elipse) formado pelos pontos no espaço das colunas é bidimensional. Em situações mais complicadas o objeto formado pode ser de 
maior dimensionalidade, e o processo de determinação dos autovetores continua até que toda a variação do conjunto de pontos possa ser explicada. A dimensão do espaço contendo as amostras é igual ao número de colunas da matriz de dados; a dimensão máxima para a representação dessas amostras é igual ao número de colunas, mas podemos representar o conjunto de amostras com menos dimensões. Podemos visualizar esse fato considerando o número de colunas da matriz original como sendo as dimensões de uma sala. Se existem objetos sobre uma mesa nesta sala, podemos descrever as posições desses objetos com apenas duas dimensões. Duas dimensões permitem que descrevamos as posições de cada objeto em relação aos demais, e os dois autovetores necessários para essa descrição formam um plano que contém o topo da mesa.

No caso de espectros, podemos associar às direções de maior variação os componentes das amostras em questão, como por exemplo proteína e açúcares, que apresentam sinais em regiões diferentes dos espectro. Sendo esses os componentes que variam de uma amostra para outra e conhecendo-se as variações através das análises de referência, podemos correlacionar os autovalores e as concentrações. e construir o modelo de calibração. Se considerarmos apenas os autovetores cujos autovalores são mais significativos. o método atua como um filtro de ruído pois apenas as direções de maior variação são consideradas e essas correspondem aos picos mais intensos do espectro, que carregam a informação desejada (Iwata \& Koshoubu. 1994).

Na figura 3.2 temos a decomposição de um espectro composto por três picos em uma combinação linear de três espectros, correspondentes às componentes principais. A 
matriz composta pelos coeficientes da combinação linear corresponde às concentrações de cada uma das componentes principais no espectro original.

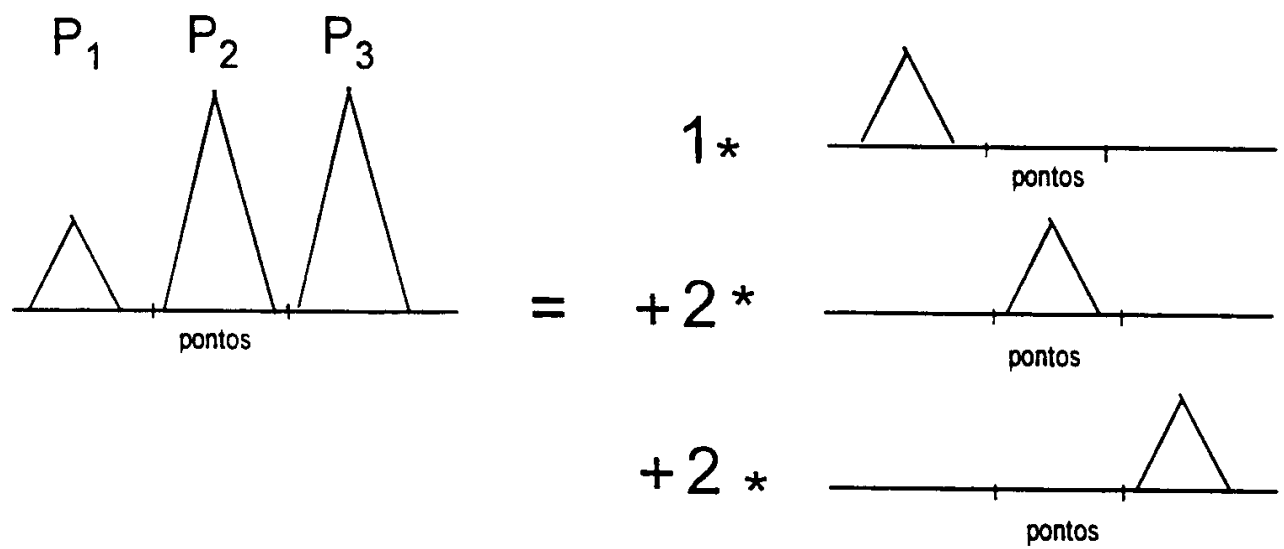

Fig̣ura 3.2. Decomposição de um espectro em uma combinação linear de espectros das componentes principais.

$\mathrm{Na}$ prática. desejamos obter as concentrações das componentes da amostra a partir do espectro de RMN. Para isso, partindo de um conjunto de amostras conhecidas, das quais dispomos dos espectros de $\mathrm{RMN}$ de ${ }^{13} \mathrm{C}$ e das concentrações de proteína e carboidratos. calcula-se a matriz de coeficientes que permite relacionar a matriz de concentrações e a matriz formada pelos espectros. Essa matriz pode então ser empregada para a determinação das concentrações de proteina e carboidratos em uma amostra desconhecida a partir do espectro.

Consideremos as seguintes matrizes:

$p(n, m) \Rightarrow$ matriz formada pelas intensidades espectroscópicas. As linhas dessa matriz correspondem aos espectros das n amostras de calibração (figura 3.4). e nas colunas temos as freqüências que compõem o espectro.

$C(n . q)=>$ matriz das concentrações das q componentes nas $n$ amostras. 
(As operações de transposição das matrizes são indicadas por um apóstrofe (p') e a inversão pelo $\operatorname{sinal}^{-1}\left(\mathbf{p}^{-1}\right)$.)

Admitindo que existe uma relação linear entre as concentrações e as intensidades espectrais, podemos encontrar a matriz dos coeficientes de regressão $\mathbf{M}_{\text {reg }}(m, q)$, que correlaciona $\mathbf{p}(n, m)$ e $\mathbf{C}(n, q)$.

$$
[\mathbf{C}]=[\mathbf{p}] *\left[\mathbf{M}_{r e g}\right]
$$

O cálculo direto da matriz de regressão, através da inversão da matriz $\mathbf{p}$, não é possível pois essa matriz não é quadrada, o que impossibilita sua inversão. Uma possibilidade de superar esse problema é calcular a inversa generalizada de p: (pp' $)^{-1}$. mas essa inversão também não é possivel nos casos em que a matriz pp' é mal condicionada. isto é, quando seu determinante é aproximadamente igual a zero.

Uma decomposição dessa matriz em novas componentes que sejam boas representações dos dados originais é possivel com a utilização da SVD, que transforma a matriz p, retangular e portanto não inversivel, em um produto de três matrizes: $\mathbf{u}, \mathbf{s}$ e v.

$$
\operatorname{svd}(\mathbf{p})=\mathbf{u} * \mathbf{s} * \mathbf{v}
$$

A matriz s é diagonal. com elementos em ordem decrescente. e as matrizes $\mathbf{u}$ e $\mathbf{v}$ são matrizes unitárias. Das propriedades de matrizes sabemos que a inversa de uma matriz diagonal é a matriz formada pelos inversos de seus elementos. e a inversa de uma matriz unitária é a transposta dessa matriz. Resolve-se assim o problema da inversão. Tomando apenas os elementos mais significativos das matrizes $\mathbf{u}, \mathbf{s}$ e $\mathbf{v}$ podemos reconstruir a matriz de espectros com menos elementos. que são os que carregam a informação importante. como mostra a figura 3.3. 
matriz de autovalores

$u^{*} \mathrm{~s}$

$\left[\begin{array}{cc}-0,27334 & -0.68791 \\ -0.32174 & -0.42446 \\ -0.33156 & -0.20942 \\ -0.37241 & 0.04781 \\ -0.44828 & 0.19869 \\ -0.39155 & 0.15674 \\ -0.46784 & 0.48368\end{array}\right]$.

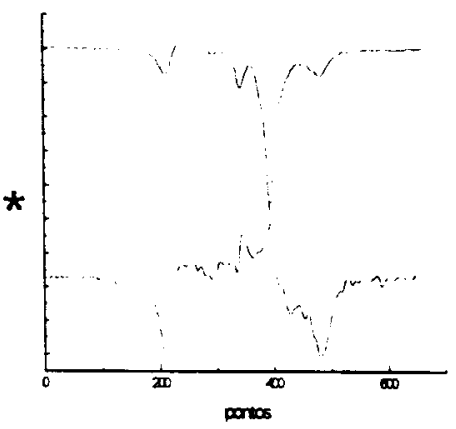

espectros reconstruidos com duas componentes principais

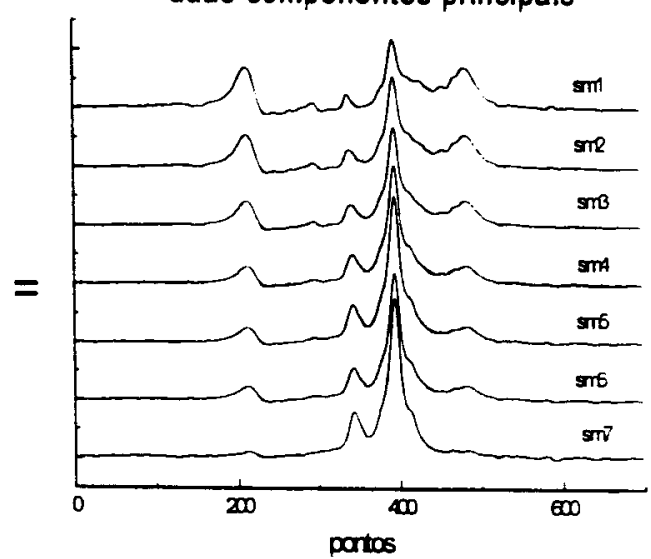

Figura 3.3. As matrizes u.s e $v$ são resultantes da decomposição em valores singulares da matriz de espectros de soja. milho e misturas destes nas proporções $4: 1,2: 1,1: 1,1: 2,1: 4$. O produto $\mathrm{u}^{*} \mathrm{~s}$ é a matriz de autovalores da base formada pelos autovetores, $v$. Consideramos aqui apenas os dois primeiros componentes das matrizes e reconstruimos os espectros.

Podemos então prosseguir com a etapa de regressão e encontrar a matriz $\mathbf{M}_{\text {rẹ }}$.

$$
\begin{aligned}
& {[\mathbf{C}]=[\mathbf{u}] *[\mathbf{s}] *[\mathbf{v}]^{1} *\left[\mathbf{M}_{r q g}\right]} \\
& {\left[\mathbf{M}_{r w}\right]=[\mathbf{u}] *[\mathbf{s}]^{-1} *[\mathbf{v}] *[\mathbf{C}]}
\end{aligned}
$$




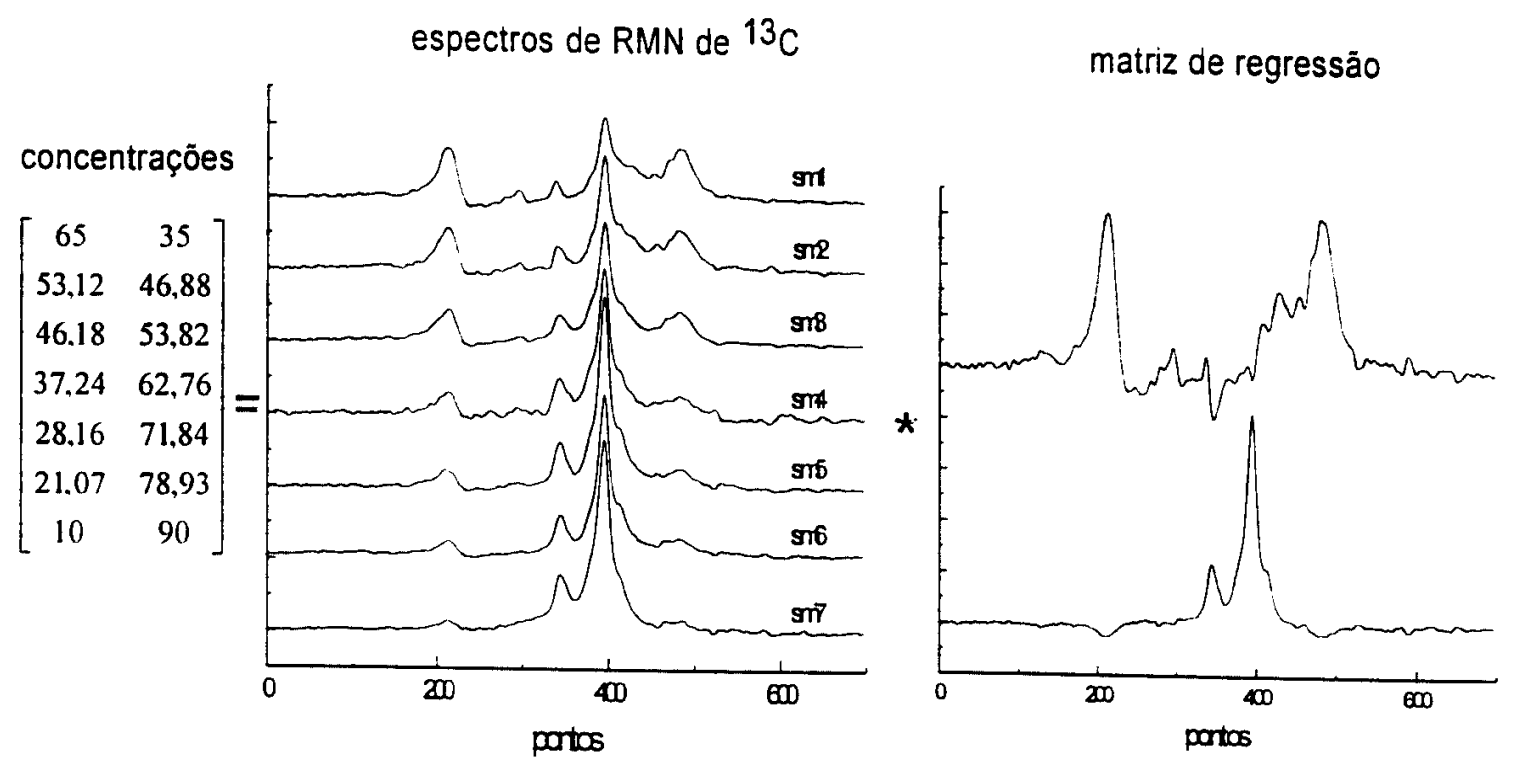

Figura 3.4. Matriz das concentrações, espectros de RMN e matriz de regressão. Espectros de soja. milho e misturas destes nas proporções 4:1, 2:1, 1:1, 1:2, 1:4.

Conhecida a matriz de regressão, a determinação das concentrações $C_{n}$ dos componentes em um novo espectro, $\mathbf{p}_{\mathbf{n}}$, é feita pela multiplicação do vetor formado pelas intensidades espectrais pela matriz $\mathbf{M}_{\mathrm{reg}}$ :

$$
\left[\mathbf{C}_{n}\right]=\left[\mathbf{p}_{n}\right] *\left[\mathbf{M}_{\mathrm{reg}}\right]
$$

A rotina utilizada para nossos cálculos. escrita na linguagem do programa MATLAB, e denominada AMV, executa a decomposição em valores singulares e constrói a matriz de regressão, utilizando o número de componentes que o usuário determinar. 


\subsection{Previsões}

Para os primeiros testes utilizamos uma base de dados composta por espectros de lisozima (proteína pura) e xiloglucano (carboidrato) . O modelo foi utilizado para a previsão das concentrações de misturas de soja e milho a partir dos espectros dessas misturas.

Somas dos espectros das substâncias puras, lisozima e xiloglucano, foram calculadas dando origem a espectros teóricos de misturas dessas substâncias em proporções tais que pudemos inferir suas concentrações. Dessa forma, a partir de dois espectros medidos pudemos criar uma base de calibração com sete (7) componentes. Essa base de dados foi fornecida ao programa, juntamente com a matriz composta pelas concentrações de proteina e amido em cada espectro. A matriz de calibração resultante foi então utilizada para a determinação das concentrações de proteína e amido em amostras de soja e milho sem óleo. Os resultados obtidos foram então comparados com estimativas baseadas em dados de Mayer,1975. A tabela 3.1 traz estes resultados iniciais:

Tabela 3.1. Concentrações de proteina e amido em sementes de soja e milho. Comparação entre valores dả literatura (Mayer. 1975) e valores calculados com a rotina AMV.

\begin{tabular}{||l|lc|lc||}
\hline \hline & \multicolumn{2}{|l|}{ PREVISTO (REFERENCIA) } & \multicolumn{2}{l||}{ CALCULADO (AMV) } \\
\hline & proteína & amido & proteina & amido \\
\hline soja & $65 \%$ & $35 \%$ & $65 \%$ & $32 \%$ \\
\hline milho & $10 \% 0$ & $90 \%$ & $11 \%$ & $85 \%$ \\
& & & & \\
\hline
\end{tabular}




\subsection{Rotina AMV}

No Anexo $\mathrm{C}$ apresentamos a rotina AMV, escrita na linguagem do programa MATLAB. Do início até a linha 36 temos a entrada de dados e a construção da matriz para o modelo de validação. Em cada passo. o programa constrói uma nova matriz de dados composta por (n-1) dos n espectros fornecidos e segue até calcular as concentrações do espectro retirado. Entre as linhas 37 e 43 temos a decomposição em valores singulares. svd, o cálculo da matriz de coeficientes de regressão, mtr, e o cálculo das concentrações do espectro retirado do conjunto. Da linha 44 em diante temos os cálculos dos coeficientes de correlação entre as concentrações calculadas e fornecidas. cálculo do desvio padrão da previsão e saída de dados. 


\section{Capítulo 4. Metodologia Experimental}

Neste capítulo descrevemos em linhas gerais o espectrômetro de alta resolução utilizado em nosso laboratório. Descrições mais detalhadas podem ser encontradas em Bonagamba, 1991 e em Silva, 1994.

\subsection{Descrição do Espectrômetro}

O espectrômetro de alta resolução do Laboratório de Espectroscopia de Alta Resolução (LEAR) do Grupo de Ressonância Magnética do Instituto de Física de São Carlos - IFSC - USP permite, além da utilização de técnicas de alta resolução em sólidos e líquidos. a espectroscopia de baixa resolução, medidas de tempos de relaxação e experimentos com variação da temperatura, de $-120^{\circ} \mathrm{a}+160^{\circ} \mathrm{C}$.

O campo magnético externo é produzido por um magneto supecondutor de $2 \mathrm{~T}$ da Oxford Instruments. modelo 85/310HR. Nesse campo, a freqüência de ressonância do ${ }^{1} \mathrm{H}$, que é a maior possível, fica em torno de $85 \mathrm{MHz}$, e a freqüência do ${ }^{13} \mathrm{C}$, em torno de 21.3MHz. O magneto possui estabilidade de $0,1 \mathrm{ppm} /$ hora e uma homogeneidade de campo de $25 \mathrm{ppm} /$ hora numa esfera de $20 \mathrm{~mm}$ de diâmetro. A homogeneidade de campo 
é garantida por um conjunto de 7 bobinas supercondutoras e 15 bobinas à temperatura ambiente, que propiciam as correções necessárias.

O funcionamento do espectrômetro é controlado pelo software MacNMR executado por um computador Macintosh IIci. A interface entre os equipamentos que compõe o espectrômetro e o computador é feita pelo sistema LIBRA, da TecMag. O sistema LIBRA constitui-se de um gerador de eventos, que controla todas as sequências de pulsos, bem como a duração e fase destes pulsos e os intervalos de tempo envolvidos no experimento, e da unidade SAKit, responsável pela amostragem, digitalização e soma dos sinais provenientes do sistema de recepção. Na figura 4.1 temos um diagrama de blocos do espectrômetro.

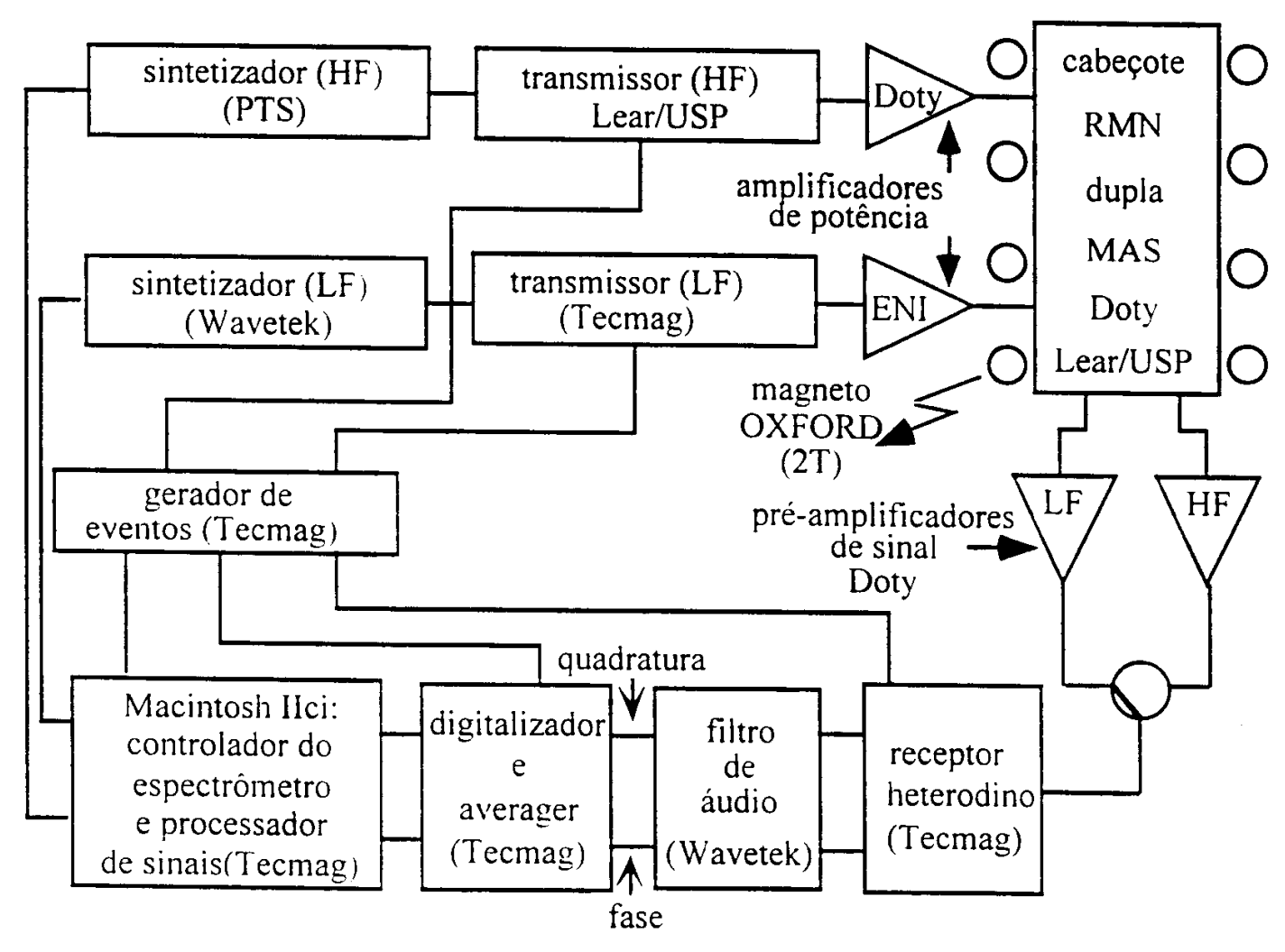

Figura 4.1. Diagrama de blocos do espectrómetro do Lear 


\subsubsection{Transmissão de RF}

Compõe o sistema de transmissão dois sintetizadores de RF, um Wavetek. modelo 5120A, para baixas freqüências (LF - Low Frequency), responsável pela excitação dos núcleos que se deseja observar $\left({ }^{13} \mathrm{C}\right)$, e um PTS 300 , para altas freqüências (HF - High Frequency), para a excitação dos núcleos abundantes $\left({ }^{1} \mathrm{H}\right)$ nos experimentos de dupla ressonância: polarização cruzada e desacoplamento.

O transmissor de HF foi desenvolvido em nosso laboratório e está acoplado a um sistema da TecMag que controla a duração. fase e amplitude dos pulsos.

O transmissor de LF é o NMRkit, da TecMag, transmissor heterodino que trabalha numa frequiência intermediária fixa, IF, igual a $11,25 \mathrm{MHz}$. Esse transmissor produz pulsos de RF na freqüência desejada através da mistura, ou mixagem, da freqüência produzida pelo sintetizador com a freqüência intermediária, IF. A partir de pulsos enviados pelo gerador de eventos, o "gate control" produz sinais que selecionam a fase da IF $\left(0^{\circ} .90^{\circ} .180^{\circ}\right.$ e $\left.270^{\circ}\right)$. controla a duração dos pulsos de RF e o tempo em que o receptor fica ligado.

Tanto o transmissor de HF como o de LF possuem um conjunto de atenuadores que controlam a RF de saída, permitindo uma atenuação de até $80 \mathrm{~dB}$ em passos de $0.1 \mathrm{~dB}$. Esse controle é utilizado no ajuste da intensidade da RF de desacoplamento e da condição de Hartmann-Hahn para os campos no experimento de polarização cruzada. 


\subsubsection{Recepção de RF - Sinal de RMN}

O receptor e o filtro de áudio fazem parte do NMRkit, da TecMag. O receptor é controlado pelo "gate control" do transmissor, que o mantém desligado durante a aplicação dos pulsos de alta potência na freqüência de detecção. Um intervalo de tempo fixo em $10 \mu$ s no início da sequência, o "tempo morto", e um tempo de espera ajustável no final da sequência de pulsos, visam a proteção do sistema de recepção contra saturação e eventuais danos causados pela alta potência da transmissão. O sinal proveniente da sonda é amplificado e sua freqüência deslocada para a freqüência intermediária através de um batimento com a freqüência do sintetizador, ocorrendo então uma demodulação para a faixa de áudio. O sinal passa então por um filtro de áudio Wavetek, modelo 442, com banda de passagem a critério do usuário. Com isso temos dois sinais em canais distintos na faixa de áudio, em fase e quadratura, que são enviados ao SAKit, dentro de uma banda pré-determinada, para a amostragem, digitalização e soma, e depois ao MacNMR. onde é feito o processamento matemático do sinal FID.

Existem ainda os amplificadores de potência e os pré-amplificadores, utilizados nas etapas de transmissão e recepção, respectivamente. São eles, um amplificador da marca Doty para HF. e um amplificador da marca AMT, modelo Pulse Amplifier M3205, para o canal de LF. colocados imediatamente antes da sonda. Na recepção é utilizado um pré-amplificador da marca Doty, imediatamente após a sonda. 


\subsubsection{Sonda de Dupla Ressonância}

A sonda, ou cabeçote de dupla ressonância é constituída basicamente de duas partes: o circuito de RF e o sistema de rotação da amostra.

Utilizamos em nossos experimentos um cabeçote da empresa Doty, para dupla ressonância e rotação da amostra - MAS.

O circuito de RF para ressonância dupla é formado pela associação de dois circuitos de ressonância simples, que discutiremos a seguir.

Para a excitação dos núcleos atômicos de uma amostra, esta deve ser colocada no interior de uma bobina, geralmente solenoidal, por onde passa uma corrente alternada com a freqüência de Larmor do núcleo em questão. A intensidade dessa corrente deve ser tal que o campo magnético oscilante produzido seja suficiente para retirar a magnetização nuclear de seu estado de equilíbrio ao longo do campo externo. A potência utilizada para a excitação dos núcleos é elevada, podendo até mesmo danificar outros equipamentos se não forem observados os cuidados necessários. Por isso as condições de casamento de impedâncias da sonda com os outros equipamentos devem ser cuidadosamente observadas. Normalmente a impedância padrão para os equipamentos de RF é de $50 \Omega$. A bobina L faz parte de um circuito ressonante de impedância $50 \Omega$. e com isso o campo em seu interior se intensifica. A bobina é a mesma tanto para a excitação como para a detecção do sinal. e pelo principio da reciprocidade, quanto mais alto é o campo de RF produzido, mais sensivel é a bobina para detectar pequenas variações de fluxo magnético. Na figura 4.2 temos um esquema do circuito ressonante 
simples, onde os capacitores $C_{S}$ e $C_{P}$ são ajustáveis, possibilitando o ajuste da impedância e a sintonia do circuito.

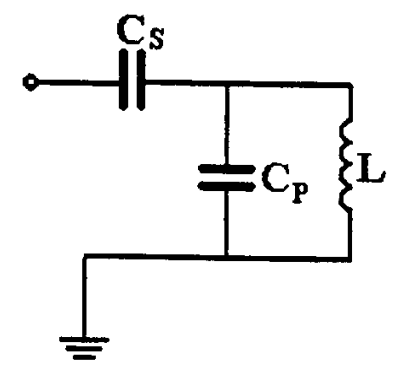

Figura 4.2. Circuito ressonante simples - "circuito tanque"- $C_{s}$ e $C_{P}$ são capacitores ajustáveis que permitem a sintonia

Nos experimentos de dupla ressonância utilizamos um circuito que permite a excitação da amostra em duas freqüências diferentes. Esse circuito deve ser construido de forma a não produzir ondas refletidas, não permitir a passagem de RF de um circuito para o outro - o que poderia danificar alguns equipamentos - além de permitir a sintonia das duas freqüências independentemente. Possibilidades de construção de tal circuito e alternativas para o desacoplamento entre os canais são discutidas em Bonagamba, 1991.

Para os experimentos de alta resolução, o melhor circuito é aquele em que apenas uma bobina é utilizada para os dois canais, como mostra a figura 4.3, o que minimiza os problemas com as inomogeneidades dos campos de RF. Nesse circuito o desacoplamento entre os dois canais de RF é feito através de filtros de rejeição. 


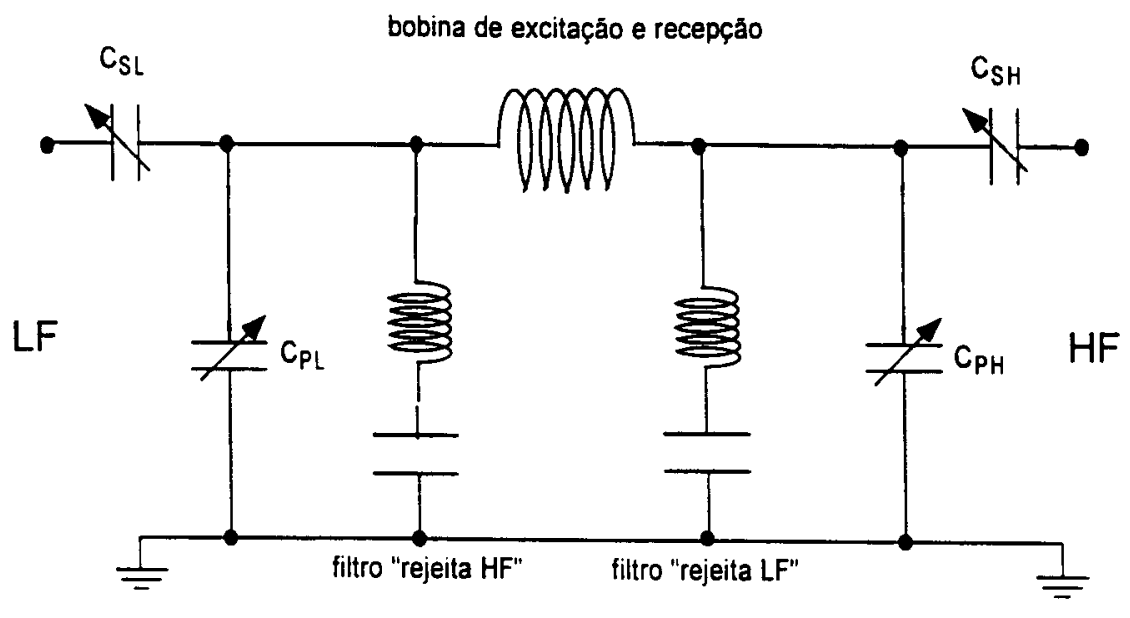

Figura 4.3. Circuito de RF de dupla ressonância.

\subsubsection{Sistema de Rotação da Amostra}

O sistema de rotação da amostra compõe-se de três partes: rotor, stator e housing.

Os rotores de alta velocidade utilizados em espectroscopia de alta resolução em sólidos por RMN, são sustentados por mancais aerostáticos e propelidos por ar comprimido ou nitrogênio gasoso. Na figura 4.4 temos um esquema do princípio de propulsão do rotor, onde as aletas são impulsionadas pela obstrução do jato de gás.

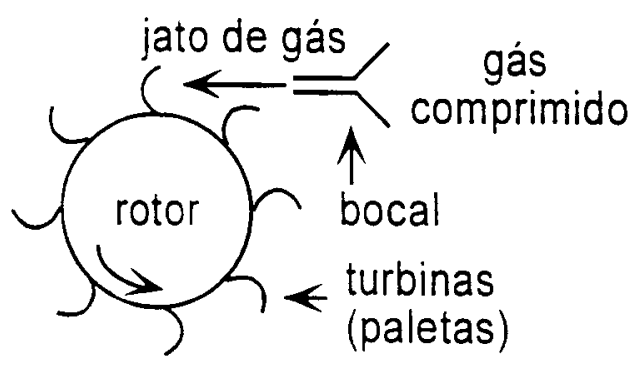

Figura 4.4. Principio de propulsão do rotor.

A sustentação do rotor também é feita por jatos de ar, que formam um colchão de ar entre o rotor e a estrutura que contém os bocais. o stator. Esse colchão de ar suporta a 
intensa carga radial que o rotor apresenta devido ao empacotamento assimétrico da amostra em seu interior.

O housing serve de reservatório de ar comprimido a uma pressão constante e como sustentação do sistema. Os jatos de ar saem por pequenos furos no stator, os bocais, e é ao redor do stator que a bobina de RF é enrolada.

O sistema de rotação é fixo no cabeçote e existe uma engrenagem que possibilita o ajuste da orientação do eixo de rotação do rotor com relação ao campo magnético externo, para o ajuste do ângulo mágico.

A alimentação do sistema é feita por compressores de ar que não utilizam óleo ou por nitrogênio comprimido.

A freqüência de rotação pode ser monitorada durante o experimento de duas maneiras, descritas em Bonagamba, 1991. Um método é óptico, em que um sinal de infravermelho é refletido pelo rotor, e devido a uma marca na superficie desse rotor pode-se detectar a freqüência da rotação através de um foto-transistor. O segundo método é o triboelétrico..Devido ao atrito com o ar, cargas elétricas surgem na superfície do rotor. $\mathrm{O}$ movimento dessas cargas gera um campo elétrico modulado na freqüência de rotação da amostra. que pode ser detectado por uma pequena antena. um fio que envolve o housing. O sinal proveniente de um desses dois métodos é amplificado, filtrado e transmitido a um frequencimetro.

Controlando a pressão do ar (ou do nitrogênio) podemos controlar a freqüência de rotação da amostra. 


\subsection{Preparação do Experimento CPDECMAS e a aquisição do sinal de ${ }^{13} \mathrm{C}$}

\subsubsection{Sintonia}

O primeiro passo no experimento é a sintonia da sonda de dupla ressonância, no qual utilizamos o procedimento de "sintonia por reflexão" esquematizado na figura 4.4. A sintonia deve ser feita antes de cada experimento para assegurar a eficiência da transferência de polarização, e em experimentos com MAS, devemos sintonizar o circuito com a amostra em rotação.

Empregamos um circuito divisor de potência, modelo PSC2-1, da MiniCircuits. que apresenta um isolamento de $\sim 30 \mathrm{~dB}$ entre suas "portas" A e B quando em sua porta S existe uma impedância de $50 \Omega$.

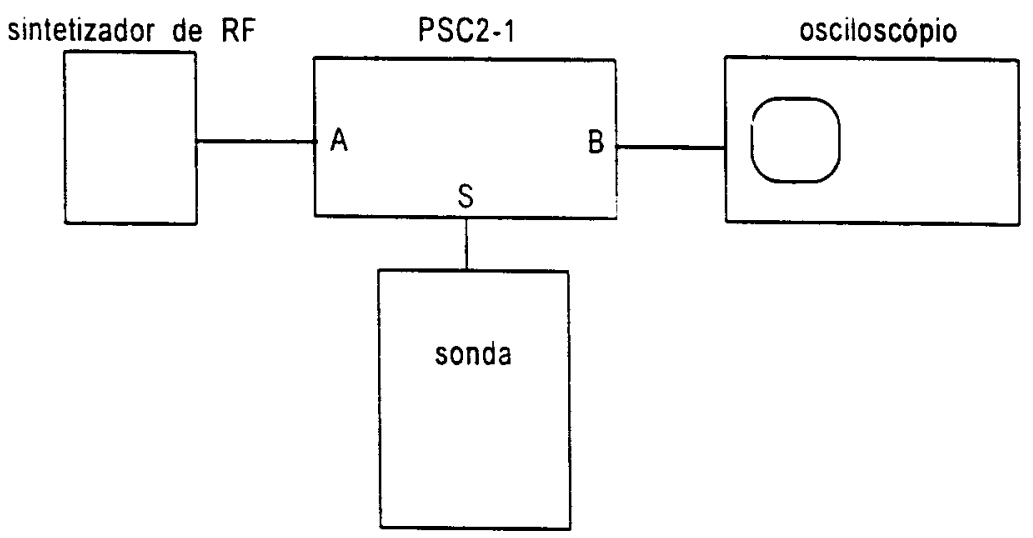

Figura 4.5. Esquema do sistema de sintonia da sonda de RMN. Quando a impedância da sonda é igual a 50S. a isolação entre as portas A e B do PSC2-1 é máxima e o sinal no osciloscópio é mínimo.

Injeta-se na porta $\mathrm{A}$ o sinal de RF de interesse. proveniente do sintetizador. e na 
porta $\mathrm{S}$ conecta-se o circuito a ser sintonizado, ou seja, ou o ramo de alta freqüência (HF) ou o de baixa freqüência (LF). Conectando a porta B a um osciloscópio (devidamente terminado em $50 \Omega$ ) e medindo o nivel de RF que chega a essa porta, inicia-se o processo de sintonia. Variam-se as capacitâncias $C_{S}$ e $C_{P}$ até que o nivel do sinal na tela do osciloscópio seja mínimo, o que ocorre quando a impedância da sonda é igual a $50 \Omega$. Sintonizam-se dessa forma os dois canais de RF independentemente.

O cabeçote é então conectado ao espectrômetro através de cabos coaxiais blindados, linhas de quarto de onda e sistemas de diodos cruzados conectados em série. Uma descrição aprofundada desses elementos pode ser encontrada em Freitas, 1994.

\subsubsection{Ajuste do ângulo mágico e pulso $\pi / 2$ para ${ }^{13} \mathrm{C}$}

Para o ajuste da condição de ângulo mágico e do pulso de $\pi / 2$ para ${ }^{13} \mathrm{C}$ utilizamos uma amostra de $\mathrm{KBr}$. A utilização do sinal do ${ }^{79} \mathrm{Br}$ para o ajuste do ângulo mágico foi proposta por Frye e Maciel em 1982. A freqüência de ressonância do ${ }^{79} \mathrm{Br}$ no campo de $2 \mathrm{~T}$ é $-21.311891 \mathrm{MHz}$, muito próxima portanto da freqüência de ressonância do ${ }^{1.3} \mathrm{C}$. o que faz com que o pulso $\pi / 2$ para o $\mathrm{KBr}$ seja uma boa estimativa inicial para a duração do pulso $\pi / 2$ para o ${ }^{1.3} \mathrm{C}$. O isótopo ${ }^{79} \mathrm{Br}$ existe com abundância natural de $50 \%$. e portanto seu sinal é bastante intenso mesmo com poucas aquisições. Rodando a amostra com uma freqüência de $1500 \mathrm{~Hz}$ e utilizando a sequência de eventos $\pi / 2$ esquematizada na figura 4.6. observamos o sinal FID no osciloscópio. Observa-se sob essas condições o aparecimento de ecos rotacionais, que dão origem às bandas laterais no espectro de 
RMN. Nas vizinhanças do ângulo mágico as intensidades dessas bandas são bastante sensiveis às variações do ângulo. Uma variação de $0,5^{\circ}$ com relação ao ângulo mágico produz uma sensivel diminuição das amplitudes das bandas laterais (Frye \& Maciel, 1982). O ajuste do ângulo acompanhado do monitoramento das amplitudes das bandas laterais, ou dos ecos rotacionais, é muito eficiente pois quando se atinge a condição de ângulo mágico as amplitudes são máximas.

Os parâmetros experimentais foram os seguintes:

- freqüência de ressonância do ${ }^{79} \mathrm{Br}: 21,311891 \mathrm{MHz}$

- freqüência de rotação : $1500 \mathrm{~Hz}$

- duração do pulso $\pi / 2\left(t_{p}\right): 15,5 \mu \mathrm{s}$

- tempo de repetição $\left(t_{R}\right): 0,5 \mathrm{~s}$

- número de aquisições : 1

- número de pontos : 4096

- filtro de áudio : $3 \mathrm{KHz}$ 


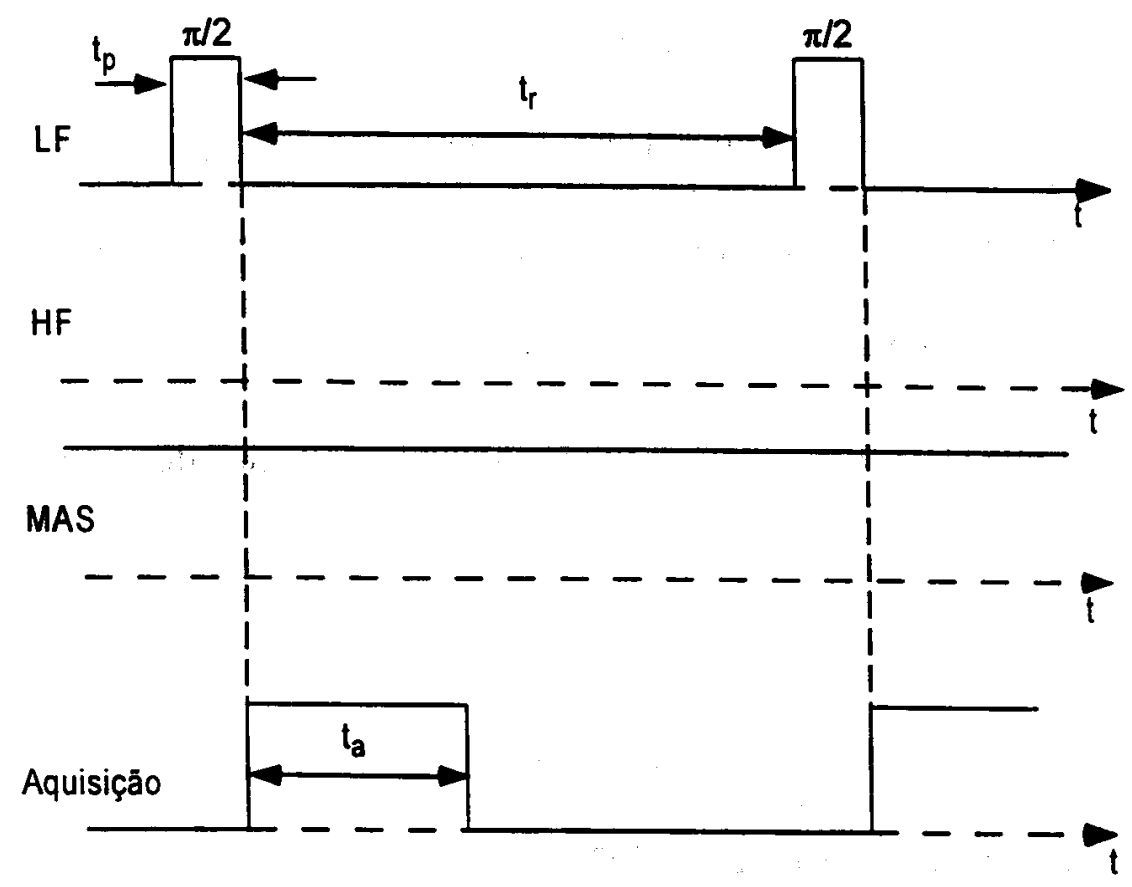

Figura 4.6. Sequência de eventos $\pi / 2$, utilizada para o ajuste do ângulo mágico no experimento com 0 $\mathrm{KBr}$

\subsubsection{Ajuste do pulso $\pi / 2$ para o ${ }^{13} \mathrm{C}$ - Sequência DEC}

A amostra utilizada para a maioria dos ajustes do experimento com ${ }^{13} \mathrm{C}$ foi o ADAMANTANO. Essa amostra é formada de dois grupos distintos $-\mathrm{CH}_{2}$ e $\mathrm{CH}-\mathrm{e}$ fornece um sinal intenso, com poucas médias, e mesmo apenas com MAS já se pode distinguir as duas linhas características. A linha espectral mais intensa, correspondente aos 6 grupos $\mathrm{CH}_{2}$, é utilizada com referência para os deslocamentos químicos medidos, visto que esta linha encontra-se em $39 \mathrm{ppm}$ com relação ao tetrametilsilano, $\operatorname{Si}\left(\mathrm{CH}_{3}\right)_{4}$ (TMS).

Após a sintonia da sonda, utilizando a sequência DEC. esquematizada na figura 4.7, procedemos ao ajuste do pulso de $\pi / 2$ para o carbono, ajustando inicialmente o valor 
de um pulso de $\pi$, que anula o sinal, e calculando a duração do pulso de $\pi / 2$, que em nossos experimentos assumiu um valor igual a $15,75 \mu \mathrm{s}$. A potência de DEC foi ajustada a partir da escolha de uma atenuação para o canal de HF capaz de garantir um desacoplamento eficiente sem introduzir grande ruido no canal de LF. A eficiência do desacoplamento em função da potência aplicada pode ser monitorada observando-se o FID do ${ }^{13} \mathrm{C}$ no osciloscópio. O sinal ideal é aquele cuja duração temporal é máxima, o que garante uma linha espectral estreita, mas não podemos injetar potência em excesso no sistema. Uma largura de linha satisfatória para o ADAMANTANO é da ordem de 0,2 ppm ou menos.

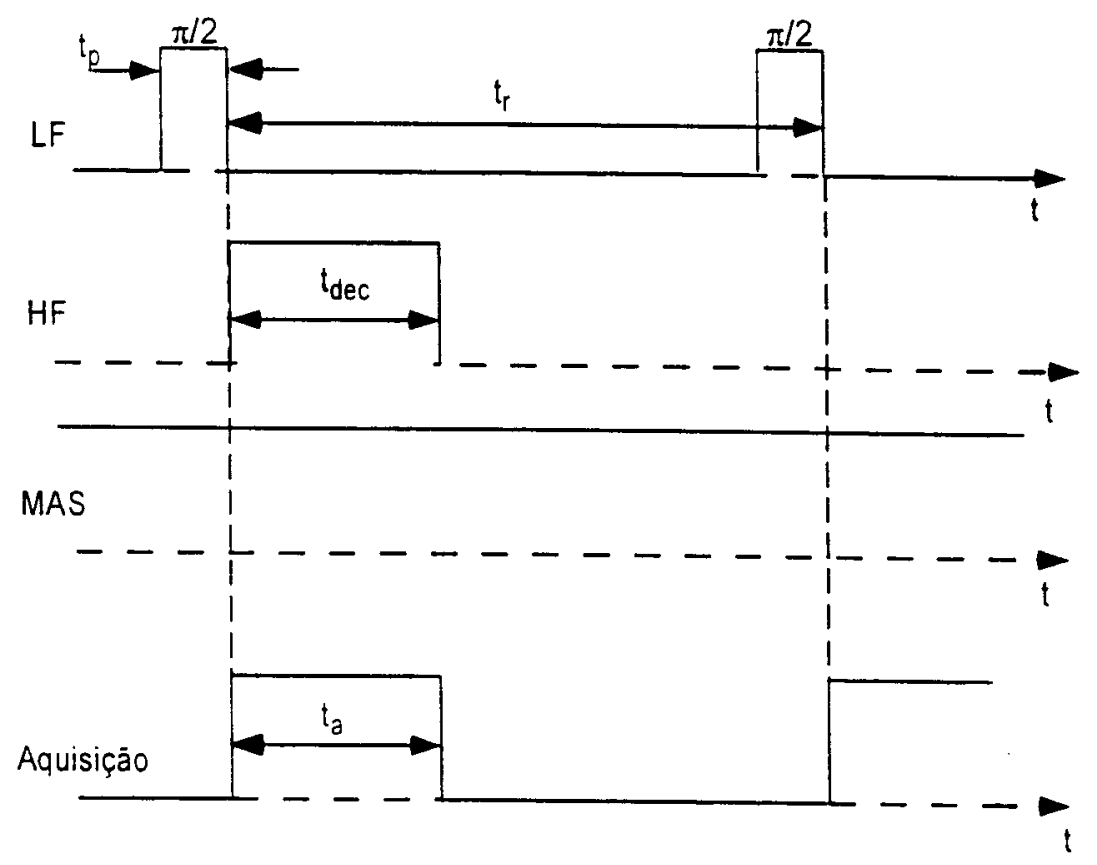

Figura 4.7. Sequência DEC/MAS 


\subsubsection{Ajuste do pulso $\pi / 2$ para ${ }^{1} \mathrm{H}$ e da condição de Hartmann-Hahn}

Ainda com o ADAMANTANO fizemos os ajustes necessários para o experimento CPDECMAS, cuja sequência de eventos encontra-se esquematizada na figura 4.8. Inicialmente ajustamos a duração de um pulso de $\pi$ para o ${ }^{1} \mathrm{H}$. Observando o sinal do ${ }^{13} \mathrm{C}$, o pulso de $\pi$ para o ${ }^{1} \mathrm{H}$ é aquele que minimiza o sinal do ${ }^{13} \mathrm{C}$, pois nessa situação não ocorre transferência de polarização. Ajusta-se assim a duração do pulso $\pi / 2$ para o ' $\mathrm{H}$.

A condição de Hartmann-Hahn é atingida através do controle das atenuações dos campos de RF aplicados às amostras durante o tempo de contato, $t_{c}$, observando o sinal do carbono no osciloscópio e buscando a condição de maximização desse sinal. As atenuações dos campos de RF aplicados nos canais de HF e LF podem ser ajustadas em passos de $0,1 \mathrm{~dB}$. O valor da atenuação no canal de HF ajustado para DEC não deve, no entanto, ser muito modificado, para que não se comprometa o desacoplamento. Após o tempo de contato, quando ocorre a transferência de polarização do ${ }^{1} \mathrm{H}$ para ${ }^{13} \mathrm{C}$, temos o desacoplamento do 'H. A RF no canal do hidrogênio é mantida durante o tempo $t_{\text {dec }}$, e ao mesmo tempo temos a aquisição do sinal do ${ }^{13} \mathrm{C}, \mathrm{t}_{\mathrm{a}}$. 


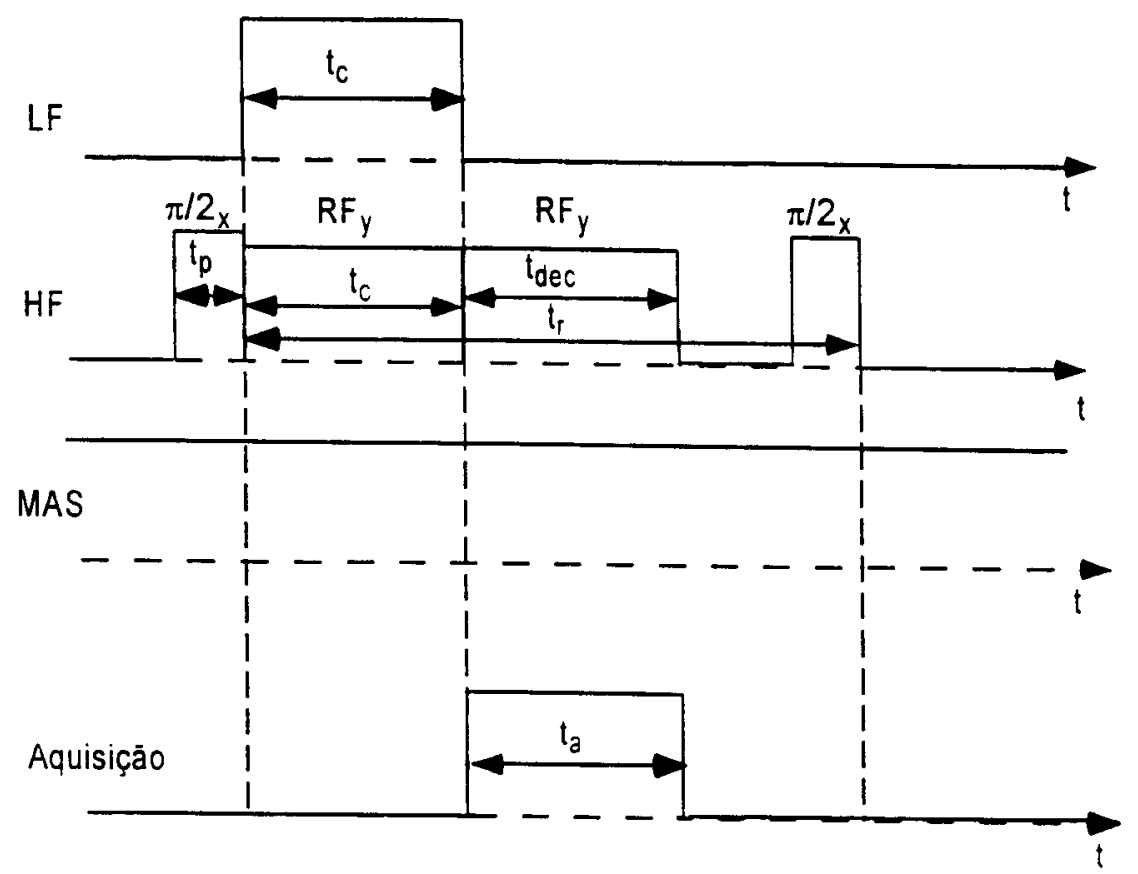

Figura 4.8. Sequéncia CPDECMAS.

Para o ADAMANTANO o tempo de contato para a polarização cruzada foi de $3 \mathrm{~ms}$ e o tempo de repetição do experimento igual a $5 \mathrm{~s}$, pois o $\mathrm{T}_{1 \mathrm{H}}$ dessa amostra é muito longo, da ordem de $1 \mathrm{~s}$. A freqüência de rotação da amostra foi de $3 \mathrm{kHz}$ e o número de pontos digitalizados igual a 2048 .

Para as amostras a serem avaliadas. na maioria cereais, o tempo de contato utilizado foi de $1 \mathrm{~ms}$, tempo padrão para substâncias orgânicas. Consideramos que o ajuste da condição de Hartmann-Hahn feito para o ADAMANTANO seja também válido para as amostras estudadas, e antes de cada experimento repetimos o procedimento de ajuste com o ADAMANTANO.

Os parâmetros experimentais mais importantes empregados com as amostras estudadas por RMN e análise multivariada são: 
- tempo de contato: $1 \mathrm{~ms}$

- tempo de repetição do experimento : $1,5 \mathrm{~s}$

- número de pontos digitalizados : 4096

- dwell time : $5 \times 10^{-6} \mathrm{~s}$

- número de médias : 20000

- filtro de áudio : $6 \mathrm{kHz}$

- freqüência de rotação: $3 \mathrm{kHz}$

\subsection{Preparação das amostras}

$\mathrm{O}$ experimento com MAS requer amostras que possam ser homogeneamente acondicionadas no rotor, ou este não atinge as velocidades de rotação exigidas pelo experimento. As amostras devem estar preferencialmente na forma de um pó fino e homogêneo, que possa ser "empacotado" no rotor com o auxílio de uma prensa manual. As sementes e alimentos avaliados passaram por processos de secagem em estufa. trituração e, no caso de soja e milho, extração do óleo. O moinho utilizado inicialmente foi um moedor manual doméstico. de ferro, que para sementes mais rígidas apresentou o inconveniente de liberar partículas de ferro' que se misturaram a algumas amostras. Empregando um ímã de terras-raras pudemos inspecionar as amostras suspeitas e retirar as partículas de ferro. Um moinho de pedra, de propriedade do CPPSE-EMBRAPA São Carlos, foi utilizado para a trituração das amostras numa etapa posterior. evitando a 
possível contaminação das amostras com partículas magnéticas. A extração do óleo das amostras de soja e milho trituradas foi feita num extrator de fluxo contínuo Soxhlet, por 24 horas com o solvente tetracloreto de carbono. As amostras foram posteriormente secas em estufa para a evaporação do solvente.

Misturas de soja e milho foram preparadas nas proporções 4:1, 2:1, 1:1, 1:2 e 1:4, e as concentrações dessas misturas estimadas a partir das estimativas para as concentrações de proteína e amido em milho e soja de Mayer,1975. Na tabela 5.1 temos as porcentagens de soja e milho em cada amostra bem como as massas utilizadas para as medidas dos espectros de ${ }^{1.3} \mathrm{C}$ e as concentrações estimadas.

Tabela 4. 1. Massas e concentrações de proteína e amido das amostras $\operatorname{sm} 1, \operatorname{sm} 2, \operatorname{sm} 3, \operatorname{sm} 4, \operatorname{sm} 5, \operatorname{sm} 6$ e

\begin{tabular}{|c|c|c|c|c|c|}
\hline amostras & $\begin{array}{c}\text { soja } \\
(\%)\end{array}$ & $\begin{array}{r}\text { milho } \\
(\%)\end{array}$ & $\begin{array}{c}\text { massa } \\
( \pm 0,0001) \mathrm{g}\end{array}$ & $\begin{array}{c}\text { proteína } \\
(\%)\end{array}$ & $\begin{array}{c}\text { amido } \\
(\%)\end{array}$ \\
\hline sm1 & 100 & 0 & 0,2637 & 65 & 35 \\
\hline sm2 & 80 & 20 & 0,2848 & 53 & 46 \\
\hline sm3 & 66 & 33 & 0,2935 & 46 & 53 \\
\hline sm4 & 50 & 50 & 0,2983 & 37 & 62 \\
\hline sm5 & 33 & 66 & 0,2632 & 28 & 71 \\
\hline $\operatorname{sm} 6$ & 20 & 80 & 0,2737 & 21 & 78 \\
\hline $\operatorname{sm} 7$ & 0 & 100 & 0,2788 & 10 & 90 \\
\hline
\end{tabular}

'Valores de concentração esperados calculados com base em Mayer.1975.

\subsection{Tratamento dos dados}

Os espectros foram obtidos através da manipulação do FID. utilizando o software MacFid. da TecMag̣. As operações realizadas foram: correção da linha de base: 5 " Left 
Shifts" - deslocamentos do FID para a esquerda, para eliminar o "tempo morto" induzido pelo filtro de áudio e pulsos de RF; "Line Broadening" de $50 \mathrm{~Hz}$ - apodização com uma função exponencial decrescente; Zero Filling - preenchimento com zeros, visando um aumento da resolução e finalmente a transformada de Fourier. Descrições detalhadas desse procedimento podem ser encontradas no manual do software: User's Manual TecMag, USA, TecMag Inc..

Para as análises com o programa MATLAB os espectros foram tratados e inicialmente gravados em formato texto (.txt) e as colunas referentes à parte real do resultado da transformada de Fourier, que são as amplitudes espectrais, e aos valores de freqüência em ppm foram mantidas. Os espectros que fazem parte da base de dados de calibração e os espectros a serem avaliados têm o mesmo número de pontos. assim, para a utilização com o programa MATLAB, apenas as colunas contendo as amplitudes foram gravadas no formato exigido pelo programa, exemplificado abaixo para um conjunto de cinco pontos, e com a extensão (.m):

DATA $=$
$[0.002$
0.234
1,323
2,212
$0,022]$

As matrizes são construidas no MATLAB, e para sua utilização com o programa AMV também devem ser formatadas nos padrôes de entrada de dados do MATLAB. Exemplificamos abaixo o procedimento de construção de uma matriz de duas colunas e cinco linhas.

Consideremos dois arquivos contendo vetores coluna (representando os 
espectros), esp 1.m e esp2.m:

\begin{tabular}{|c|c|c|}
\hline 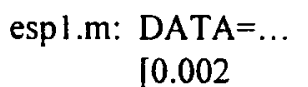 & esp2.m: & $\begin{array}{l}\text { DATA }=. . \\
{[0.001}\end{array}$ \\
\hline 0.234 & & 0.099 \\
\hline 1,323 & & 2,876 \\
\hline 2,212 & & 0,109 \\
\hline 0,022$]$ & & $0.007\}$ \\
\hline
\end{tabular}

No MATLAB, inicialmente procedemos à leitura dos arquivos:

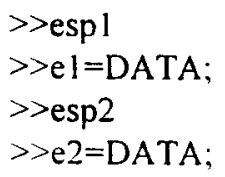

Para a construção das matrizes de calibração utilizamos em alguns casos, dois espectros reais e cinco espectros simulados, construidos a partir de somas dos dois espectros originais nas proporções $4: 1,2: 1,1: 1$. 1:2 e 1:4, abaixo temos os comandos utilizados para a normalização dos espectros pela soma. para que todas as áreas fíquem iguais à unidade. e os comandos para a construção dos espectros simulados. Consideremos dois espectros hipotéticos. de soja e milho. denominados so.m e mi.m: 
$>>_{\mathrm{S}}=\mathrm{DATA}$;

$>_{\mathrm{s}}=\mathrm{s} / \operatorname{sum}(\mathrm{s})^{*} 100$;

$>>\mathrm{mi}$

$>>m=D A T A$;

$>>\mathrm{m}=\mathrm{m} / \mathrm{sum}(\mathrm{m}) * 100$;

$>s 2=4^{*} \mathrm{~s}+\mathrm{m}$

$>>s 2=s 2 /$ sum $(s 2) * 100$;

$>\mathrm{s} 3=2 * \mathrm{~s}+\mathrm{m}$;

$>\mathrm{s} 3=\mathrm{s} 3 / \mathrm{sum}(\mathrm{s} 3) * 100$;

$>>\mathrm{s} 4=\mathrm{s}+\mathrm{m}$;

$>>\mathrm{s} 4=\mathrm{s} 4 / \mathrm{sum}(\mathrm{s} 4) * 100$;

$>\mathrm{s} 5=\mathrm{s}+2 * \mathrm{~m}$;

$>\mathrm{s} 5=\mathrm{s} 5 / \mathrm{sum}(\mathrm{s} 5) * 100$;

$>>\mathrm{s} 6=\mathrm{s}+4^{*} \mathrm{~m}$;

$>>s 6=s 6 /$ sum $(s 6) * 100$;

em seguida podemos construir a matriz dos sete espectros:

$>\mathrm{s} 17=[\mathrm{s} \mathrm{s} 2 \mathrm{~s} 3 \mathrm{~s} 4 \mathrm{~s} 5 \mathrm{~s} 6 \mathrm{~m}]$;

> save s17.dat s17-ascii

abrindo o arquivo s17.dat no editor de texto e formatando a matriz como descrevemos acima e salvando-a com a extensão (.m) temos o arquivo pronto para a utilização com o programa AMV.

A matriz de concentrações pode ser construída diretamente no editor de texto. e a seguir temos a matriz das concentrações de misturas de soja e milho nas proporções indicadas acima. com valores baseados em Mayer, 1975:

DATA $1=$.

$[6535$

$53.1246,88$;

46,18 53,82:

37.2462 .76 :

28.1671.84;

21.0778 .93 :

1090 ]; 


\section{Capítulo 5. Resultados e Discussão}

Os parâmetros operacionais do espectrômetro se encontram descritos no capítulo anterior, no entanto é importante ressaltar que mesmo com a utilização das técnicas de espectroscopia de alta resolução em sólidos, a obtenção de espectros com boa relação sinal/ruído requer experimentos longos. Somando o tempo necessário para a sintonia da sonda, ajuste da condição de Hartmann-Hahn com o adamantano, sintonia da sonda com a amostra e o experimento com aquisição de 20.000 transientes (FIDs), temos para a obtenção de cada espectro um periodo de aproximadamente 12 horas num campo magnético de $2 \mathrm{~T}$, disponivel em nosso laboratório.

\subsection{Espectros de $\mathrm{RMN}$ de ${ }^{13} \mathrm{C}$ e resultados das previsões com análise multivariada}

Os espectros de " $\mathrm{C}$ por espectroscopia de RMN de alta resolução em sólidos medidos para o conjunto de amostras de soja e milho e misturas se encontram sumarizados na figura 5.1 . 


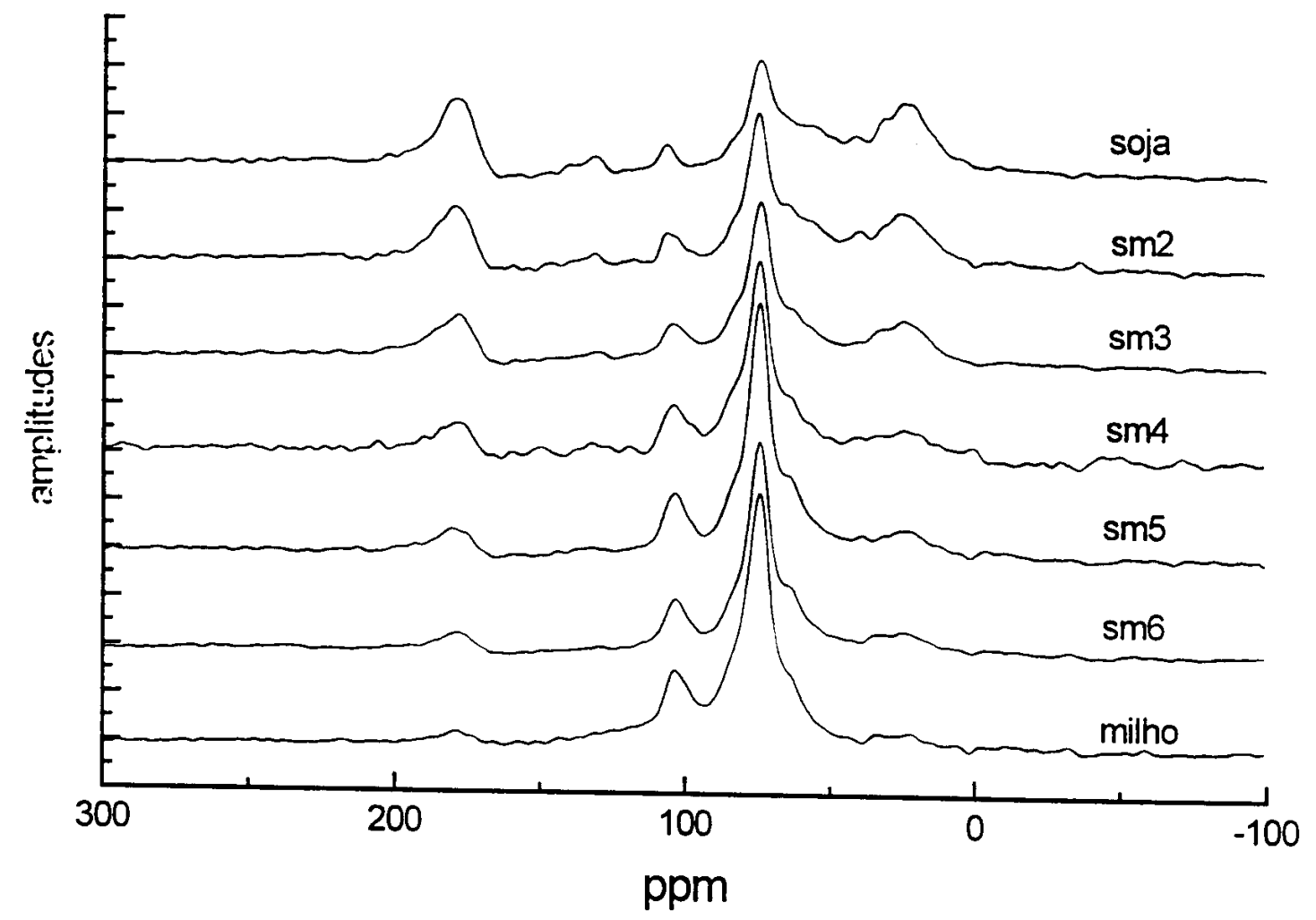

Figura 5.1. Espectros de $\mathrm{RMN}$ de ${ }^{13} \mathrm{C}$ de soja, milho e misturas destes nas proporções 4:1 (sm2); 2:1 (sm3); 1:1 (sm4); 1:2 (sm5); 1:4 (sm6).

Uma proteína pura, Lisozima marca Sigma, e um amido puro. xiloglucano de Copaifera, foram medidos em conjunto com novas amostras de soja e milho, e os espectros desse grupo de amostras encontram-se na figura 5.2: 


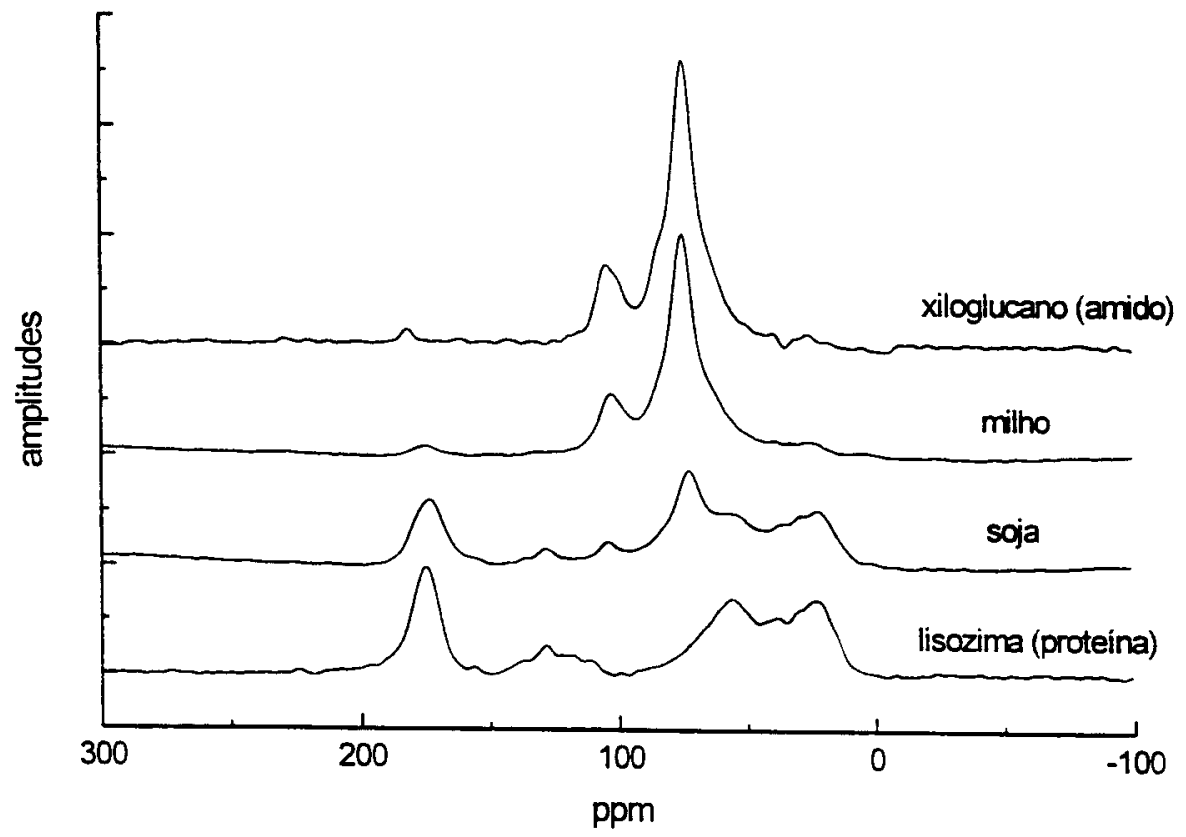

Figura 5.2. Espectros de RMN de ${ }^{13} \mathrm{C}$ de soja, milho, lisozima e xiloglucano de Copaifera.

Uma inspeção inicial desses conjuntos de espectros permite a distinção dos sinais correspondentes aos carbonos de proteina, de 25 a $60 \mathrm{ppm}$ e em torno de $175 \mathrm{ppm}$, de acordo com Rutar et al, 1980, e sinais relativos a carboidratos, entre 60 e $125 \mathrm{ppm}$. Como esperado, temos no espectro da lisozima a predominância de sinais relativos aos carbonos de proteína, com destaque para o pico em $\sim 175$ ppm, correspondente à carbonila $(\mathrm{C}=\mathrm{O})$, sinal considerado como principal indicativo da presença de proteina segundo Rutar. 1982. Também de acordo com o que era previsto temos no espectro do xiloglucano a predominância dos sinais relacionados aos carboidratos, em torno de 75 e 106 ppm. A unidade básica estrutural dos carboidratos é a glicose, formada por seis carbonos. Na figura 5.3 temos representações das fórmulas estruturais das juas formas de ocorrência da glicose: $\alpha$-glicose e $\beta$-glicose (Stryer. 1988). De Haw at al.. 1984. 
temos que aos sinais no espectro de RMN correspondem os carbonos da glicose da forma indicada na tabela 5.2. O carbono na posição 1 é mais próximo dos oxigênios o que o deixa menos "blindado" magneticamente pois o oxigênio, sendo muito eletronegativo, atrai a nuvem eletrônica. Por isso o sinal desse carbono é mais deslocado para a esquerda, tem maior deslocamento químico, o que significa que o campo efetivo no seu sítio nuclear é menor.

O que distingue as duas formas da glicose é a conformação do carbono na posição 1 (C1) o que faz com que as ligações entre duas glicoses ocorra de duas formas denominadas ligações $\alpha$-glicosídicas e $\beta$-glicosídicas. A celulose é formada por glicoses unidas por ligações do tipo $\beta$-glicosidicas e o amido é formado por glicoses unidas por ligações $\alpha$-glicosídicas. Na figura 5.5 temos espectros de $\mathrm{RMN}$ de ${ }^{13} \mathrm{C}$ de dois amidos, xiloglucano e maizena, e da celulose, e podemos verificar que os sinais aparecem nas mesmas regiões, impossibilitando a diferenciação das estrututras componentes desses carboidratos.

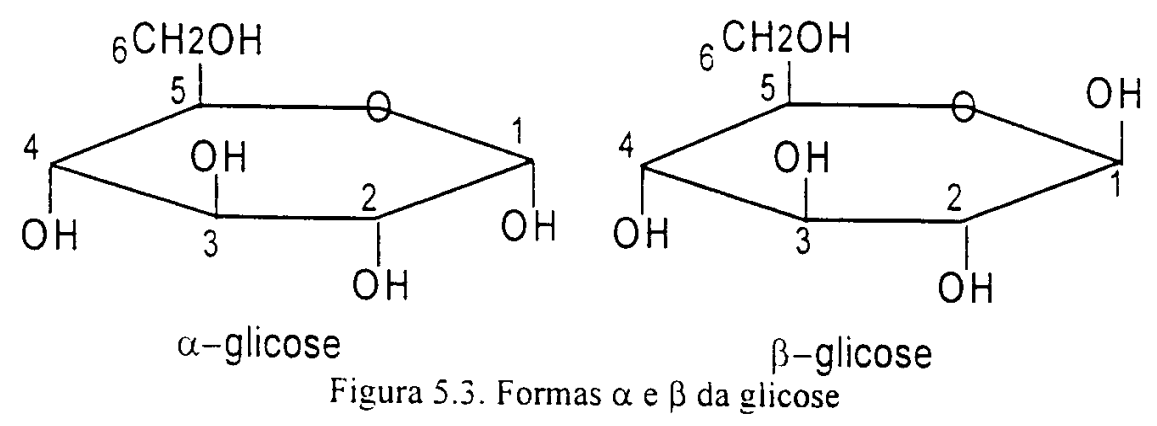


Tabela 5.2. Deslocamentos Químicos no espectro de RMN de ${ }^{13} \mathrm{C}$ dos carbonos de carboidratos

\begin{tabular}{|c|c|}
\hline carbono & deslocamento químico (ppm) \\
\hline $\mathrm{C} 1$ & 105 \\
\hline $\mathrm{C} 4$ & 89 a 84 \\
\hline $\mathrm{C} 2, \mathrm{C} 3$ e C5 & 70 a 80 \\
\hline $\mathrm{C} 6$ & 63 a 66 \\
\hline
\end{tabular}

\subsection{Construção das bases de dados para calibração e resultados das previsões}

Inicialmente tomamos os espectros da lisozima e do xiloglucano e construímos uma matriz de 7 espectros, LX, onde cinco novos espectros foram calculados pela soma dos espectros originais de lisozima e xiloglucano nas proporções $4: 1,2: 1,1: 1,1: 2$ e 1:4. Construímos também uma matriz com as concentrações de proteina e amido considerando as proporções citadas, matriz esta composta de 7 linhas e duas colunas, a primeira com os valores de concentrações de proteina e a segunda com as concentrações de amido. Consideramos para tal a lisozima e o xiloglucano compostos de $100 \%$ proteina e 100\% amido respectivamente. Na construção dessas matrizes devemos respeitar o formato exigido pelo programa MATLAB para a entrada de dados, exemplificado abaixo para uma matriz $3 \times 4$ :

$$
\begin{aligned}
& \multicolumn{5}{c}{D A T A=\ldots} \\
& {\left[\begin{array}{cccc}
5 & 6 & 8 & 2 \\
2 & 6 & 1 & 4 \\
3 & 6 & 8 & 4
\end{array}\right] ;}
\end{aligned}
$$

Todos os espectros utilizados foram normalizados pela soma, ou seja. tiveram suas áreas totais igualadas a um (1). O arquivo da matriz de concentrações deve ser 
iniciado com a palavra DATA1, ao invés de apenas DATA, para que possa ser entendido pelo nosso programa.

A matriz construída a partir dos espectros de lisozima e xiloglucano, LX. e a matriz das concentrações foram fornecidas ao programa AMV. Considerando dois fatores, ou componentes principais, obtivemos como resultado a matriz de coeficientes de regressão, denominada MTRLX. Utilizamos então a matriz MTRLX para o cálculo das concentrações de proteína e amido das amostras de soja e milho e misturas cujos espectros se encontram na figura 5.1. Na tabela 5.3 temos os resultados das previsões e os valores esperados para as concentrações.

Tabela 5.3. Resultados das previsões das concentrações de proteína e amido a partir dos espectros de RMN de ${ }^{13} \mathrm{C}$ de amostras de soja, milho e misturas (figura 5.1). A base de dados utilizada para calibração é composta de espectros de Lisozima e Xiloglucano e somas (vide texto).

\begin{tabular}{|l|c|c|c|c|}
\hline & $\begin{array}{l}\text { concent.proteína } \\
\text { (esperado) (\%) }\end{array}$ & $\begin{array}{l}\text { concent.proteina } \\
\text { (calculado) (\%) }\end{array}$ & $\begin{array}{l}\text { concent.amido } \\
\text { (esperado) (\%) }\end{array}$ & $\begin{array}{l}\text { concent.amido } \\
\text { (calculado) (\%) }\end{array}$ \\
\hline $\mathrm{sm} 1$ & 65 & 70 & 35 & 35 \\
\hline $\mathrm{sm} 2$ & 53 & 53 & 46 & 50 \\
\hline $\mathrm{sm} 3$ & 46 & 40 & 53 & 58 \\
\hline $\mathrm{sm} 4$ & 37 & 24 & 62 & 71 \\
\hline $\mathrm{sm} 5$ & 28 & 17 & 71 & 86 \\
\hline $\mathrm{sm} 6$ & 21 & 19 & 78 & 81 \\
\hline sm7 & 10 & 3 & 90 & 92 \\
\hline
\end{tabular}

Valores esperados calculados com base em Mayer, 1975 .

A mesma matriz de calibração, MTRLX, foi utilizada para a previsão das concentraçōes de proteína e amido das amostras de soja e milho cujos espectros aparecem na figura 5.2. e os resultados das previsôes se encontram na tabela 5.4 . 
Tabela 5.4. Resultados das previsões das concentrações de proteína e amido a partir dos espectros de RMN de ${ }^{13} \mathrm{C}$ de amostras de soja e milho (figura 5.2). A base de dados utilizada para calibração é composta de espectros de Lisozima e Xiloglucano (figura 5.2) e somas (vide texto).

\begin{tabular}{|c|c|c|c|c|}
\hline & $\begin{array}{l}\text { concent.proteína } \\
\text { (esperado) }(\%)^{\prime}\end{array}$ & $\begin{array}{l}\text { concent.proteina } \\
\text { (calculado) (\%) }\end{array}$ & $\begin{array}{l}\text { concent.amido } \\
\text { (esperado) (\%) }\end{array}$ & $\begin{array}{l}\text { concent.amido } \\
\text { (calculado) (\%) }\end{array}$ \\
\hline soja & 65 & 65 & 35 & 32 \\
\hline milho & 10 & 11 & 90 & 85 \\
\hline
\end{tabular}

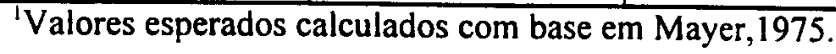

Tomamos então os espectros de soja e milho representados na figura 5.2 e seguindo o mesmo procedimento adotado para com os espectros de lisozima e xiloglucano, construímos uma base de dados para calibração formada pelos espectros originais e cinco simulações obtidas de somas desses espectros nas proporções 4:1. 2:1, 1:1, 1:2 e 1:4. A matriz de concentrações foi construída com valores estimados para as misturas com base nos valores das concentrações fornecidas por Mayer,195. Utilizamos a matriz de coeficientes de regressão, MTRSM, calculada através do rograma AMV com duas componentes principais, para a previsão dos valores das concentrações de proteína e amido a partir dos espectros das amostras de soja milho e misturas (figura 5.1) e os resultados se encontram sumarizados na tabela 5.5.

Tabela 5.5. Resultados das previsões das concentrações de proteina e amido a partir dos espectros de RMN de ${ }^{13} \mathrm{C}$ de amostras de soja. milho e misturas (figura 5.1). A base de dados utilizada para calibração é composta de espectros de soja. milho e somas (vide texto).

\begin{tabular}{|c|c|c|c|c|}
\hline & $\begin{array}{l}\text { concent.proteína } \\
\text { (esperado) }(\%)^{1}\end{array}$ & $\begin{array}{l}\text { concent.proteina } \\
\text { (calculado) }(\%)\end{array}$ & $\begin{array}{l}\text { concent.amido } \\
\text { (esperado) }(\%)^{\prime}\end{array}$ & $\begin{array}{l}\text { concent.amido } \\
\text { (calculado) }(\%)\end{array}$ \\
\hline $\mathrm{sm} 1$ & 65 & 69 & 35 & 37 \\
\hline $\mathrm{sm} 2$ & 53 & 52 & 46 & 53 \\
\hline $\mathrm{sm} 3$ & 46 & 39 & 53 & 61 \\
\hline $\mathrm{sm} 4$ & 37 & 24 & 62 & 75 \\
\hline $\sin 5$ & 28 & 16 & 71 & 90 \\
\hline sm6 & 21 & 17 & 78 & 85 \\
\hline $\operatorname{sm} 7$ & 10 & 2 & 90 & 96 \\
\hline
\end{tabular}

Valores esperados calculados com base em Mayer. 1975. 
Os espectros de soja e milho e das misturas destes (figura 5.1) também foram utilizados para a construção de bases de dados de calibração. A primeira. composta pelos 7 espectros foi utilizada para a previsão das concentrações das amostras de soja e milho cujos espectros se encontram na figura 5.3, e os resultados dessa previsão se encontram na tabela 5.6. A segunda base foi construida com 4 dos 7 espectros e a matriz de coeficientes de regressão utilizada para a previsão das concentrações das 3 amostras restantes do conjunto. Os resultados dessa etapa encontram-se na tabela 5.7.

Tabela 5.6. Resultados das previsões das concentrações de proteina e amido a partir dos espectros de RMN de ${ }^{1 /} \mathrm{C}$ de amostras de soja e milho (figura 5.2). A base de dados utilizada para calibração é composta de espectros de soja, milho e misturas (figura 5.1).

\begin{tabular}{|c|c|c|c|c|}
\hline & $\begin{array}{l}\text { concent.proteina } \\
\text { (esperado) }(\%)^{\prime}\end{array}$ & $\begin{array}{l}\text { concent.proteina } \\
\text { (calculado) (\%) }\end{array}$ & $\begin{array}{l}\text { concent.amido } \\
\text { (esperado) (\%) }\end{array}$ & $\begin{array}{l}\text { concent.amido } \\
\text { (caiculado) (\%) }\end{array}$ \\
\hline soja & 65 & 50 & 35 & 33 \\
\hline milho & 10 & 17 & 90 & 70 \\
\hline
\end{tabular}

'Valores esperados calculados com base em Mayer, 1975.

Tabela 5.7. Resultados das previsões das concentrações de proteína e amido a partir dos espectros de RMN de ${ }^{13} \mathrm{C}$ de amostras de misturas de soja e milho nas proporções $2: 1(\operatorname{sm} 3)$, 1:2 (sm5) e 1:4 (sm6) (figura 5.1). A base de dados utilizada para calibração é composta de espectros de soja (sm l). milho (sm7) e misturas nas proporções 4:1 (sm2) e $1: 1$ (sm4) (figura 5.1).

\begin{tabular}{|c|c|c|c|c|}
\hline & $\begin{array}{l}\text { concent.proteina } \\
\text { (esperado) }(\%)^{\prime}\end{array}$ & $\begin{array}{l}\text { concent.proteina } \\
\text { (calculado) }(\%)\end{array}$ & $\begin{array}{l}\text { concent.amido } \\
\text { (esperado) }(\%)\end{array}$ & $\begin{array}{l}\text { concent.amido } \\
\text { (calculado) }(\%)\end{array}$ \\
\hline $\mathrm{sm} 3$ & 46 & 45 & 53 & 52 \\
\hline $\mathrm{sm} 5$ & 28 & 36 & 71 & 73 \\
\hline $\mathrm{sm} 6$ & 21 & 35 & 78 & 69 \\
\hline
\end{tabular}

'Valores esperados calculados com base em Mayer, 1975 .

Experimentos com outros cereais e alimentos processados foram conduzidos com a mesma padronização já detalhada no capítulo anterior. Os experimentos foram conduzidos com intervalos em que o espectrômetro foi utilizado para outros experimentos de rotina do laboratório. com outros núcleos e diferentes configurações de algumas partes do sistema. Este e um problema grave com a utilização da polarização 
cruzada, que para a comparação e quantificação de vários espectros requer ajustes cuidadosos e muita atenção por parte do espectroscopista para os ajustes de sintonia e da condição de Hartmann-Hahn, que devem ser exatamente iguais para os experimentos de um grupo de amostras de calibração e análise

Os espectros medidos nessa fase de experimentos se encontram nas figuras 5.4 e 5.5

Inicialmente seguimos o mesmo procedimento anterior para a construção da base de dados com os novos espectros de lisozima e xiloglucano. Os resultados dessas previsões para as sementes de soja, milho. feijão, arroz. lentilha e sorgo; para os cereais matinais comerciais CornFlakes (matinal cf) e Fibrel(matinal f1); para o biscoito integral Ativa (biscoito A) e para o amido de milho Maizena se encontram na tabela 5.8. Pesquisando as razões para os valores acima de $100 \%$ para as concentrações de amido verificamos que o espectro do xiloglucano utilizado para a construção da base de dados não apresenta uma das principais condições exigidas para os componente de uma base de calibração,que é responder por toda a variância dos dados a serem avaliados pelo modelo. Podemos verificar dos espectros que a amplitude do pico em $\sim 73 \mathrm{ppm}$. característico dos carboidratos, é menor para o xiloglucano que para alguns dos outros espectros do conjunto. Isso pode ser uma consequência de um aịuste ruim da polarizacão cruzada para o experimento. e o espectro do xiloglucano não é neste caso um bom componente da base de dados. apesar de em alguns casos os resultados obtidos foram satisfatórios. Ainda nas tabelas 5.8 e 5.9 temos os resultados da análise do conteúdo de 
proteína feita com o método Kjedahl (AACC, 1986). Essas análises fora conduzidas na Fazenda Canchim - EMBRAPA São Carlos.

Da observação desses espectros (figuras 5.4 e 5.5) podemos ver que a Maizena, que é um amido. é uma boa candidata a componente da base de dados de calibração. Construimos uma base com Lisozima e Maizena, também nos mesmos moldes da primeira base composta por lisozima e xiloglucano, e os resultados das previsões desta base se encontram na tabela 5.9. 


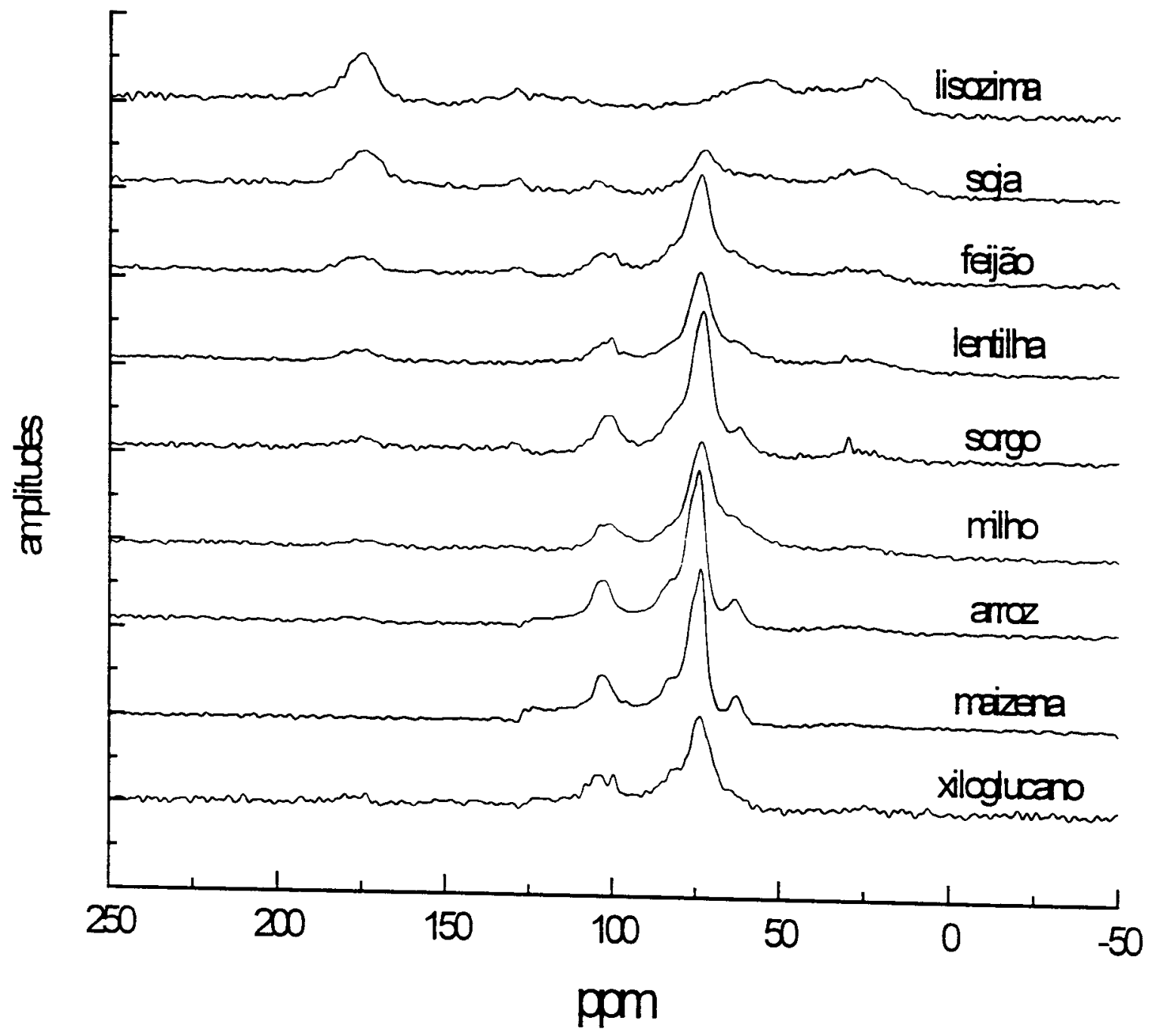

Figura 5.4. Espectros de $\mathrm{RMN}$ de ${ }^{13} \mathrm{C}$. 


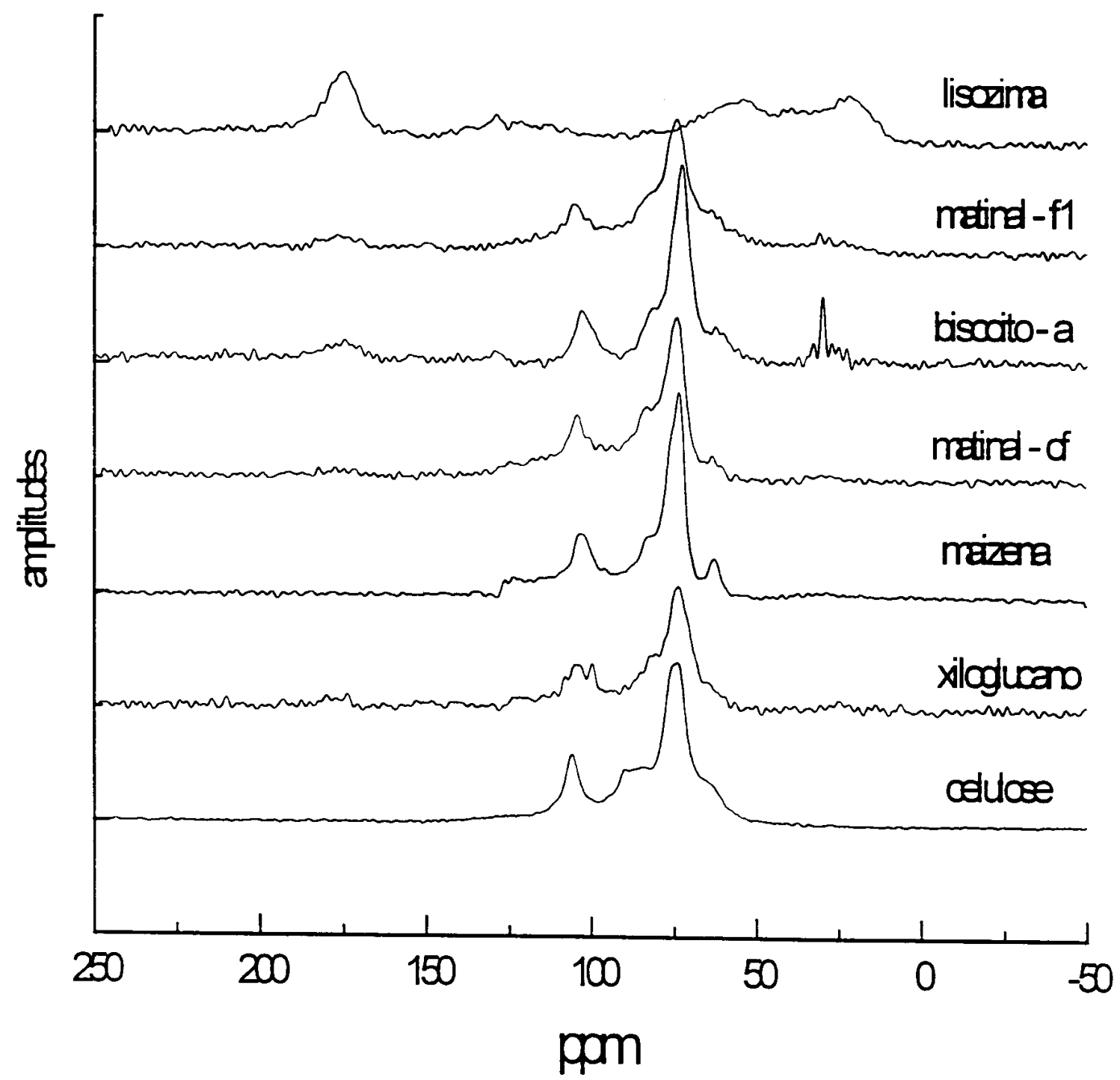

Figura 5.5. Espectros de $\mathrm{RMN}$ de ${ }^{13} \mathrm{C}$. 
Tabela 5.8. Resultados das previsões das concentrações de proteína e amido a partir dos espectros de RMN de ${ }^{13} \mathrm{C}$ de amostras de sementes e alimentos (figuras 5.3 e 5.4 ). A base de dados utilizada para calibração é composta de espectros de Lisozima e Xiloglucano (figura 5.3) e somas (vide texto).

\begin{tabular}{|l|c|l|l|c|}
\hline & $\begin{array}{l}\text { concent.proteína } \\
\text { (esperado) (\%) }\end{array}$ & $\begin{array}{l}\text { concent.proteina } \\
\text { (calculado) (\%) }\end{array}$ & $\begin{array}{l}\text { concent.amido } \\
\text { (esperado) (\%) }\end{array}$ & $\begin{array}{l}\text { concent.amido } \\
\text { (calculado) (\%) }\end{array}$ \\
\hline soja $^{1}$ & 52.37 & 71 & 47.63 & 29 \\
\hline milho' $^{1}$ & 9.43 & 14 & 90.57 & 104 \\
\hline biscoito $\mathrm{A}^{2}$ & $9.37(12)$ & 5 & $90.6(70)$ & 117 \\
\hline matinal cf & 7.7 & -14 & 92.3 & 120 \\
\hline maizena & 0.7 & -16 & 99.3 & 130 \\
\hline matinal f1 & 2 & 9 & $88.75(50)$ & 101 \\
\hline arroz & $11.25(10)$ & -14 & 90.94 & 133 \\
\hline feijão & 9.06 & 21 & 78.0 & 94 \\
\hline lentilha & 22.0 & 23 & 77.44 & 87 \\
\hline sorgo & 22.56 & -1 & 89.82 & 125 \\
\hline
\end{tabular}

'Valores esperados para as concentrações baseados na análise com o método Kjedahl.

${ }^{2}$ Valores de concentração fornecidos pelo fabricante (entre parêntesis).

Tabela 5.9. Resultados das previsões das concentrações de proteína e amido a partir dos espectros de RMN de ${ }^{13} \mathrm{C}$ de amostras de sementes e alimentos (figuras 5.3 e 5.4 ). A base de dados utilizada para calibração é composta de espectros de Lisozima e Maizena (figura 5.3) e somas (vide texto).

\begin{tabular}{|l|c|c|c|c|}
\hline & $\begin{array}{l}\text { concent.proteina } \\
\text { (esperado) (\%) }\end{array}$ & $\begin{array}{l}\text { concent.proteina } \\
\text { (calculado) (\%) }\end{array}$ & $\begin{array}{l}\text { concent.amido } \\
\text { (esperado) (\%) }\end{array}$ & $\begin{array}{l}\text { concent.amido } \\
\text { (calculado) (\%) }\end{array}$ \\
\hline soja $^{1}$ & 52.37 & 76 & 47.63 & 20 \\
\hline milho' $^{1}$ & 9.43 & 29 & 90.57 & 74 \\
\hline biscoito $\mathrm{A}^{2}$ & $9.37(12)$ & 22 & $90.6(70)$ & 84 \\
\hline matinal cf & 7.7 & 2 & 92.3 & 89 \\
\hline matinal f1 & $11.25(10)$ & 24 & $88.75(50)$ & 73 \\
\hline arroz & 9.06 & 3 & 90.94 & 101 \\
\hline feijão & 22.0 & 34 & 78.0 & 68 \\
\hline lentilha & 22.56 & 35 & 77.44 & 63 \\
\hline sorgo & 10.18 & 16 & 89.82 & 91 \\
\hline
\end{tabular}

'Valores esperados para as concentrações baseados na análise com o método Kjedahl.

${ }^{2}$ Valores de concentração fornecidos pelo fabricante (entre parêntesis)

Os melhores resultados das previsões foram obtidos nos casos em que os experimentos para obtenção dos espectros das amostras da base de dados e dos espectros das amostras para avaliação foram consecutivos. Vemos também que a obtenção de dois espectros de substâncias padrão é suficiente para a construção de uma base para calibração dos espectros quando existem duas componentes cuja concentração 
se deseja prever. O número de espectros que compôe a base deve ser maior que o número de componentes, e os resultados com bases formadas por espectros reais e espectros construídos a partir de somas destes em proporções conhecidas mostram ser este um procedimento válido.

Contruimos uma base de dados para calibração com espectros de celulose, proteína (lisozima) e lignina e dois espectros contruídos a partir de somas destes (celulose e lisozima, lisozima e lignina). A celulose utilizada é da marca Avicel. A lignina foi fornecida pela Sra. Débora, do grupo de Eletretos do IFSC - USP. As fibras de sisal com e sem lignina foram fornecidas pelo Dr. Luis Mattoso, pesquisador do CNPDIA-EMBRAPA São Carlos. Utilizando o programa AMV calculamos as concentrações aproximadas de celulose, proteina e lignina em duas amostras: fibras de sisal e fibras de sisal sem lignina. Os espectros de celulose, lignina, fibras de sisal e fibras de sisal sem lignina encontram-se na figura 5.6 e na tabela 5.10 temos os valores previstos para as concentrações de celulose, proteina e lignina nas fibras de sisal. 


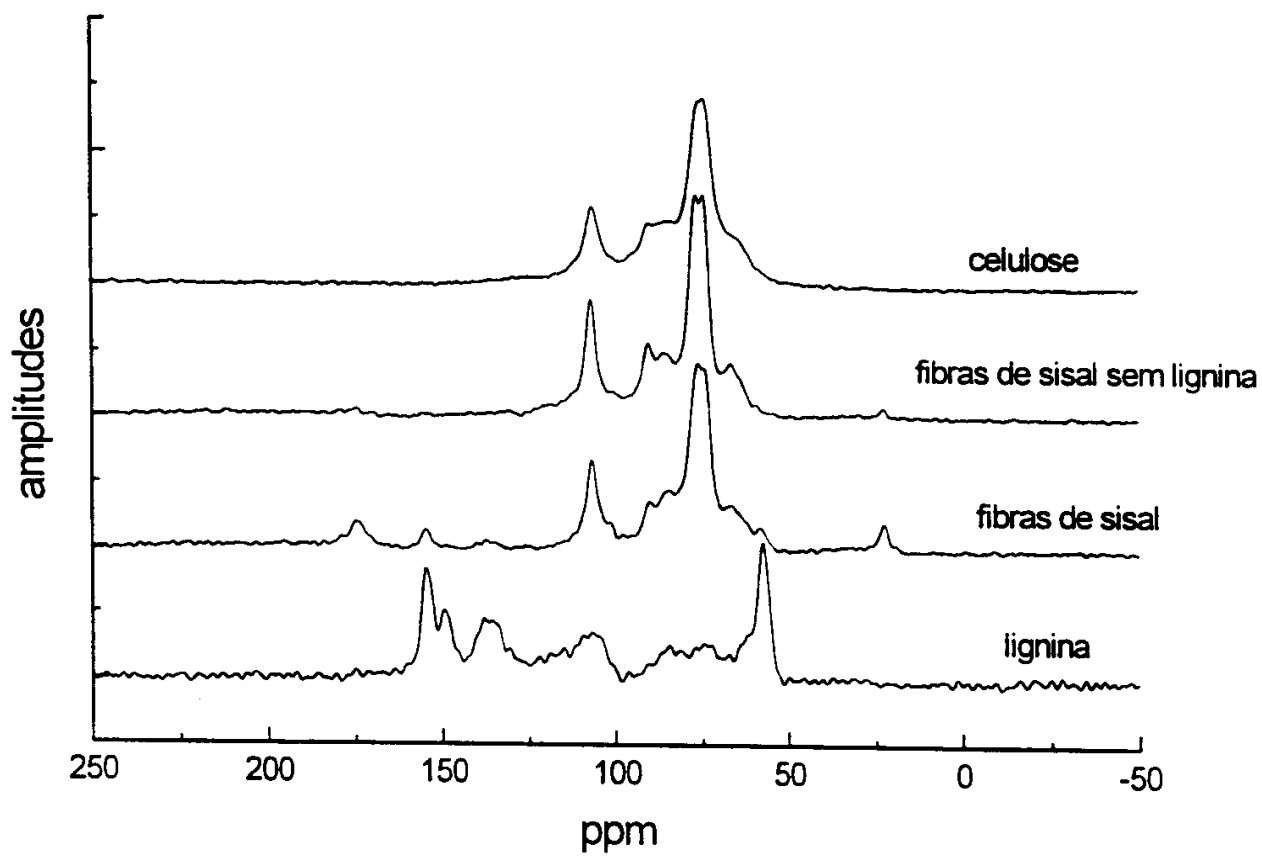

Figura 5.6. Espectros de $\mathrm{RMN}$ de ${ }^{13} \mathrm{C}$ de celulose, lignina, fibras de sisal e fibras de sisal sem lignina.

Tabela 5.10. Resultados das previsões das concentrações de celulose, proteina e lignina a partir dos espectros de RMN de ${ }^{13} \mathrm{C}$ de fibras de sisal e fibras de sisal sem lignina. A base de dados utilizada para calibração é composta de espectros de celulose e lignina ( figura 5.6) e lisozima.

\begin{tabular}{|l|l|l|l|}
\hline & $\%$ celulose & $\%$ proteina & $\%$ lignina \\
\hline fibras de sisal & 86.8 & 11.7 & 1.5 \\
\hline $\begin{array}{l}\text { fibras de sisal sem } \\
\text { lignina }\end{array}$ & 109.5 & -1.3 & -6.1 \\
\hline
\end{tabular}




\section{Capítulo 6. Conclusões e Perspectivas}

A partir de uma boa base de dados pode-se quantificar as concentrações dos diferentes grupos químicos constituintes de uma amostra quando estes apresentam distintos deslocamentos químicos. Amostras contendo substâncias formadas por grupos químicos idênticos não são adequadas a essa metodologia. Amido e celulose por exemplo, apresentam sinais nas mesmas regiões do espectro relativas aos carboidratos em geral, vide figura 5.4, impossibilitando a quantificação simultânea de amido e fibras. O mesmo não acontece com carboidratos e proteínas, pois os sinais dos grupos químicos envolvidos aparecem em regiões diferentes do espectro.

Apesar do imenso aumento de sensibilidade obtido com a aplicação conjunta dos métodos de Rotação da Amostra em torno do Ângulo Mágico, Desacoplamento Heteronuclear e Polarização Cruzada, a Ressonância Magnética Nuclear ainda é uma técnica espectroscópica de baixa sensibilidade quando espectrômetros de baixo campo magnético $(\sim 2 \mathrm{~T})$ são utilizados. Para a construção de uma boa base de dados, formada por espectros de substâncias puras ou de misturas com concentrações conhecidas. devemos utilizar espectros com boa relação sinal/ruído. Isto envolve experimentos longos. da ordem de uma dezena de horas para cada espectro num campo magnético de 
2T, o nosso caso. Existem ainda os problemas introduzidos pela necessidade de utilização da técnica de Polarização Cruzada, que dependem fortemente da experiência do operador do sistema.

Além disso, os melhores resultados das previsões foram obtidos quando os espectros das amostras avaliadas e os espectros constituintes das bases de dados de calibração foram adquiridos em experimentos consecutivos, quando as condições do equipamento mudaram pouco entre eles.

Portanto, superados os problemas de sensibilidade, a combinação da técnica de Espectroscopia de Alta Resolução em Sólidos por RMN com a Análise Multivariadas dos dados visa e pode promover uma melhora considerável na interação usuárioequipamento.

Perspectivas de aplicação dessa metodologia estendem-se à análise de solos, com a possivel quantificação de substâncias húmicas e fúlvicas; análises de composição de alimentos e quantificação de nutrientes em sementes e vegetais. Quantificação de espectros de $\mathrm{RMN}$ de ${ }^{31} \mathrm{P}$ de material biológico (Kuessel et al.. 1996) detecção de adulterantes em suco de laranja (Vogels et al., 1996) e aplicações em experimentos de RMN bidimensional (Goux \& Weber, 1993) são exemplos do potencial de aplicações das técnicas de análise multivariada em conjunto com Ressonância Magnética Nuclear e abrem uma vasta gama de possibilidades de estudo.

Métodos de análise e calibração multivariada encontram-se em franco desenvolvimento. com a aplicação crescente de técnicas estatísticas a análises químicas e bioquímicas. O procedimento de calibração empregado neste trabalho é dos mais 
simples, ficando pois como uma proposta de continuidade o desenvolvimento de programas e metodologias de calibração mais elaboradas aplicadas à espectroscopia de alta resolução em sólidos por RMN. 


\section{Bibliografia}

ABRAGAM, A., Principles of Nuclear Magnetism, University Press, England, 1986. AMERICAN ASSOCIATION OF CEREAL CHEMISTS. 1983. Approved Methods of the AACC, $8^{a}$ ed. Método 46-12, aprovado em Outubro de 1976, revisto em Outubro de 1982, revisado em Novembro de 1986.

ANDREW, E.R., BRADBURY, A., EADES, R. G., Removal of dipolar broadening of NMR spectra of solids by specimen rotation, Nature, v.183, 1802, 1959.

ANDREW, R.E., Introduction to Nuclear Magnetic Resonance, in NMR in Phisiology and Biomedicine, GILLIES, R.J., ed., Academic Press, San Diego, 1994.

BEEBE, K.R., KOWALSKI, B.R., An Introduction to Multivariate Calibration and Analysis, Anal. Chem., v.59, n.17, p.1007A-1017A, 1987.

BONAGAMBA,T.J., Espectroscopia de Alta Resolução em Sólidos por Ressonância Magnética Nuclear, Dissertação (física aplicada), São Carlos, Instituto de Física e Química de São Carlos - USP, 1991.

CARRINGTON, A., Mc LACHLAN, A. D. , Introduction to Magnetic Resonance with Applications to Chemistry and Chemical Physics, Harper \& Row, USA, 1967.

CHAN, K.Y., WASSERMAN, B.P., Rapid Solid-Phase Determination of Cereal Protein Using Bicinchonic Acid, Cereal Chem., v.70, n.1, p.27-28, 1993.

COHEN-TANNOUDJI, C.; DIU, B.; LALOË, F; Quantum Mechanics, vol 1, John Wiley and Sons, Hermann, Paris, 1977.

COMPTON, L.A., CURTIS JOHNSON, W., Jr., Analysis of Protein Circular Dichroism Spectra for Secondary Structure Using a Simple Matrix Multiplication, Anal. Biochem., v.155, p.155-167, 1986.

FREITAS. J. C. C., Espectroscopia de Alta Resolução por Ressonância Magnética Nuclear aplicada ao estudo de Zeólitas, IFQSC - USP, São Carlos, ( Disssertação de Mestrado), 1994.

FRYE, J.S.; MACIEL, G.E. Setting the Magic Angle Using a Quadrupolar Nuclide. Journal of Magnetic Resonance, v.48, p.125-131, 1982.

GELADI, P., KOWALSKI, B.R., Partial Least-Squares Regression: A Tutorial, Anal. Chim. Acta, v.185, p.1-17, 1986.

GIL, V.M.S.; GERALDES, C.F.G.C; Ressonância Magnética Nuclear - Fundamentos Métodos e Aplicações, Fundação Calouste Gulbenkian. Lisboa, 1987.

GOUX, W.J., WEBER, D.S., The application of NMR-pattern-recognition methods to the classification of reduced, paracetylated oligossacaride residues, Carboidrate Research, v.240, p.57-69, 1993. 
GREENFIELD, N.J., Methods to Estimate the Conformation of Proteins and Polypeptides form Circular Dichroism Data, Anal. Biochem., v. 235, p.1-10, 1996.

HAALAND, D.M., THOMAS, E.V., Partial Least-Squares Methods for Spectral Analysis. 1. Relation to Other Quantitative Calibration Methods and the Extraction of Qualitative Information, Anal.Chem., v. 60, p.1193-1202, 1988.

HAALAND, D.M., THOMAS, E.V., Partial Least-Squares Methods for Spectral Analysis. 2.Aplication to Simulated and Glass Spectral Data, Anal.Chem., v. 60, p.1202-1208, 1988.

HARTMANN, S.R. e HAHN, E. L., Nuclear double resonance in the rotating frame, Phys.Rev. 128, 5, 1962.

HAW, J.F.; MACIEL, G.E.; SCHROEDER, H.A. Carbon-13 Nuclear Magnetic Resonance Spectrometric Study of Wood and Wood Pulping with Cross Polarization and $M A S$; Anal. Chem., 56, p.1323-1329, 1984.

HRUSCHKA, W.R., NORRIS, K.H., Least-squares Curve Fitting of Near Infrared Spectra Predicts Protein and Moisture Content of Ground Wheat, Applied Spectroscopy, v.36, n.3, p.261-265.

IWATA, T., KOSHOUBU, J., New Method to Eliminate Background Noise from a Line Spectrum, Applied Spectroscopy, v.48, n.12, 1994.

KUESSEL, A.C.. STOYANOVA, R., AIKEN, N.R., LI, C.W., SZWERGOLD, B.S., SHALLER, C., BROWN, T.R., Quantitation of Resonances in Biological 31P NMR Spectra via Principal Component Analysis: Potential and Limitations, NMR in Biomedicine, v.9, p.93-104,1996

LENHOLM, H., IVERSEN, T., Estimation of Cellulose I and II in Cellulosic Samples by Principal Component Analysis of ${ }^{13} C-C P / M A S$ - NMR Spectra, Holzforschung, v. 49, p.119-126, 1995.

LOWE, I.J., Free Induction decays of rotating solids, Phys. Rev. Lett., v.2, 285, 1959.

LOWRY, O.H.. ROSEBROUGH, N. J., FARR, A.L. , RANDALL, R.J., Protein measurement with the Folin phenol reagent, J. Biol. Chem., v.193, p.265-275, 1951.

MARTIN, A., Near-Infrared Reflectance Spectroscopy, Appl. Spect. Rev., v.27, p.325383, 1992.

MAYER, A.M.,The Germination of Seeds, Pergamon Press, $2^{\text {nd }}$ ed., 1975.

MEHRING, M.. High Resolution NMR Spectroscopy in Solids, Springer-Verlag, Germany, 1982.

NUSSENZVEIG, H. M., Curso de Física Básica, vol.1 - Mecânica, 2a. ed., Edgar Blücher Ltda., São Paulo, 1981.

PINES, A., GIBBY, M.G., WAUGH, J.S., Proton-enhanced NMR of dilute spins in solids, J. Chem. Phys., v.59, n.2, 569,1973.

PRESTON, C. ; Applications of NMR to Soil Organic Matter Analysis: History and Prospects, Soil Science, vol.161, No. 3, 144 - 166,1996.

REDFIELD, A. G.. Nuclear spin thermodynamics in the rotating frame, Science, v.164, n.3883, 1969

RUTAR. V., A New Possibility for Nondestructive Protein Content Determinations in Viable Seeds, Applied Spectroscopy, v.36, n.3, 1982. 
SARLES,L.R., COTTS, R.M., Double nuclear magnetic resonance and the dipole interaction in solids, Phys. Rev., vol 111, n.3, 853, 1958.

SARVER, R.W., Jr., KRUEGER, W.C., Protein Secondary Structure from Fourier Transform Infrared Spectroscopy: A Data Base Analysis, Anal. Biochem., v. 194, p.89100, 1991.

SCHAEFER, J., STEJSKAL, E.O., Carbon-13 nuclear magnetic resonance of polymers spinning at the magic angle, J. Am. Chem. Soc., v.98, n.4, 1031, 1976.

SILVA, E.G., Desenvolvimento de Técnica de Desacoplamento Heteronuclear em Banda Larga para Espectroscopia de Alta Resolução por RMN, Dissertação de mestrado, Instituto de Física e Química de São Carlos - USP, São Carlos, 1994.

SLICHTER, C.P.; Principles of Nuclear Magnetic Resonance, $3^{\mathrm{a}}$ edição, SpringerVerlag, 1989.

STOYANOVA, R., KUESSEL, A.C., BROWN, T.R., Application of Principal Component Analysis for NMR Spectral Quantitation, J. Magn. Reson., s.A 115, 265269, 1995.

STRYER, L. Biochemistry, W.H.Freeman and Co., Nova York, 1988.

THOMAS, E.V., HAALAND, D.M., Comparison of Multivariate Calibration Methods for Quantitative Spectral Analysis. Anal.Chem., v. 62, p.1091-1099, 1990.

VOGELS, J.T.W.E., TERWEL. L., TAS, A.C., van den BERG, F.. DUKEL, F., van der GREEF, J., Detection of Adulteration in Orange Juice by a New Screening Method Using Proton NMR Spectroscopy in Combination with Pattern Recognition Techniques, J. Agric. Food Chem., v.44, n.1, p.175-180, 1996. 


\section{Anexo A. Valores médios das componentes do momento magnético nuclear}

Calculando os valores médios das componentes do momento magnético nuclear sob a ação de um campo magnético externo podemos mostrar que o vetor momento magnético executa um movimento de precessão ao redor do eixo do campo.

Vimos da equação 1.19 que os valôres médios das componentes nas direções $\mathrm{x}, \mathrm{y}, \mathrm{z}$ do momento magnético nuclear podem ser calculados da forma

$$
\left\langle\mu_{j}\right\rangle=\hbar\left\langle I_{j}\right\rangle=\hbar \hbar\left\langle\Psi\left|I_{j}\right| \Psi\right\rangle \text { com } \mathrm{j}=\mathrm{x}, \mathrm{y}, \mathrm{z}
$$

onde a autofunção para um sistema de dois níveis é (Cohen-Tannoudji, 1977) :

$$
|\Psi\rangle=c_{+} \exp \left(\frac{-i E_{+} t}{\hbar}\right)|+\rangle+c_{-} \exp \left(\frac{-i E_{-} t}{\hbar}\right)|-\rangle .
$$

(os sinais $+e-$ correspondem a $m_{1}=1 / 2$ e $-1 / 2$ respectivamente)

Para a componente na direção $\mathrm{z}$ temos:

$$
\begin{gathered}
\left\langle\mu_{z}\right\rangle=\gamma \hbar\left\langle I_{z}\right\rangle \\
\left\langle\mu_{z}\right\rangle=\gamma \hbar\left[c _ { + } ^ { * } \operatorname { e x p } ( \frac { i E _ { + } t } { \hbar } ) \left\langle+\left|+c_{-}^{*} \exp \left(\frac{i E_{-} t}{\hbar}\right)\langle-1] I_{=}\left[c_{+} \exp \left(-\frac{i E_{+} t}{\hbar}\right)|+\rangle+c_{-} \exp \left(-\frac{i E_{-} t}{\hbar}\right)|-\rangle\right]\right.\right.\right. \\
\left\langle\mu_{z}\right\rangle=\gamma \hbar\left[c_{+}^{*} c_{+} \frac{1}{2}+c_{-}^{*} c_{-}\left(-\frac{1}{2}\right)\right] \\
\left\langle\mu_{z}\right\rangle=\gamma \hbar\left[\frac{\left|c_{+}\right|^{2}}{2}-\frac{\left|c_{-}\right|^{2}}{2}\right]
\end{gathered}
$$

na última equação podemos substituir $\left|c_{+}\right|^{2}=a^{2}$ e $\left|c_{-}\right|^{2}=b^{2}$ e chegamos a:

$$
\left\langle\mu_{z}\right\rangle=\frac{\not \hbar}{2}\left(a^{2}-b^{2}\right)
$$

Da equação (1.10), que descreve a atuação dos operadores $I^{+}$e I' temos:

$$
\begin{aligned}
& I^{-}|+\rangle=|-\rangle \\
& I^{-}|-\rangle=0 \\
& I^{+}|-\rangle=|+\rangle \\
& I^{+}|+\rangle=0
\end{aligned}
$$

e para a componente do momento magnético na direção $\mathrm{x}$ :

$$
\begin{aligned}
& \left\langle\mu_{x}\right\rangle=\gamma \hbar\left[c _ { + } ^ { * } \operatorname { e x p } ( \frac { i E _ { + } t } { \hbar } ) \left\langle+\left|+c_{-}^{*} \exp \left(\frac{i E_{-} t}{\hbar}\right)\langle-|\right] I_{x}\left[c_{+} \exp \left(-\frac{i E_{+} t}{\hbar}\right)|+\rangle+c_{-} \exp \left(-\frac{i E_{-} t}{\hbar}\right)|-\rangle\right]\right.\right. \\
& \left\langle\mu_{x}\right\rangle=\gamma \hbar\left[c _ { + } ^ { * } \operatorname { e x p } ( \frac { i E _ { + } t } { \hbar } ) \left\langle+\left|+c_{-}^{*} \exp \left(\frac{i E_{-} t}{\hbar}\right)\langle-1]\left(\frac{I^{+}+I^{-}}{2}\right)\left[c_{-} \exp \left(-\frac{i E_{+} t}{\hbar}\right)|+\rangle+c_{-} \exp \left(-\frac{i E_{-} t}{\hbar}\right)|-\rangle\right]\right.\right.\right. \\
& \left\langle\mu_{x}\right\rangle=\gamma \hbar\left[c _ { + } ^ { * } \operatorname { e x p } ( \frac { i E _ { + } t } { \hbar } ) \left\langle+\left|+c_{-}^{*} \exp \left(\frac{i E_{-} t}{\hbar}\right)\langle-|\right] \frac{1}{2}\left[c_{-} \exp \left(-\frac{i E_{-} t}{\hbar}\right)|+\rangle+c_{-} \exp \left(-\frac{i E_{+} t}{\hbar}\right)|-\rangle\right]\right.\right.
\end{aligned}
$$




$$
\left\langle\mu_{x}\right\rangle=\frac{\hbar \hbar}{2}\left\{c_{+}^{*} c_{-} \exp \left[-\frac{i\left(E_{-}-E_{+}\right) t}{\hbar}\right]+c_{-}^{*} c_{+} \exp \left[\frac{i\left(E_{-}-E_{+}\right) t}{\hbar}\right]\right\}
$$

definindo $\omega_{0}=\left(\frac{E_{-}-E_{+}}{\hbar}\right)$ e sendo $c_{+}=a e^{i \alpha}$ e $c_{-}=b e^{i \beta}$ :

$$
\begin{gathered}
\left\langle\mu_{x}\right\rangle=\frac{\gamma \hbar}{2}\left[a e^{-i \alpha} b e^{i \beta} e^{-i \omega_{n^{\prime}}}+b e^{-i \beta} a e^{i \alpha} e^{i \omega_{n^{\prime}}}\right] \\
\left\langle\mu_{x}\right\rangle=\gamma \hbar a b\left[\frac{e^{-i\left(\omega_{0}+\alpha-\beta\right)}+e^{i\left(\omega_{n}+\alpha-\beta\right)}}{2}\right] \\
\left\langle\mu_{x}\right\rangle=\gamma a b \cos \left[\left(\omega_{0}+\alpha-\beta\right) t\right]
\end{gathered}
$$

Analogamente, para a componente na direção y:

$$
\begin{gathered}
\left\langle\mu_{y}\right\rangle=\gamma \hbar\left[c _ { + } ^ { * } \operatorname { e x p } ( \frac { i E _ { + } t } { \hbar } ) \left\langle+\left|+c_{-}^{*} \exp \left(\frac{i E_{-} t}{\hbar}\right)\langle-|\right] I_{y}\left[c_{+} \exp \left(-\frac{i E_{+} t}{\hbar}\right)|+\rangle+c_{-} \exp \left(-\frac{i E_{-} t}{\hbar}\right)|-\rangle\right]\right.\right. \\
\left\langle\mu_{y}\right\rangle=\gamma \hbar\left[c _ { + } ^ { * } \operatorname { e x p } ( \frac { i E _ { + } t } { \hbar } ) \left\langle+\left|+c_{-}^{*} \exp \left(\frac{i E_{-} t}{\hbar}\right)\langle-|\right]\left(\frac{I^{+}-I^{-}}{2 i}\right)\left[c_{+} \exp \left(-\frac{i E_{+} t}{\hbar}\right)|+\rangle+c_{-} \exp \left(-\frac{i E_{-} t}{\hbar}\right)|-\rangle\right]\right.\right. \\
\left\langle\mu_{y}\right\rangle=\gamma \hbar\left[c _ { + } ^ { * } \operatorname { e x p } ( \frac { i E _ { + } t } { \hbar } ) \left\langle+\left|+c_{-}^{*} \exp \left(\frac{i E_{-} t}{\hbar}\right)\langle-1] \frac{1}{2 i}\left[c_{-} \exp \left(-\frac{i E_{-} t}{\hbar}\right)|+\rangle-c_{+} \exp \left(-\frac{i E_{+} t}{\hbar}\right)|-\rangle\right]\right.\right.\right. \\
\left\langle\mu_{y}\right\rangle=\frac{\gamma \hbar}{2 i}\left\{c_{+}^{*} c_{-} \exp \left[-\frac{i\left(E_{-}-E_{+}\right) t}{\hbar}\right]-c_{-}^{*} c_{+} \exp \left[\frac{i\left(E_{-}-E_{+}\right) t}{\hbar}\right)\right\} \\
\left\langle\mu_{y}\right\rangle=\frac{\gamma \hbar}{2 i}\left[a e^{-i a} b e^{i \beta} e^{-i \omega_{n^{\prime}} t}-b e^{-i \beta} a e^{i \alpha} e^{i \omega_{\omega^{\prime}}}\right] \\
\left\langle\mu_{y}\right\rangle=\gamma \hbar a b\left[\frac{e^{-i\left(\omega_{0}+\alpha-\beta\right)}-e^{i\left(\omega_{n}+\alpha-\beta\right)}}{2 i}\right] \\
\left\langle\mu_{y}\right\rangle=-\gamma a b \operatorname{sen}\left[\left(\omega_{0}+\alpha-\beta\right) t\right]
\end{gathered}
$$

Uma outra maneira de verificar o movimento de precessão do momento magnético é considerar inicialmente a hamiltoniana $\mathrm{H}$ dependente do tempo; uma solução $\psi(\mathrm{t})$ da equação de Schrödinger:

$$
i \hbar \frac{\partial \psi}{\partial}=H \psi
$$

e um operador $\mathrm{Q}$ independente do tempo. Pode se provar que é verdadeira a relação:

$$
\frac{d}{d t}\langle\psi|Q| \psi\rangle=\frac{d}{d t}\langle Q\rangle=\frac{i}{\hbar}\langle[H, Q]\rangle
$$

onde $[\mathrm{H}, \mathrm{Q}]=\mathrm{HQ}-\mathrm{QH}$, é o comutador de $\mathrm{H}$ e $\mathrm{Q}$.

Sabendo ainda que as componentes do operador de spin obedecem às seguintes regras de comutação: 


$$
\begin{aligned}
& {\left[I_{x}, I_{y}\right]=i I_{z}} \\
& {\left[I_{y}, I_{z}\right]=i I_{x}} \\
& {\left[I_{z}, I_{x}\right]=i I_{y}}
\end{aligned}
$$

temos, para um spin num campo estático cuja hamiltoniana de interação é $\mathrm{H}=-\gamma \hbar \mathrm{B}_{0} \mathrm{I}_{\mathbf{z}}$,

onde:

$$
\frac{d}{d t}\left\langle\mu_{x}\right\rangle=\gamma \hbar \frac{d}{d t}\left\langle I_{x}\right\rangle=\gamma \hbar \frac{i}{\hbar}\left\langle\left[H, I_{x}\right]\right\rangle
$$

então:

$$
\left[H, I_{x}\right]=\left(-\gamma \hbar B_{0}\right)\left[I_{z}, I_{x}\right]=\left(-\gamma \hbar B_{0}\right) i I_{y}
$$

Para a componente y:

$$
\frac{d}{d t}\left\langle\mu_{x}\right\rangle=\gamma B_{0}\left\langle\mu_{y}\right\rangle
$$

$$
\begin{aligned}
& {\left[H, I_{y}\right]=\left(-\gamma \hbar B_{0}\right)\left[I_{z}, I_{y}\right]=\left(-\gamma \hbar B_{0}\right)\left(-i I_{x}\right)} \\
& \frac{d}{d t}\left\langle\mu_{y}\right\rangle=-\gamma B_{0}\left\langle\mu_{x}\right\rangle
\end{aligned}
$$

E para a componente na direção z:

$$
\begin{aligned}
& \frac{d}{d t}\left\langle\mu_{z}\right\rangle=\xi \hbar \frac{d}{d t}\left\langle I_{z}\right\rangle=\eta \hbar \frac{i}{\hbar}\left\langle\left[H, I_{z}\right]\right\rangle \\
& {\left[H, I_{z}\right]=\left(-\eta \hbar B_{0}\right)\left[I_{z}, I_{z}\right]=0} \\
& \frac{d}{d t}\left\langle\mu_{z}\right\rangle=0
\end{aligned}
$$

As equações (AA.5),(AA.6) e (AA.7) podem ser escritas na forma :

$$
\frac{d}{d t}\langle\bar{\mu}\rangle=\gamma\langle\bar{\mu}\rangle \times \vec{B}
$$

A equação (AA.8) é equivalente à equação do movimento de precessão de um giroscópio sob a ação do campo gravitacional terrestre (Nussenzveig, 1981). 


\section{Anexo B. Cálculo da Probabilidade de Transição}

Apresentamos a seguir os cálculos que levam da equação 1.32 para o coeficiente $c_{b}(T)$ à equação 1.33, a probabilidade de transição entre dois niveis a e b.

$$
\begin{aligned}
& c_{h}(T)=-i \frac{V_{h a}}{\hbar} \int_{0}^{T}(\exp (i \omega t)+\exp (-i \omega t)) \exp \left(i \omega_{b a} t\right) d t \\
& c_{b}(T)=-i \frac{V_{b c t}}{\hbar} \int_{0}^{T}\left\{\exp \left[i\left(\omega+\omega_{b a}\right) t\right]+\exp \left[-i\left(\omega-\omega_{b a}\right) t\right]\right\} \\
& c_{b}(T)=-i \frac{V_{b u t}}{\hbar}\left\{\frac{\exp \left[i\left(\omega+\omega_{b a}\right) t\right]}{i\left(\omega+\omega_{b a}\right)}+\frac{\exp \left[-i\left(\omega-\omega_{b a}\right) t\right]}{-i\left(\omega-\omega_{b a}\right)}\right\}_{0}^{T} \\
& c_{b}(T)=-i \frac{V_{b a}}{\hbar}\left\{\frac{\exp \left[i\left(\omega+\omega_{b a}\right) T\right]}{i\left(\omega+\omega_{h a}\right)}+\frac{\exp \left[-i\left(\omega-\omega_{b a}\right) T\right]}{-i\left(\omega-\omega_{b a}\right)}-\frac{1}{i\left(\omega+\omega_{b a}\right)}+\frac{1}{i\left(\omega-\omega_{b a}\right)}\right\} \\
& c_{b}(T)=-\frac{V_{b a}}{\hbar}\left\{\frac{\exp \left[i\left(\omega+\omega_{b a}\right) T\right]-1}{\left(\omega+\omega_{b a}\right)}-\frac{\exp \left[-i\left(\omega-\omega_{b a}\right) T\right]-1}{\left(\omega-\omega_{b a}\right)}\right\} \\
& P(a, b)=\left|c_{b}(T)\right|^{2} \\
& \left|c_{b}(T)\right|^{2}=\frac{V_{b a t}^{2}}{\hbar^{2}}\left\{\frac{\exp \left[i\left(\omega+\omega_{b a}\right) T\right]-1}{\left(\omega+\omega_{b a}\right)}-\frac{\exp \left[-i\left(\omega-\omega_{b a}\right) T\right]-1}{\left(\omega-\omega_{b a}\right)}\right\} \times \\
& \left\{\frac{\exp \left[-i\left(\omega+\omega_{h a}\right) T\right]-1}{\left(\omega+\omega_{b a}\right)}-\frac{\exp \left[i\left(\omega-\omega_{b a}\right) T\right]-1}{\left(\omega-\omega_{b a}\right)}\right\}
\end{aligned}
$$

Multiplica-se os termos entre chaves na última equação e considerando $\omega \cong \omega_{\text {ba }}$ pode-se desprezar aqueles termos cujo denominador é a soma de $\omega$ e $\omega_{b a}$, temos então: 


$$
\begin{aligned}
& P(a, b)=\left|c_{b}(T)\right|^{2} \cong \frac{V_{b a}^{2}}{\hbar^{2}}\left[\frac{1-\exp \left(i\left(\omega-\omega_{b a}\right) T\right)+1-\exp \left(i\left(\omega-\omega_{b a}\right) T\right)}{\left(\omega-\omega_{b a}\right)^{2}}\right] \\
& P(a, b) \cong \frac{V_{b a}{ }^{2}}{\hbar^{2}}\left[\frac{2-2 \cos \left(\omega-\omega_{b a}\right) T}{\left(\omega-\omega_{b a}\right)^{2}}\right]=\frac{2 V_{b a}{ }^{2}}{\hbar^{2}}\left[\frac{1-1 \cos \left(\omega-\omega_{b a}\right) T}{\left(\omega-\omega_{b a}\right)^{2}}\right]
\end{aligned}
$$

utilizando na última equação a relação: $1-\cos (\mathrm{y})=2 \operatorname{sen}^{2}(\mathrm{y} / 2)$,

$$
\begin{aligned}
& P(a, b) \cong \frac{2 V_{b a}{ }^{2}}{\hbar^{2}}\left[\frac{2 \operatorname{sen}^{2}\left[\frac{\left(\omega-\omega_{b a}\right) T}{2}\right]}{\left(\omega-\omega_{b a}\right)^{2}}\right] \\
& P(a, b) \cong \frac{2 \pi V_{b u}{ }^{2}}{\hbar^{2}}\left[\frac{\operatorname{sen}^{2}\left[\frac{\left(\omega-\omega_{b a}\right) T}{2}\right]}{2 \pi T\left(\frac{\left(\omega-\omega_{b a}\right)}{2}\right)^{2}}\right] T
\end{aligned}
$$

Chegamos assim à equaçãol.33, onde o termo entre colchetes é uma representação da função delta de Dirac, que só é diferente de zero se $\omega=\omega_{\mathrm{ba}}$. 


\section{Anexo C - Rotina AMV}

$1 \quad$ clear

$a=$ input ('Dê o nome do arquivo de RMN: ');

r=input ('Dê o nome do arquivo de CONCENTRAÇÕES: ');

nfp= input ('Dê o número de fatores: ');

p=DATA

r=DATAl;

10

$[11, \mathbf{c} 1]=\operatorname{size}(\mathbf{p})$

$[12, \mathrm{c} 2]=\operatorname{size}(\mathrm{r})$

for $\mathrm{j}=1: 11$;

end

$p t(j, 1: c l)=p(j, 1: c l)$

$\mathbf{k}=1$;

20 for $i=1: 11$

$\mathrm{j}=1$;

$\mathrm{n}=1$

while $\mathrm{n}<$ II

if $n=i$

$\mathrm{j}=\mathrm{j}+\mathrm{l}$;

$\operatorname{paux}(\mathrm{n}, 1: \mathrm{c} 1)=\mathrm{p}(\mathrm{j}, 1: \mathrm{cl})$;

$\operatorname{raux}(\mathrm{n}, 1: \mathrm{c} 2)=\mathrm{r}(\mathrm{j}, 1: \mathrm{c} 2)$;

else

$\operatorname{paux}(\mathrm{n}, \mathrm{l}: \mathrm{cl})=\mathrm{p}(\mathrm{j}, \mathrm{l}: \mathrm{cl})$

30 $\operatorname{raux}(\mathrm{n}, 1: \mathrm{c} 2)=\mathrm{r}(\mathrm{j}, 1: \mathrm{c} 2)$;

end;

$\mathrm{j}=\mathrm{j}+1$;

$n=n+1$;

end;

$\mathrm{k}=\mathrm{k}+1$;

[u s v] = svd(paux $)$

scores $=\mathrm{u}^{*} \mathrm{~s}$;

$\mathrm{v}=\mathrm{v}(:, 1: \mathrm{nfp})$;

$40 \quad \mathrm{u}=\mathrm{u}(:, 1 \mathrm{nfp})$;

$s=\operatorname{inv}(s(1: n f p, 1: n f p))$;

$\mathrm{mtr}=\mathrm{v}^{*} \mathrm{~s}^{*}\left(\mathrm{u}^{\prime}\right)^{*}$ raux;

paux3(i,1:c2)=p(i,1:c1 $)^{*} \mathrm{mtr}$;

end;

AC. 1 
\%resultado da rotina de PCR

$\%$ PROTEÍNA AÇÚCAR

echo off

paux3

echo on

\%diferenca entre o "real"(RMN) e o previsto por PCR

$\%$ PROTEÍNA AÇÚCAR

60

echo off

difpcr=r-paux 3

for $i=1: c 2$

$\operatorname{mp} 3(i)=\operatorname{mean}(\operatorname{paux} 3(1: 12, i))$;

end;

$\operatorname{mr}(i)=\operatorname{mean}(r(1: 12, i))$;

$\mathrm{mp} 3=\mathrm{mp} 3$

$\mathrm{mr}=\mathrm{mr}^{\mathrm{r}}$

70

$\operatorname{corr} 2=z e r o s(\operatorname{size}(1: c 2))$;

echo on

\% cálculo do coeficiente de correlação PCR

$\%$ PROTEÍNA

echo off

for $\mathrm{i}=1: \mathrm{c} 2$

num(i) $=\left(\operatorname{sum}\left((\operatorname{paux} 3(1: 12, \mathrm{i})-\mathrm{mp} 3(\mathrm{i})){ }^{*}(\mathrm{r}(1: 12, \mathrm{i})-\mathrm{mr}(\mathrm{i}))\right)\right)$;

$\operatorname{den}(\mathrm{i})=\left(\left(\left(\operatorname{sum}\left((\operatorname{paux} 3(1: 12, \mathrm{i})-\mathrm{mp} 3(\mathrm{i})) .^{\wedge} 2\right)\right) .^{*}\left(\left(\operatorname{sum}\left((\mathrm{r}(1: 12, \mathrm{i})-\operatorname{mr}(\mathrm{i})) .^{\wedge} 2\right)\right)\right)\right)^{\wedge} .5\right)$

$80 \operatorname{corr} 2(\mathrm{i})=$ num $(\mathrm{i}) / \mathrm{den}(\mathrm{i})$;

end

corr2

echo on

\% cálculo do desvio padrão da previsão feita com PCR

$\%$ PROTEINA ACCÚCAR

echo off

$90 \quad$ for $\mathrm{i}=1: \mathrm{c} 2$

$\operatorname{stdvpcr}(\mathrm{i})=\left(\left(\operatorname{sum}\left((\operatorname{paux} 3(1: 12, \mathrm{i})-\mathrm{r}(1: 12, \mathrm{i})) \wedge^{\wedge} 2\right)\right) / 12\right)^{\wedge} .5$;

end;

stdvpcr

AC. 2 
A próxima rotina, $\mathrm{ACP}$, baseada na rotina $\mathrm{AMV}$, faz a decomposição da matriz de espectros em componentes principais e reconstrói esse mesmo conjunto de espectros, no arquivo "pr" utilizando o número de componentes principais que o usuário determinar (nfp). Sob esse aspecto, a decomposição em valores principais atua como um filtro de ruído, pois as componentes principais aparecem em ordem decrescente de importância, sendo portanto as primeiras que carregam a informação espectral útil (Iwata \& Koshoubu, 1994)

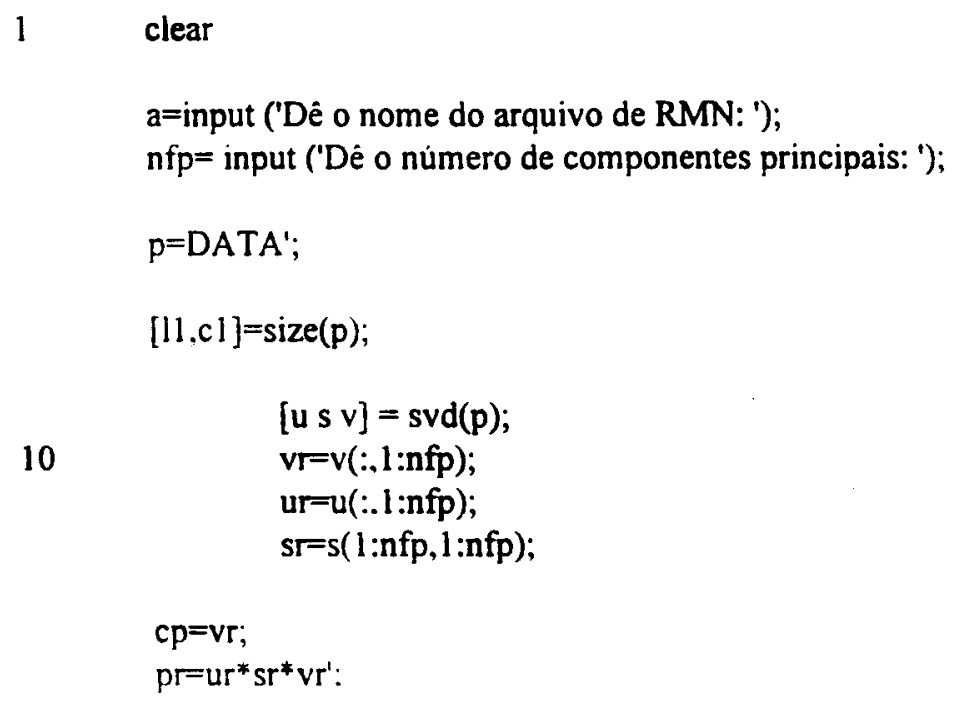

